\title{
Faculty perceptions of the role of foreign language education at West Virginia University
}

\author{
William L. White \\ West Virginia University
}

Follow this and additional works at: https://researchrepository.wvu.edu/etd

\author{
Recommended Citation \\ White, William L., "Faculty perceptions of the role of foreign language education at West Virginia \\ University" (2007). Graduate Theses, Dissertations, and Problem Reports. 2773. \\ https://researchrepository.wvu.edu/etd/2773
}

This Dissertation is protected by copyright and/or related rights. It has been brought to you by the The Research Repository @ WVU with permission from the rights-holder(s). You are free to use this Dissertation in any way that is permitted by the copyright and related rights legislation that applies to your use. For other uses you must obtain permission from the rights-holder(s) directly, unless additional rights are indicated by a Creative Commons license in the record and/ or on the work itself. This Dissertation has been accepted for inclusion in WVU Graduate Theses, Dissertations, and Problem Reports collection by an authorized administrator of The Research Repository @ WVU.

For more information, please contact researchrepository@mail.wvu.edu. 


\title{
Faculty Perceptions of the Role of Foreign Language Education at West Virginia University
}

\author{
William L. White
}

\author{
Dissertation submitted to the \\ College of Human Resources and Education
}

at West Virginia University

in partial fulfillment of the requirements for the degree of

\author{
Doctor of Education \\ in \\ Curriculum and Instruction
}

West Virginia University

Morgantown, WV 2007

Patricia Obenauf, Ed.D., Chairperson

David Callejo, Ed.D.

Ahmed Fahkri, Ph.D.

Ernest Goeres, Ph.D.

Perry Philipps, Ed.D.

Keywords: foreign language education, faculty perspectives, qualitative study, higher education

Copyright William L. White 


\title{
ABSTRACT
}

Faculty Perceptions of the Role of Foreign Language Education at West Virginia University

\author{
William L. White
}

Foreign language education has a long history within higher education. However, since the late 1960s, foreign language enrollment, measured by percentages of students taking language courses, has declined by almost $50 \%$ in American colleges and universities. The author contends that much of this decline can be explained by three concomitant forces; including (1) the rise of professional programs that are constrained by an exactness of education that precludes study beyond rather narrowly defined plans of study; (2) the lack of language learning success that foreign language students demonstrate upon completion of language programs; and (3) the failure of language departments to extend the concept of language and culture learning beyond traditional language-for-literature based curricula. When coupled with societal forces that view language learning as an essential tool in the nation's economic/political battles and intra-university notions of accountability that view a department's centrality to the university based on its ability to generate revenue, foreign language departments face internal and external challenges to their long-term survival. The author believes that an in depth understanding of the perspectives of others within higher education can assist foreign language programs recover their own place within universities and establish strategic cross-disciplinary alliances that will secure the long-term success of foreign language programs. The present study, based on the theoretical frameworks provided by Bandura's socio-cognitive theory and Bourdieu's models of Field and Habitus, uses qualitative methods, including semi-structured interviews and document analysis, to explore the perspectives of faculty from three academic colleges (Arts and Sciences, Engineering, and Business) toward the role and purpose of foreign language education within the context of the university. Finally, the author suggests that the findings of the study point to the need to develop an ecology of foreign language learning that allows for a reconceptualization of the modern foreign language department in higher education. 


\section{TABLE OF CONTENTS}

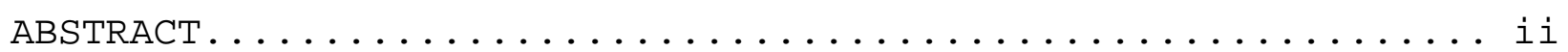

TABLE OF CONTENTS $\ldots \ldots \ldots \ldots \ldots \ldots \ldots \ldots \ldots \ldots \ldots \ldots \ldots \ldots \ldots \ldots \ldots \ldots$

LIST OF TABLES $\ldots \ldots \ldots \ldots \ldots \ldots \ldots \ldots \ldots \ldots \ldots \ldots \ldots \ldots \ldots \ldots \ldots$

LIST OF FIGURES $\ldots \ldots \ldots \ldots \ldots \ldots \ldots \ldots \ldots \ldots \ldots \ldots \ldots \ldots \ldots \ldots \ldots$

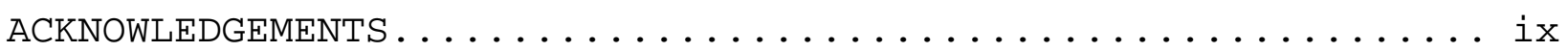

CHAPTER ONE: INTRODUCTION.................... 1

Overview of the study $\ldots \ldots \ldots \ldots \ldots \ldots \ldots \ldots \ldots \ldots \ldots$

Foreign Language Education $\ldots \ldots \ldots \ldots \ldots \ldots \ldots \ldots \ldots$

Statement of the Problem and Purpose of the Study ....... 16

Research Questions ...................... 18

Qualitative Research Methodology ............... 19

Significance of the study $\ldots \ldots \ldots \ldots \ldots \ldots \ldots \ldots \ldots \ldots \ldots \ldots$

Study Components ........................ 22

Operational Definitions $\ldots \ldots \ldots \ldots \ldots \ldots \ldots \ldots \ldots \ldots \ldots$

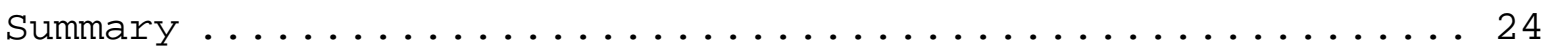

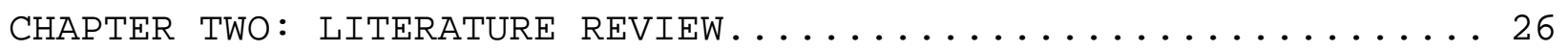

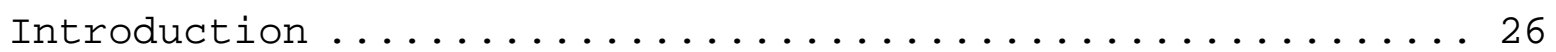

Foreign Language Education - History $\ldots \ldots \ldots \ldots \ldots \ldots \ldots 28$

National Trends in Foreign Language Enrollments .........44 43

Foreign Language Departments: Phase Separation ..........49 49

Structural Issues in Foreign Language Education $\ldots . \ldots \ldots 53$

The Role of Foreign Language Education in Universities ... 56 
Field, Habitus, Social-Cognitive Theory and Faculty ......6 65 The Context of the Study: West Virginia University . . . . 72 Summary and Rationale for the Current Study $\ldots \ldots \ldots \ldots \ldots 78$

CHAPTER THREE: METHOdOLOGY $\ldots \ldots \ldots \ldots \ldots \ldots \ldots \ldots \ldots \ldots$

Introduction $\ldots \ldots \ldots \ldots \ldots \ldots \ldots \ldots \ldots \ldots \ldots \ldots \ldots \ldots \ldots$

Statement of the Research Problem .............. 82

Statement of the Research Questions $\ldots \ldots \ldots \ldots \ldots \ldots \ldots 4$

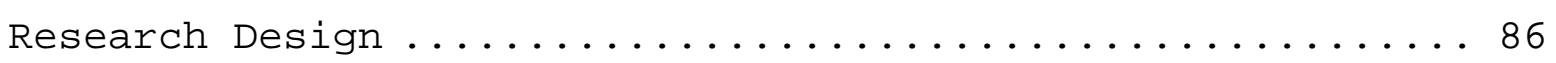

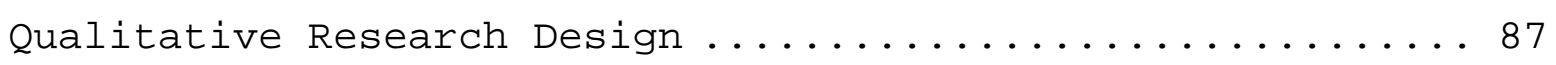

Limitation of Qualitative Research .............. 91

Participant Selection and IRB Approval $\ldots \ldots \ldots \ldots \ldots \ldots$

Data Collection Procedures ................... 95

Data Organization and Analysis ................ 96

Reliability and Internal Validity $\ldots \ldots \ldots \ldots \ldots \ldots \ldots$

Relevant Past Experiences . . . . . . . . . . . . . 98

Statement of Personal Context $\ldots \ldots \ldots \ldots \ldots \ldots \ldots \ldots \ldots$

CHAPTER FOUR: RESULTS . . . . . . . . . . . . . . . . 101

Introduction $\ldots \ldots \ldots \ldots \ldots \ldots \ldots \ldots \ldots \ldots \ldots \ldots \ldots \ldots \ldots \ldots$

Reasons for Foreign Language Study $\ldots \ldots \ldots \ldots \ldots \ldots \ldots \ldots 102$

Perception of Problems $\ldots \ldots \ldots \ldots \ldots \ldots \ldots \ldots \ldots \ldots \ldots$

Cross-Curricular Links .................... 133

The Purpose of Foreign Language Study $\ldots \ldots \ldots \ldots \ldots \ldots \ldots 142$ 
Summary and Conclusion $\ldots \ldots \ldots \ldots \ldots \ldots \ldots \ldots \ldots \ldots \ldots$

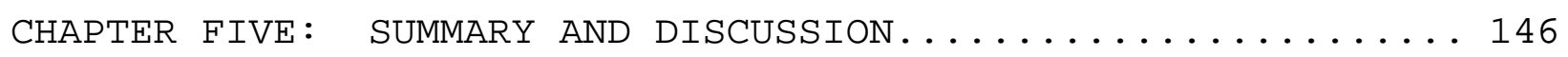

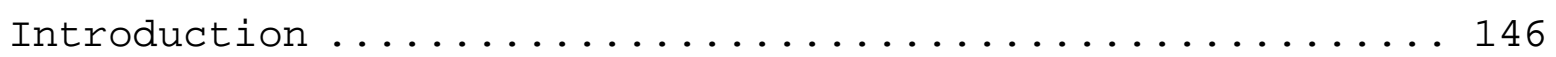

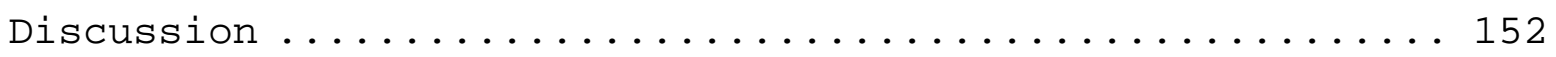

Reconceptualizing the Foreign Language Department ..... 166

Implications for Foreign Language Departments . . . . . . 176

A Word of Optimism, Maybe $\ldots \ldots \ldots \ldots \ldots \ldots \ldots \ldots \ldots \ldots$

Suggestions for Further Research . .............. 190

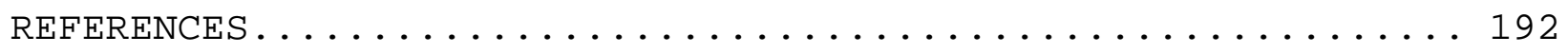

Appendix A............................... 205

Interview Protocol $\ldots \ldots \ldots \ldots \ldots \ldots \ldots \ldots \ldots \ldots \ldots \ldots \ldots$

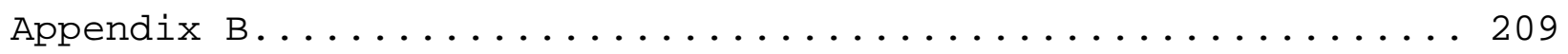

Documents Reviewed ......................... 209

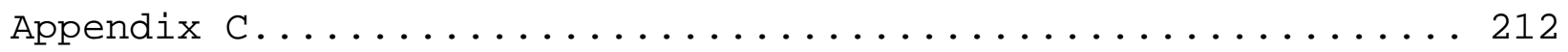

Curriculum Vitae, William L. White $\ldots \ldots \ldots \ldots \ldots \ldots \ldots 212$

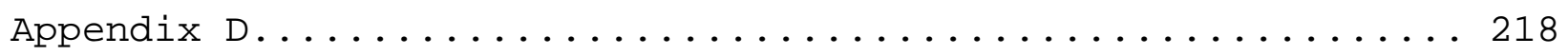

Lens Paper of William $L$. White $\ldots \ldots \ldots \ldots \ldots \ldots \ldots \ldots \ldots$

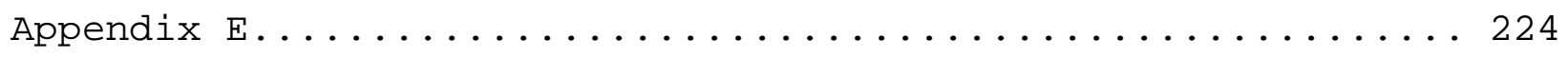

Exempt Application ....................... 224 


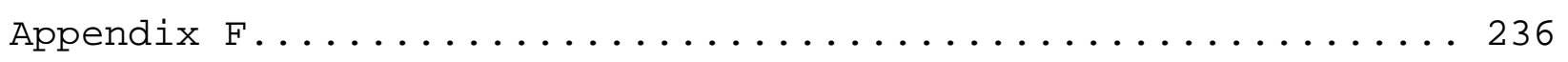

Institutional Review Board Approval ............ 236

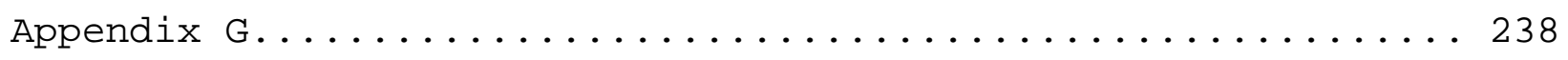

Participant Pseudonyms and College Affiliation ........ 238

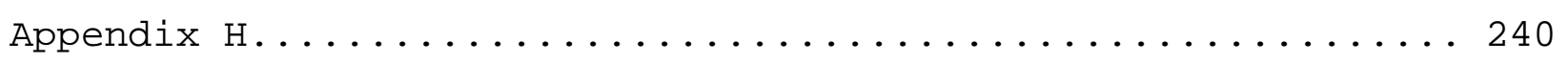

Seventeen Values of Foreign Language Study ........... 240

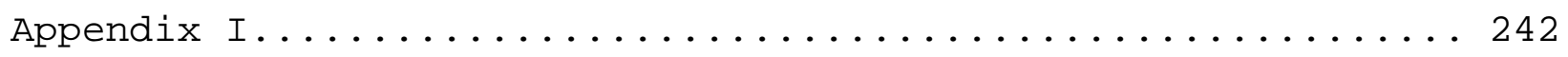

Invitation to Participate in the Study $\ldots \ldots \ldots \ldots \ldots \ldots 242$ 


\section{LIST OF TABLES}

Table 1.1. Modern Foreign Language (MFL) Enrollments, 1960-2002.... 14

Table 1.2. Foreign Language Enrollments for Selected Languages..... 14

Table 2.1. Foreign Language Enrollments for Selected Languages..... 45

Table 2.2. Statistical Profile of West Virginia University Enrollment

in Selected Years.............................. 74

Table 2.3. Statistical Profile of West Virginia University.......74

Enrollment in Selected Years and Selected Colleges.............74

Table 2.4. Foreign Language Credit Hour Production............75

Table 3.1. Research Questions and Means of Data Collection........85

Table 3.2. Research Questions Aligned with Interview Protocol.....86

Table 4.1. Skills Attributable to Foreign Language Education...... 112

Table 5.1. Foreign Language Enrollment Percentages by College..... 189 
Faculty Perceptions - FLE viii

\section{LIST OF FIGURES}

Figure 5.1. Incomplete Framework for Reconceptualizing Foreign Language Departments............................ 175 


\section{ACKNOWLEDGEMENTS}

In many ways, the termination of a dissertation and plan of study seems to be the end of a long and arduous journey. Yet, in fact, it is simply a part of a longer passage along which many people act as guides, friends, and counselors. In my present journey, there are so many people who deserve credit for helping me through the past three years. However, first in line is Lennon, my son. He has calmly persevered through the ups and downs of the process that brought me to this point. While I was spending too much time in the library, reading books and articles, or editing papers, he played soccer, lacrosse, and learned to bowl. I was often physically absent, but my mind was always there. I need to also thank my parents. Until just a few months before the end of this journey, my mom and dad stood beside me, encouraging me to continue and helping me emotionally as well as in other ways. My one true regret is that my mom's journey on earth ended only a few short months before I completed this process. Although gone from our sight, she is a constant inspiration to me and one of the main reasons I took up a doctoral program after finishing an MA more than 15 years ago.

I would also like to thank Dr. Patricia Obenauf and $\mathrm{Dr}$. David Callejo, two inspirational professors from the College of Human Resources and Education. Dr. Obenauf showed me a new way of approaching meaning making in life that has greatly 
influenced my personal, professional, and educational relationships. More specifically, during this dissertation process, her keen intellect and patience kept me on track when my mind and thoughts began to wonder. Without a doubt, this document would be much less focused without her input and ability to see clearly what was, at times, muddled in my head. Dr. Callejo's arrival at WVU only two years ago provided a much needed shot in the arm to the Curriculum and Instruction program. Throughout this dissertation journey, David offered suggestions, additions, and alternative means at looking at the questions I wished to address. Finally, David's willingness to work with graduate students in our struggles to understand the underlying meaning of education has inspired many of us to present papers at conferences and to engage in the ego shattering process of sending papers off for publication.

I must also thank Dr. Ahmed Fakrhi, from the Foreign Language Department. From my first arrival at WVU, almost 20 years ago, Dr. Fakhri has been the model that I have followed in my teaching and intellectual travels. His keen insights and unpresuming ways are a hallmark of an individual who is capable and competent yet understanding and patient. I value Ahmed as a friend, a colleague, a mentor, and as a practicing intellectual whose contributions to my maturation are far more important than he realizes. 
It is also essential to thank Dr. Perry Phillips and Dr. Ernest Goeres, the final members of Doctoral Committee. Their patient readings of my prospectus and dissertation were accompanied by suggestions that improved the quality of the final project. Their tireless work and assistance were invaluable and will never be forgotten.

Finally, I would like to thank all my fellow doctoral students within C\&I. From our first meetings, I have marveled at the intelligence of Cyprien, Sarah, Angie, Rae, Mishal, Erin, and Ahmed. Through our conversations, group projects, and conference presentations, I have learned much about myself and about the field of education. Given that I believe education is a dialogical process that leads to the exploration of ideas in a collegial atmosphere, I am led to the conclusion that the ultimate worth of an educational program is as much about the quality of the participants as the books we read or the classes we took. From this viewpoint, the Ed.D. program at west Virginia University has been of the highest quality. 
Faculty Perceptions - FLE xii

For

Mom 


\title{
CHAPTER ONE: INTRODUCTION
}

\author{
Overview of the Study
}

The purpose of this study was to determine the perspectives of West Virginia University (WVU) faculty from the Eberly College of Arts and Sciences, the College of Business and Economics, and the College of Engineering and Mineral Resources toward foreign language learning in the context of higher education. As an extension of this basic question, I addressed five subsidiary areas including (1) the current/historical state of foreign language education at WVU; (2) the understanding of the role and purpose that faculty from the various colleges have concerning foreign language learning at West Virginia University; (3) the benefits that skills and knowledge learned in a foreign language classroom have for students from each in each individual academic area; (4) whether changes in accreditation and certification requirements have altered the role and content of the traditional liberal core and general education classes; and (5) whether changes in the focus of foreign language study might provide links across diverse content areas?

The study was based on concepts borrowed from sociology because this discipline is the field 
in which the most characteristic and sustained effort is made to subject the events, interactions, motives, attitudes, and other elements of social behavior around us to structural analysis: that is, to throw light on these elements by discerning the patterns of norm, role, function, and meaning in which these elements are in fact to be found. (Nisbet, 1974, 73)

More specifically, the study exploits Albert Bandura's (1969/1986) social-cognitive theory and Pierre Bourdieu's (1983) field theory as its theoretical underpinning. For Bandura (1969/1986), learning is significantly influenced by the observed actions of those who surround the individual. In this sense, learners model the behaviors of those with whom they wish to associate in social or professional groups. For the purposes of this study, I am questioning whether university professors, via socialization into their academic departments and the unconscious acceptance of the mores held therein, hold differing views on questions surrounding general education requirements as well as the benefits of foreign language education. For his part, Bourdieu's (1983) models and theories influence this study by providing a framework within which we can understand that professors, administrators, and external constituents occupy the same territory within the field of education. Bourdieu (1983) 
reminds us, however, that we must be cognizant of the fact that while inhabiting the same space and "playing" the same game, each group of players possesses goals that are divergent.

Throughout this project, I will use the term "player" and its plural form to refer to individuals and groups who possess a role in the university's determination of the curricular needs of its students. In so doing, I am following in the footsteps of Bourdieu (1983) who developed many aspects of his field theory as he watched soccer matches in the Andorran region of France. Indeed, as Bourdieu observed these matches, he noticed that two teams occupied the same champs (field), each with its own set of joueurs (players) and its own set of goals set in direct opposition to its adversary. Bourdieu (1983) extended this concept of field, players, and oppositional goals, couched in the same game, to many other areas of social, political, and economic interactions. The present study, relying on Bourdieu and Passerson's (1977) extension of the concept of field to education, uses Bourdieu's (1983) models and theories to explore the actions and reactions of university professors to the changing realities of higher education curriculum.

With these ideas in mind, we can better understand how elements of Bandura's (1969/1986) and Bourdieu's (1983) models and theories can lead to a more complete understanding of the research questions being studied and a more thorough explanation 
of how the actions of individuals within a well defined context can be both complementary and oppositional. When coupled with the notion that faculty from different academic areas within the university hold divergent views, attitudes, and beliefs toward academic matters, field theory and social-cognitive theory provide a basis for delving into the basic belief systems that undergird these faculty's thoughts on the value of foreign language learning with higher education. In turn, the examination and description of the academic values that their peers hold can help the Foreign Language Department engage their academic peers in a dialog intended to create a basis for crossprogrammatic alliances and mutual understanding. That is to say that the information contained in this dissertation can be used by professors and administrators from several academic areas to find commonalities in their philosophies of education that will allow curricular and other cross-disciplinary links.

Finally, as hinted at earlier, this study was partially conceived to explore the author's personal beliefs about the construction and development of curriculum within higher education. For many, the curriculum is considered to be a contract between students and the university. It is, in this view, a document which outlines the requirements for graduation and the scope of potential courses that can be taken to complete the desired degree. Enveloped within this rather prosaic view 
of curriculum is the common, but naïve, notion that curriculum is developed in a political vacuum that harbors no unarticulated and hidden agendas. In essence, this view perceives curriculum development as an open process that emanates from frank conversation about the philosophy of education and the implications of what it means to be educated.

In the author's view, the process of determining the curriculum at the university level is far from apolitical. Rather, the process that leads to the acceptance and publication of a clean and concise document is subject to hostile actions, ill-intentions, and power plays that ultimately result in a document with which few are happy. In the end, this dirty process of concluding the curriculum contract reinforces or realigns strategic alliances formed during previous curricular battles and exposes fundamental differences in the way various academic departments, as well as university administrators and external stakeholders, view intellectual truth and the very nature of education within our society.

This view of the curriculum process as a negotiation of contractual obligations is reminiscent of Emile Durkheim's thoughts on contracts. Nisbet (1974) reminds us that for Durkheim the negotiation and conclusion of contracts, such as curriculum, create alliances that are ephemeral at best. These alliances, however, are built on more tangible experiential 
foundations that each negotiator possesses prior to and during contractual negotiations. As Durkheim suggests, these experiences are, at once, both anterior and superior to the contract itself and hinge upon the expectations of future actions and advantages. Durkheim's theories on contracts and their negotiation therefore border on Bourdieu's (1983) notions of field and habitus. In each case, players participate in a game that has pre-set and easily identifiable boundaries and rules. Yet, each player or group of players possesses divergent goals that are set in opposition to their opponents. The curriculum, therefore, is a political document informed by a myriad of groups within and outside the university while also displaying, in a public forum, the relative power structure of academic departments within the university.

Within the negotiations and compromise that precede the publication of the curriculum, all players participating in the game bring their own backgrounds, biases, subjectivities, and agendas to the process. In short, they bring radically different belief systems that must be deconflicted during the curriculum development process. Concomitant with divergent world views, players also bring varying abilities to affect the outcome of the game. That is to say that the symbolic power of their disciplines and their centrality to the emerging mission of universities privilege the contributions of some while 
forcing others into the role of silent observers of a game over which they have little real control. Given the nuances of curriculum revision and the establishment of general education academic requirements within the university, it behooves academic departments and areas that lack symbolic power to ascertain how those areas that possess both real and symbolic power view their programs and the roles that their academic disciplines play in the education of collegiate and university students. Without this knowledge, the curriculum and general education curriculum revision processes become cloaked in a darkness that privileges those who carry the guiding light of the emerging corporate university.

Beyond the author's interest in Bourdieu's and Bandura's social theories and the process of curriculum development, this study emanates from three additional sources. First, the author has worked as an instructor of both French and English as a Second Language (ESL) at the college and university level for well over fifteen years. In addition to teaching languages, the author also spent 12 years as the director of ESL programs in West Virginia and Texas. These experiences are the basis for many of the beliefs and questions that underpin this study. Secondly, in spite of recent calls for a renewed emphasis on the study of languages, students are abandoning foreign language study in favor of academic fields that have more apparent 
immediate work or research related benefits. Finally, universities are increasingly adopting a for-profit accountability structure that has resulted in the downsizing of liberal arts programs in favor of technical fields that promise an influx of federal or industrial research funds. In significant ways, this shift in emphasis has led to the creation of vocationalized institutions of higher education that privilege job training over traditional notions of education for individual growth and personal emancipation (Grubb \& Lazeron, 2005; Bagnato, 2005; and Clowes \& Levin, 1989). The author of this study believes that this new phase of higher education has greatly eroded the importance of academic areas situated within the liberal arts that had traditionally underpinned academic requirements, including foreign language departments.

\section{Foreign Language Education}

Like almost all academic programs within higher education, foreign language departments respond to both local and national social, economic, and security shifts (Hines, 2003; Lantolf \& Sunderman, 2001; and Clowes \& Levin, 1989). Often, new trends and an increased interest in the teaching and learning of foreign languages are pressed upon the academic community by geo-political events that shock the national government into action. Indeed, the onset of World War II and the need for 
specialized language users pushed the United States Army to employ second-generation Japanese living in California to instruct service men in the Japanese language. From these humble beginnings, the Army Language School (later renamed the Defense Language Institute), one of the oldest and most wellknown language learning centers in the United States, expanded to teach more than 30 languages considered central to national security (Aggeler, 1950). When, only a few years later, the Soviet Union launched Sputnik in the fall of 1957, the nation was once again confronted with an unexpected and urgent need for speakers of other languages as well as scientists and engineers capable of turning the tide in the nation's intellectual battles with the Soviet Union (Kliebard, 1995). Following the launch of the satellite and scathing criticism of the nation's schools by such public intellectuals as Admiral Hyman Rickover, the United States congress passed the National Defense and Education Act (NDEA) of 1958. This direct response to the launch of sputnik provided significant funding for research and scholarship intended to improve the nation's competence in many areas, including foreign languages, and continued the trend of reactionary changes in language policy (Hines, 2003; and Hohendahl, 1998).

Again today, the importance of foreign language learning is being discussed in the halls of the White House, the Capital, 
and American business and industry. President George W. Bush's National Security Language Initiative, a call for increased study of languages important for national security, continues a dialog that places the nation's ability to interact with others as a key element in combating terrorist actions against the country (Liebowitz, 2006). In recommending that the nation's colleges and universities focus their language teaching efforts on less commonly taught languages, including Arabic, Farsi, Chinese, and Hindi, President Bush and policy makers within and outside the government hope to not only augment the nation's ability to fight terrorism at home, but also wish to promote democracy and America's brand of freedom around the world (Graham, 2006; Liebowitz, 2006).

National security and attempts to avoid foreign policy disasters (Long \& Long, 2001; Unks, 1983; and Simon, 1981) are not, however, the only motive underpinning renewed efforts to privilege foreign language education. Paralleling these security-oriented arguments for language study, neoconservatives and neo-liberals clamor for language study as a means to halt American business's long slide into economic irrelevancy (Graham, 2006). Their rhetoric centers on the decline in the nation's ability to conduct business abroad and consists of dire warnings of economic collapse amid a loss of global competitiveness brought on, at least in part, by 
America's inability to communicate with potential trading partners (Apple, 1996; Liebowitz, 2006).

Yet, in the context of a renewed interest in foreign language education, two powerful undercurrents appear to diminish the potential that foreign language programs have to recover their place in higher education. First, as hinted at above, language study has come to epitomize the essentialist movement in education. That is to say that language study no longer embodies liberating principles and the idea that via the understanding of "the other" we can better understand ourselves. Rather, language study is seen as a utilitarian tool that must be a part of the country's toolbox as it repairs industry's global competitiveness and national security networks. The effects of this removal from the core academic foundations to an important, yet peripheral role in education has destabilized foreign language departments and left them ungrounded in a changing academic landscape.

The second undercurrent that prevents foreign language education from recovering its place in higher education is the lack of articulation between national education policy and student choice. Just as national leaders call for more speakers of diverse languages, students in both secondary and higher education are taking fewer foreign language classes. This trend, in evidence since the early 1960s, is born out in a 
recent study conducted by the American Council on the Teaching of Foreign Languages. Findings from this study suggest that only one-third of high school and nine percent of college students take courses in foreign languages.

Still worse, perhaps, is the discovery that another government initiative, the No Child Left Behind Act (NCLB), has had the unintended consequence of pushing school districts to privilege language arts and math over foreign language and science education (Ashford, 2004). The privileging of these subject areas can be attributed to their intuitive relationship to high stakes tests that purport to measure the skill levels of American students in core academic areas vis-à-vis their counterparts from other nations. As a consequence of focusing rather narrowly on standardized tests as a measurement of ability, foreign languages and other equally important liberal arts subjects have been de-emphasized.

In addition to the contradictory nature of national initiatives, colleges themselves have become enamored of the business model of education. In the spirit of cost cutting, which is not to say downsizing, the nation's colleges and universities have begun to look critically at academic departments that have low enrollment and high associated costs (Hohendahl 1998). This streamlining, or what institutions innocuously refer to as "retrenchment," provides the rationale 
on which the evaluation of programs can be based on their "centrality" to the university, a code word for the potential generation of revenue (Rhoades \& Slaughter, 1997). This move toward bottom-line accountability has resulted in the loss of faculty jobs in the liberal arts area in favor of faculty lines in the applied social sciences (Frank \& Gabler, 2006; Rhoades \& Slaughter, 1997).

A part of this move toward accountability stems from a decline in student enrollment in foreign language courses and the accompanying perception that foreign language departments are overstaffed. Welles' (2004) recent study on foreign language enrollment within higher education provides longitudinal evidence that enrollment in foreign language classes, with the sole exception of Spanish, has been in steady decline over the past $4 \odot$ years. The figures are clear and depressing. In 1960, 16 percent of students enrolled in higher education took a foreign language class. By 1995, this number had fallen to only 7.6 percent (Brod and Huber, 1996). Today, while the overall slide in enrollments in foreign languages programs has tapered off, foreign language enrollments only comprise roughly eight percent of total college/university enrollments (See Table 1.1). 
Table 1.1. Modern Foreign Language (MFL) Enrollments, 1960-2002

\begin{tabular}{ccc} 
Year & MFL & MFL Enrollments \% \\
\hline 1960 & 608,749 & 16.1 \\
1965 & 975,777 & 16.5 \\
1970 & $1,067,217$ & 12.4 \\
1977 & 883,222 & 7.8 \\
1980 & 877,691 & 7.3 \\
1986 & 960,588 & 7.7 \\
1990 & $1,138,880$ & 8.2 \\
1995 & $1,096,603$ & 7.7 \\
1998 & $1,151,283$ & 7.9 \\
2002 & $1,347,036$ & 8.6 \\
\hline
\end{tabular}

Table Adapted from Welles (2004)

Table 1.2. Foreign Language Enrollments for Selected Languages

Enrollments in Selected Languages

\begin{tabular}{lccccccc}
\hline & 1960 & 1970 & 1980 & 1990 & 1995 & 1998 & 2002 \\
\hline Spanish & 178,689 & 389,150 & 379,379 & 533,944 & 606,286 & 656,590 & 746,267 \\
French & 228,813 & 359,313 & 248,361 & 272,472 & 205,351 & 199,064 & 201,979 \\
German & 146,116 & 202,569 & 126,910 & 133,348 & 96,263 & 89,020 & 91,100 \\
Japanese & 1,746 & 6,620 & 11,506 & 45,717 & 44,723 & 43,141 & 52,238 \\
Russian & 30,570 & 36,189 & 23,987 & 44,626 & 24,729 & 23,791 & 23,921 \\
Arabic & 541 & 1,333 & 3,466 & 3,475 & 4,444 & 5,505 & 10,584 \\
\end{tabular}

Table Adapted from Welles (2004)

What is not evident in this stabilization of foreign language enrollments, however, is a hidden undercurrent of systemic problems that continue to threaten the health and 
existence of college/university-based foreign language departments. First, the data presented in Table 1.2 clearly indicates that enrollments in the traditional foreign languages, including French and German, have suffered significant losses. Data from the 1990s show that enrollment in French courses declined by almost $25 \%$ while German courses, with a decline of almost 28\%, suffered even greater losses (Hohendahl, 1998). Second, the slight growth of foreign language enrollments in recent years is offset by increases in overall enrollment in higher education that have outpaced foreign language enrollment growth (Welles, 2004). Additionally, only $10 \%$ of foreign language students actually achieve functional proficiency in the language they study (Hines, 2003). This figure stands in stark contrast to European countries where national language policies have resulted in more than $50 \%$ of adults self-reporting fluency in a second, and sometimes third, foreign language (Christian, 2005). Another problem that foreign language programs face is the hegemony of Spanish in their language programs. While the number of students enrolled in less commonly taught languages has grown over the past several years, Spanish continues to dominate the language teaching landscape. Of the almost 1.4 million language learners accounted for in 2002, over one-half were enrolled in Spanish programs, making this single language more popular than all other languages combined (Welles, 2004). 
Finally, the rise of English as a Second Language (ESL) and the use of English as the world's lingua franca threaten the potential that foreign language departments have for regaining relevance in higher education. With all these factors in mind, it is clear that internal and external constraints pressure language programs and affect their ability to enter into constructive dialog with administrators or other academic departments .

Statement of the Problem and Purpose of the Study Foreign language education has been an important part of higher education since the founding of the nation's first colleges in the Colonial period of American history. However, as the purpose of education and language study evolved from privileging the study of esoteric phenomena to a vocationalized version of education that promotes job training, foreign language programs were trapped and eventually isolated by their failure to reform their language programs. The failure of foreign language programs to embrace practical language training resulted in an erosion of funding and a loss of place within the university. Today, foreign language programs face administrative demands to "right size," a rather innocuous term for downsizing. These external pressures, when coupled with internal strain caused by the domination of spanish in foreign 
language departments, have caused foreign language programs to further isolate themselves from the university community. In turn, this has resulted in a failure to seek out and create strategic cross-departmental alliances that can forestall departmental closings or further erosion of funding and academic place. Finally, the rise of non-traditional languages threatens the once-dominant western languages and creates fissures in foreign language departments that can ill afford internal power struggles and strife.

A primary consideration, therefore, in conducting this study was to gather information, in the form of documents, statistical profiles, and faculty perceptions, of the historical and current state of foreign language education at West Virginia University. A second consideration was to assess faculty perceptions of the role of foreign language education within the contemporary university. Concomitant with this second rationale, this research attempted to uncover faculty understanding of the skills and knowledge that learning a second language can offer students engaged in a wide-range of academic programs. Along with these areas, the project attempted to delve into issues associated with the rise of accreditation and its role in the restructuring of degree plans. Finally, the project questioned how the Foreign Language Department at west Virginia University might create alternative curricular programs 
that would serve to broaden its appeal to students who have traditionally not been interested in foreign language study.

\section{Research Questions}

The discussion in this study centers on the question of differences among faculty with regards to their attitudes and views toward foreign language learning within the context of higher education. Given the importance of context and the academic values, behaviors, and beliefs of individuals who inhabit the educational environment, the theoretical framework on which the study is based is Albert Bandura's (1986) socialcognitive theory and Pierre Bourdieu's (1983) field theory and concept of habitus. The purpose of this study is to determine the perceptions of WVU faculty from the Eberly College of Arts and Sciences (ECAS), the College of Business and Economics (CB\&E), and the College of Engineering and Mineral Resources (CEMR) toward foreign language learning in the context of higher education. In addition to the primary question, the following subsidiary questions will be addressed:

1. What is the historical/current state of foreign language education at WVU?

2. What is the faculty's understanding of the role and purpose of foreign language learning at WVU? 
3. What benefits do the skills and knowledge learned in a foreign language classroom have for students from your academic area?

4. How have changes in accreditation and certification requirements altered the role and content of the traditional liberal core and general education classes?

5. How might an increase in applied foreign language study, defined as practical applications of language use, provide a link across diverse content areas?

\section{Qualitative Research Methodology}

This work will be based on qualitative fieldwork conducted at West Virginia University, in Morgantown, West Virginia. I chose to use qualitative research methods because they lend themselves well to exploratory questions in areas that have not been previously studied (Strauss \& Corbin, 1990). Additionally, Patton (2002) emphasizes that qualitative methods allow the researcher to determine what participants know, think, and feel via the use of interviews that provide rich and textured data filled with possibilities for determining the "meaning people have constructed" and "how they make sense of their world and the experiences they have in the world" (Merriam, 1998, p. 6). 
I have chosen to follow Albert Bandura (1986) and Pierre Bourdieu (1983) for the theoretical framework because their theories lend themselves to the discovery of how individuals make sense of their world and act to influence the conditions in which they live and work. In the case of professors who work within the confines of the higher education context, past experiences and their understanding of the purpose of education influence their concepts and appreciation of the relevance of foreign language study. By understanding how habitus, the term Bourdieu (2002) uses for cumulative past experiences and future expectations, influences the actions and beliefs of professors, I can better judge professorial attitudes toward foreign language learning.

To capture these attitudes, I used individual guided interviews that lasted between 45 and 75 minutes. I was granted approval from the West Virginia University Institutional Review Board for the Protection of Human Subjects (IRB)(See Appendix E, pages 128-139 for the IRB Application and Appendix F, pages 140141, for the letter of approval), and interviewed between 12 university professors and members of the university's staff. The faculty participants were equally distributed among the university's Eberly College of Arts and Sciences (ECAS), College of Business and Economics (CB\&E), and College of Engineering and Mineral Resources (CEMR). 
To provide a measure of triangulation, briefly defined as the collection and use of multiple data sources to ensure the reliability of results (Wiggins, 1998; Jacob, 1990; and Maxwell, 1996), I analyzed university documents that offered a glimpse into the recent past and changes in enrollment trends within the university. This included statistical profiles published by the university until $1998^{i}$ and various other documents, including course bulletins, mission statements, and course requirements, gathered from West Virginia University's Wise Library.

\section{Significance of the Study}

The importance of understanding the attitudes of university professors who hail from widely different academic backgrounds toward the role and purpose of foreign language education in the context of higher education is an important component in the formation of dialog and communal understanding of the future of foreign language education in the United States. However, the author found no previous studies that purport to explore the questions addressed in this research project. Therefore, the results of this study

1. can be used to situate foreign language education within its historical context and to explore its 
future within the increasingly vocationalized and corporatized university

2. can provide information to WVU's Foreign Language Department as it examines its place within its own specific context and as it seeks links with the broader university community

3. can provide other universities of similar size, scope, and mission with a better understanding of their own faculty's attitudes toward foreign language education and the possibilities of improving the integration of the foreign language program in the university academic community.

\section{Study Components}

This study drew on interviews of faculty from west Virginia University's Eberly College of Liberal Arts, College of Business and Economics, and College of Engineering and Mineral Resources. The personal responses and experiences of these individuals were complemented by information gathered from west Virginia University publications and statistical profiles from the 1960s to the present. Finally, I used a variety of sources, including Carnegie Foundation reports and other literature to triangulate the results of the study. 
This study is divided into five chapters. Chapter one contains the introduction to the study as well as the rationale, statement of the problem, and research questions. Chapter Two contains a brief introduction to the history of foreign language learning within higher education in the United States as well as a literature review that encompasses current trends in foreign language enrollment in higher education, a brief discussion on traditional rationale underpinning foreign language study within the university system, and a section that provides a brief overview of the importance of Bourdieu's field theory and habitus. Chapter Three provides the proposed research methodology to be used in the study. Chapter Four provides the results of the study. Chapter Five offers a discussion centered on the author's findings and interpretation of the results, a section outlining implications for the future of foreign language departments and foreign language study within the university, and a final discussion of suggestions for further study .

Operational Definitions

Attitudes: Attitudes are defined as "a positive or negative sentiment, or mental state, that is learned and organized through experience and that exercises a discrete influence on the affective and conative 
responses of an individual toward some other individual, object, or event" (Palaigeorgiou 2005, p. 39) .

Qualitative Method: A research technique that relies on the extensive collection of narrative data in a naturalistic context to gain insights about not possible with other types of method (Patton, 2002). Purpose of Foreign Languages: The concept of why foreign language education is important in the broader community (national and international) that surrounds the university.

Role of Foreign Languages: The concept of what place the foreign language and foreign language requirement has within the academic core of university studies.

\section{Summary}

This introductory chapter included the introduction to the study as well as specific information on the current state of foreign language education in the United States, statements of the problem and the purpose of the study, a description of the proposed research model, as well as the research questions, significance of the study, and the operational definitions employed. Overall, it is suggested that although foreign language departments are a historical part of higher education, 
they are facing unprecedented pressure in light of declining enrollments, the changing nature of higher education, and essentialist concept of the benefits of learning a foreign language that focus on utilitarian rather than humanistic goals. 


\title{
CHAPTER TWO: LITERATURE REVIEW
}

\author{
Introduction
}

Foreign language education has a long history as an integral part of higher education. Yet, in the contemporary university, foreign language learning has not kept apace of the perceived needs of the university or society, higher education's primary stakeholders. That is to say that foreign language departments have continued to espouse the notion of language for literature even as it becomes increasingly apparent that foreign language learning has been given over to an essentialism that sees languages as a tool that can help the nation gain economic advantages in the global marketplace or that can be used in the nation's battles against terrorism. Compounding this problem is the university's recent turn to bottom-line accountability practices that privilege growth-oriented and revenue-positive academic and research areas. Given that enrollment in foreign language programs has been in steady decline since the late 1960s, even in the face of renewed calls for the development of America's linguistic capacity, foreign language departments and traditional language study find themselves in jeopardy of succumbing to the constricting forces of the educational essentialist and accountability movements. 
This general assessment of the current state of foreign language education serves as the basis for the review of literature that follows. In specific terms, this chapter provides a brief overview of the history of foreign language education in the United States and portrays changes in the role of language learning as a move away from the study of languages for self-liberalization (expanding one's horizons) toward the utilitarian roles mentioned above. Further, the review of literature sets the context of this study by focusing on foreign language programs within the university setting and by outlining the historical raison d'être of language study that foreign language departments provide. This section is followed by a brief introduction to the importance of Bandura's (1969/1986) Cognitive-Social learning theory and Bourdieu's (1983) field theory and concept of habitus as they relate to the primary research questions addressed in this project. Finally, the chapter concludes with an overview of West Virginia University, the context within which this study is set.

Overall, this review of literature suggests that foreign language departments face unprecedented challenges as they struggle to recover a significant place within the modern multiversity. The precarious position of foreign language programs is exacerbated by an ill-preparedness to confront the crisis that stems from loss of enrollment and a change in the 
values that underpin the university curriculum. Even within this rather bleak scenario, however, foreign language programs possess the capacity to halt the erosion that has led to loss of faculty and place within the university. To begin the process of recovery, the literature suggests that foreign language faculty and administrators must attempt to understand how others view the role foreign language education plays within higher learning. Through the comprehension and consideration of the beliefs and values that faculty from various university academic colleges hold toward foreign language education, foreign language programs can begin to engage the academic community in constructive dialog as they seek to recover meaning in an academic world from which they seem increasingly alienated.

$$
\text { Foreign Language Education - History }
$$

Foreign language education has been a part of higher education curricula since the founding of the nation's first colleges in the late $17^{\text {th }}$ century. Classical languages, including Latin, Greek, and Hebrew were not only a part of the courses required of students, they were closely intertwined with the concept of higher education. Indeed, although there were occasional concessions to the students and the general public, the majority of all official public activities at these early colleges were conducted in Latin (Thelin, 2004; Cohen, 1998). 
In addition, all classroom activities, including responses to questions posed by professors as well as exams and recitations were conducted in Latin (Rudolph, 1977). With this in mind, it is not unreasonable to suggest that the classical languages, although no longer used in society at large, formed the backbone on which early collegiate education was based in the United States.

While Latin, Greek, and Hebrew dominated the language teaching field, there were numerous early attempts, including curriculum proposals at the University of the State of New York and Princeton to overthrow the hegemony of the classical languages. For example, specially admitted non-degree seeking students at Princeton were allowed to enroll in language courses that taught French and which provided a certificate of proficiency upon completion of the program (Kliebard, 1995). Ultimately, this, and other, early curriculum revisions in favor of modern languages failed and resulted more often than not in curricular changes that altered the scope of classes that students were allowed to take outside the core and required courses (Kliebard, 1995). It was not until the late 1700s that American universities began an experiment with other languages that challenged and to a small degree supplanted the primacy of the classical languages. 
In 1779, French entered the formal program of studies at William and Mary in Virginia. Only a few short years later, Hampden-Sydney, also in Virginia, allowed courses in French to substitute for Greek in Bachelor of Arts programs. At about the same time, Harvard (1787) allowed French to substitute for Hebrew and Williams (1793-1799) permitted French to replace Greek as an admissions subject (Rudolph, 1977). This turn toward French was caused, at least in part, by America's fascination with the French Revolution and the democratic ideals that it espoused. However, Rudolph (1977) suggests that the appeal of France and the French language quickly evaporated as the nation's academic structure cooled to the French nation and language as the excesses of the French revolution became public and a conservative reaction to the quickly changing college curriculum surfaced.

These early reactions against Latin, Greek, and Hebrew demonstrated one immediate and one long-term undercurrent in foreign language education. First, the initial reaction to calls for change showed that classical languages, while holding an important and respected place in the American university curriculum, were vulnerable to challenges from living languages. Secondly, the unfolding history of foreign language education within higher education would reveal that flirtation with quick changes, often reactionary in nature, was to become a near 
constant in the policies that affected foreign language curricula at American colleges and universities (Rudolph, 1977). Indeed, one of the earliest examples of changes to language curriculum and policy intended to meet the challenges of the time was the revamping of university admissions requirements that occurred in the late 1800s. As the number of colleges grew in the United States during the $19^{\text {th }}$ century, the number of college students stayed relatively flat (Rudolph, 1977; Thelin, 2004; and Cohen, 1998). The stable enrollment rates, when coupled with an increase in the supply of colleges, created intense competition among the colleges and resulted in an admissions compromise that allowed students to substitute a modern language for one of the classical languages (Rudolph, 1977). This concession to students ultimately signaled the beginning of the end of the classical language hegemony in the nation's colleges.

While changes in admissions requirements and courses required for graduation were an important development in the history of foreign language education in American colleges, the issue of which languages to teach was eventually decided not by reason and artfully expressed rhetoric on the inherent value of classical and modern languages. Rather, the founding of Johns Hopkins, based on the German system of higher education, introduced the American academic community to the university 
model in 1876 (Thelin, 2004). While use of the German model of higher education hastened the American university's establishment of academic units and departments, the influence that Germany's universities had on their American counterparts went beyond the administrative level. Indeed, the vast quantities of research and publications emanating from Germany had an important affect on foreign language education in the United States. Enrollment in university-based German language courses increased as American students in doctoral and other advanced programs were encouraged to learn German as a means of accessing the cutting edge work coming from Germany.

The prevalence of German and the availability of other modern languages completed the decline of classical languages within the university. Yet, even as more courses became available to students, the manner in which foreign language courses were conducted changed little. As with other academic areas, the language faculty held onto the belief that the study of language promoted the exercise of the students' mental faculties. It was not until the outbreak of World War II that the need for functional language users broke the foundations on which languages were taught and prompted instructors to focus on oral and aural skills rather than verb conjugations and rote vocabulary translations. 
When the Army Language School (ALS) at Monterrey, California opened its doors in the 1940s, it originally used native speakers of Japanese to teach American servicemen Japanese for wartime service to the nation. From these beginnings, the ALS, later renamed the Defense Language Institute (DLI) expanded to teach a variety of languages deemed important in the defense of the American nation (Aggeler, 1950). Although very successful in its efforts to teach less commonly taught languages, the opening and immediate achievements of the DLI represented a little understood threat to the idea of foreign language education as part of the liberal arts core. By teaching languages deemed important to the security of the country, foreign language education was co-opted by the federal government and removed, at least philosophically, from the liberal arts core and placed firmly in a vocational area inhabited by sciences, math, and other disciplines placed on the front line of national defense.

The move toward the study of languages for utilitarian purposes and national defense was further hastened in the late 1950s when geo-political events pushed foreign language education even deeper into an essential role. With the Soviet launch of Sputnik, Americans were lifted from the complacency of their increasingly suburban lives while the government initiated its own series of educational reforms intended to overcome 
perceived deficiencies in American higher education (Thelin, 2004, Hohendahl, 1998). Indeed, the post-Sputnik passage of the National Defense and Education Act (NDEA) of 1958 and world events set the stage for increased outside control of education and increased pressure on foreign language programs to produce speakers of foreign languages who could interact almost flawlessly with the nation's enemies (Hohendahl, 1998; Hines, $2003)$.

In many ways, America's re-opening to the world following the conclusion of World War II and the terror brought on by what was perceived as creeping Soviet domination in world affairs, enabled by their advantages in languages and sciences, created a new and perhaps golden era for foreign languages in the United States. As the United States forewent its pre-war isolationist tendencies, the nation sought increased engagement with the world and more specifically, Europe (Stavans, 2005). The second half of the twentieth century also saw a fundamental change in the way in which the study of languages was approached and built on earlier pedagogical efforts to teach language use and not simply the literature of the language. Indeed, Stavans (2005) notes that teachers began to question, although with limited early success, the taken-for-granted teaching practices that had been imposed, in a top down fashion, from language purists in the literary tradition. 
The questioning of language teaching that began with the development of the DLI accelerated as research in pure linguistics (Chomsky, 1957/1959), pragmatics and performance (Hymes, 1972/2000), and second language acquisition (Terrell, 1977; Krashen, 1982; and Dulay \& Burt, 1974) altered the way in which language professionals considered both first and second language acquisition. When coupled with Canale and Swain's (1980) and Savignon's (1972/1983) work in aspects of communicative competence, these changes affected the way in which language teachers approached teaching and helped usher in an era dominated by communicative approaches to teaching.

In a very real sense, language teaching in the communicative era, with its goal of producing individuals who are capable of communicating with native speakers of the foreign language, meshes well with the educational essentialist movement that sees languages as a tool in the nation's battles for economic competitiveness and national security (Grosse, et al., 1998; Unks, 1983; and Vogel, 2001). Moreover, with language now tied to measurable results, language programs have become accountable for their efforts at teaching students the skills needed for economic and international security success.

Riding the growing tide of accountability, accreditation, not long ago regarded as outdated and disappearing, is reappearing with a vengeance on the nation's college and 
university campuses (Wergin, 2005). This time, however, accreditation no longer focuses on the processes, procedures, and various other inputs that were central to the accreditation process prior to 1980 (Davenport, 2001). Rather, as the nation strives for greater accountability for student learning, accreditation is incorporating outcomes into the review process (Wergin, 2005; Davenport, 2001; and Zionts, Shellady, \& Zionts, 2006 ) and requiring that universities demonstrate student achievement "as the sine qua non of academic quality" (Wergin, 2005, 35). While accreditation, especially program specific accreditation, is often associated with professional programs (Davenport, 2001; Wergin, 2005), foreign language departments and foreign language teacher training programs have not escaped the accreditation frenzy or the growing emphasis on student outcomes. Standards adopted by the National Council for Accreditation of Teacher Education (NCATE) in 2000 require that foreign language teachers, in most commonly taught languages, achieve at least an advanced proficiency level ${ }^{i i}$ on the American Council on the Teaching of Foreign Languages (ACTFL) proficiency exam prior to certification. By focusing on speaking ability, the new standards conflict with the traditional notions, present in foreign language programs, about what it means to know a foreign language and sends an unmistakable message to foreign 
language departments that change in the way foreign languages are taught must occur.

Any mention of accountability cannot, however, be limited to academic outcomes and measurable student results. In today's modern multiversity, bottom-line financial accounting has assumed an important and perhaps determining role in the planning and operations of institutions of higher learning. As states faced severe budget crises in the early 1980s, brought on part by taxpayer revolts and a continued downturn in the nation's and states' economies, university allocations were significantly cut. Between 1980 and 2000, Lyall and Sell (2006) show that "the share of state revenues appropriated to public higher education declined from 9.8 percent to 6.9 percent, a nearly $30 \%$ decline in two decades" (p. 11). In one particularly harsh year (1990-1991), 30 states not only slashed their allocations to higher education, but also raised tuition rates by over $30 \%$ to offset these declines (Cage, 1991).

Economic problems of the Reagan-era were no doubt a catalyst for fiscal changes at universities. However, the origins of the fiscal accountability movement that swept the nation's colleges and universities in the latter portion of the twentieth century can be traced to the earlier work of James B. Conant, the long-time president of Harvard. Conant worked hard to come to terms with the intricacies of administration by 
developing a management plan that could be applied to the typical American university (Douglas, 1954). While Conant acknowledged three essential elements, namely financial solvency, a study body of high quality, and an outstanding faculty, as necessary for the existence of a university, his chief concern was for a strong fiscal policy that balanced the university's budget and provided a margin for unexpected expenditures. For Conant, this insistence of bottom-line thought processing was fundamental for a flourishing university poised to meet immediate and long-term challenges (Douglas, 1954). Following this logic, Conant espoused the notion that each department must stand or fall on its own merit and that the university should privilege academic programs from which the most overall benefit could be derived (Douglas, 1954). In the late twentieth century, similar evaluations of the centrality of programs to the university have become more common as programs such as sociology (Coughlin, 1992), humanities (Heller, 1993), and classics (Monaghan, 1993) have been removed from universities or merged with other programs in moves intended to help universities cut operating expenditures.

Questions of accountability and educational essentialism have also led to a re-evaluation of education at the highest levels. Indeed, a final and important element in understanding the history and role of foreign languages at the university and 
more particularly faculty beliefs about language learning came from movements to eliminate the foreign language requirement for Ph.D. students that began in the late 1960s. From the beginning of the American university movement in the late 1800s, America institutions of higher education adopted the German model of university structure and tailored it to the needs of the nation (Thelin, 2004; Sleeper, 2001; and Cohen, 1998). A significant part of this educational model was the creation of the Ph.D. with an array of accompanying traditions and assumptions that underpinned the requirements for these advanced degrees (Damrosch, 2000). Among these traditions, of course, was the requirement for proficiency in at least one, and more often than not, two foreign languages. Although students in advanced programs of study often railed against the necessity of learning to read in a second or third language, this requirement produced generations of scholars who were, at a minimum, familiar with languages and language study.

Against the backdrop of the social upheaval that occurred in the 1960s, many traditions in academe, including the foreign language requirement for doctoral degrees, were re-examined and often eliminated. Lurking behind these actions were two forces that pushed for democratization of education as well as the creation of technically savvy researchers who were well versed in their particular fields. Regarding the first concept, 
Sleeper (2001) suggests that the perception of elitism associated with foreign language study drove many of the malcontents of the era to push for changes that promoted democratic principles in education. A significant symbol of the elitism that had, in the minds of these reformers, restricted access to the Ph.D. was the foreign language requirement. Student and faculty reformers of the period sought and won concessions that eliminated many of the foreign language requirements for the Ph.D. as well as other advanced degrees. At the same time, many people in and out of education looked back to the origins of the land-grant university and its emphasis on the practical with a longing for the simplicity of the model and mission of these institutions (Damrosch, 2000). Indeed, returning to the roots of the land-grant tradition in American education, dating from the passage of the Morrill Land Grant Acts of the late nineteenth century, many universities began to prize serviceable knowledge that was laced with a practical tilt (Stimpson, 2004). With this mind, it is clear that as technical fields became more complex and began their ascent to dominance in the modern university, the meaning of education within the sciences changed. Philosophy was pushed aside for technical courses and the need to know other languages was eliminated as the majority of the world's scientific publications began to be produced in English. 
Within the context of academic and financial accountability and educational essentialism, foreign language departments face challenges to their educative role in the corporatized multiversity. Indeed, whereas colleges and universities were once a single community comprised of students and masters, held together by their unified belief in the purpose of the institution, today, the related functions originally present in the diverse student body and faculty members seem to have melted into a cacophonic onslaught of myriad voices intent on protecting and enlarging their space, often at the expense of their academic brethren (Kerr, 2001). Long gone, and perhaps lost forever, is Cardinal Newman's (2003) vision of the university as a cohesive intellectual cloister that fortifies the mind with intellectual pursuits, fosters an intellectual culture for its own sake, and privileges "liberal knowledge" over the practical knowledge of the day that faded quickly with each new scientific or technical advance.

In this new era of higher education, some (Illich, 1970; Zehev, 2006) suggest that as professional schools overtook and eventually surpassed the importance and place of their more traditional rivals in the academic community, universities ceased to be places of "truth searching" and became "certificate mills" and job-training units intent on chasing the latest academic fads that promise increased enrollment, even if only 
temporarily. In essence, following a long history in higher education, foreign language departments and the contemporary multiversity, intent on implementing accountability-based management principles, are meeting in a collision of two grand narratives, one embracing the power of traditional learning as a means of enlightenment and the other extolling the virtues of practical and profitable information. It is at the intersection of these two grand narratives that liberal arts and foreign language programs now find themselves. Further, it is in this new and unfamiliar environment that foreign language programs must now work to articulate a clear message of what they can offer vocational and corporatized universities so that they can create and recover a sense of place within the academic community .

Yet, as we will see below, the role and importance of foreign language learning has been circumscribed by loss of enrollment at the national and local (West Virginia University) levels as well as a stubborn insistence on maintaining the outdated status quo within foreign language programs. When structural issues and the rise of the technical fields are also factored into the equation, foreign language programs are increasingly disconnected from the academic mainstream and find creating or recovering their sense of purpose and place difficult, at best. 
National Trends in Foreign Language Enrollments

The Modern Language Association of American has long amassed figures on the growth, decline, and tepid resurgence of foreign language education in the United States (Welles, $2002 / 2004)$. Over the course of the $20^{\text {th }}$ century, enrollments in foreign language classes and the distribution of students among the languages taught in the nation's schools and colleges have fluctuated with each new geo-political event (Lantolf \& Sunderman, 2001; Werner, 2006). In the early stages of the $20^{\text {th }}$ century, the study of German dominated the field as higher education in the United States modeled itself after German institutions. However, with the outbreak of World War I and the turmoil of the interwar years, the influence and importance of German waned. Following the outbreak of World War II, national security and the war-time effort once again brought German to the forefront of language education. This time, however, it was joined by an increasingly varied array of languages, including Japanese and Russian. Following the end of World War II, national attention was caught by the need to continue and expand the study of Russian as the cold war heated up and the world became a political and cultural battlefield for the two superpowers. However, as important as earlier world political and social events were, perhaps no single episode of international Super Power play hastened the country's need for 
language experts more than the launch of Sputnik, the small Soviet satellite sent into orbit in the fall of 1957 . This single event brought about a dizzying array of new programs, begun by appropriations from the National Defense and Education Act of 1958 (Kliebard, 1995; Hines, 2003; and Hohendahl, 1998). This act provided funding for the teaching of languages, math, and sciences, three areas considered essential for national security (Hines, 2003; Hohendahl, 1998). It is not surprising therefore, that Modern Language Journal figures show a spike in foreign language enrollments in the 1960 s as well as an accompanying diversification of the languages taught. However, with the cooling of the cold war and the immediacy of the Sputnik era gone, foreign language enrollment figures from the 1970 s and 1980s show a marked decline (Welles, 2002/2004). Within this overall decline of foreign languages, the data presented in Table 2.1 paint a tale of three distinct trends. First, and perhaps most important for the traditional university-based foreign language department, is the decline (with the exception of Spanish) of the established foreign languages. Although French and German remain more popular than all languages except Spanish, their privileged place among languages has been eroded over the past 35 years. As recently as the late 1960s, French was the language of choice among students. Yet, in the intervening 40 years, enrollment in 
French has declined (by $48.0 \%$ ) to the point where French programs now have less than one-third the enrollment of Spanish. German, once almost equal in stature to Spanish and French, has lost $57.9 \%$ of its enrollment and now competes as a third-tier language vying for a place with such upstart languages as Japanese, Chinese, and Arabic. Finally, in the post-Cold War world, Russian has lost almost half of its enrollment, a situation exacerbated by traditionally smaller numbers than in either French or German (Welles, 2004).

Table 2.1. Foreign Language Enrollments for Selected Languages

\begin{tabular}{lccccccc}
\hline \multicolumn{7}{c}{ Enrollments in Selected Languages } \\
\hline Spanish & 178,689 & 389,150 & 379,379 & 533,944 & 606,286 & 656,590 & 746,267 \\
French & 228,813 & 359,313 & 248,361 & 272,472 & 205,351 & 199,064 & 201,979 \\
German & 146,116 & 202,569 & 126,910 & 133,348 & 96,263 & 89,020 & 91,100 \\
Japanese & 1,746 & 6,620 & 11,506 & 45,717 & 44,723 & 43,141 & 52,238 \\
Russian & 30,570 & 36,189 & 23,987 & 44,626 & 24,729 & 23,791 & 23,921 \\
Arabic & 541 & 1,333 & 3,466 & 3,475 & 4,444 & 5,505 & 10,584 \\
& & & & & & 1998 \\
\hline
\end{tabular}

Table Adapted from Welles (2004)

The second trend apparent in Welles' (2004) study is the rapid rise of less-commonly taught languages. Arabic, Japanese, Chinese, and American Sign Language have all gained enrollment at the expense of the more commonly taught languages. For 
Japanese, significant increases occurred during the 1980s when Japanese business practices launched the nation onto the global economic scene. More recently, the study of Arabic has gained ground as the American nation attempts to come to terms with and combat the threat of terrorism in the post september 11 world. Finally, the third trend apparent in the data is the ascendance of Spanish to the role of the dominant language in foreign language departments. While the data suggest that Spanish had been, since at least 1960, an important player in the foreign language field, the rapid rise of Spanish during the latter portion of the $20^{\text {th }}$ century caught many foreign language departments off guard and gave rise to tensions within the departments that continue to simmer only slightly below the surface (Bernhardt, 1997; Foster, 1999; Gay-Crosier, 1987; and Hines, 2003).

In Welles' (2004) study, overall enrollment in foreign language programs stood at approximately 1.4 million students, or about $8 \%$ of the overall student population. Although this figure has been relatively constant over the past several years, the stabilization of foreign language enrollment hides an undercurrent of doubt that serves to temper optimism. Perhaps the primary culprit for this fear within the field stems from the distorted enrollment figures so visible in Welles' (2004) survey. Indeed, of the 1.4 million students enrolled in foreign 
language classes at American institutions of higher education, over one-half opt for Spanish (Welles, 2000; Nichols, 2000). Although there are important historical and geographic reasons for this situation, the growth and dominance of spanish pressures other, less well attended, languages by dictating allocation of resources within traditionally under funded foreign language departments. Researchers (Swaffar, 2003; Stavans, 2005; and Nichols, 2000) concerned with the state of foreign language education note that the data suggest that the hegemony of Spanish has two significant consequences. First, poorly trained and often unmotivated instructors, co-opted from the peripheral fields of culture and civilization, have been conscripted into Spanish language classrooms (Stavans, 2005). Secondly, the dominance of Spanish has created internal conflicts that blur more important issues that many foreign language departments currently face (Stavans, 2005). When looking closely at foreign language enrollment data, two additional points emerge. First, foreign language enrollments have stabilized at a relatively constant $8 \%$ of overall college and university enrollment. This figure, while not as elevated as was once the case, provides foreign language department administrators the chance to project enrollments into the future and to undertake strategic planning that can assist foreign language departments in the recovery of their place 
within academe. Secondly, it is clear that the languages upon which many foreign language departments were built are no longer as attractive to students as they once were. In essence, the traditional languages are losing their dominant role in foreign language departments and are being forced to share their place with Western and non-Western languages that once formed, at most, the periphery of language education. When coupled with changes in the way languages are taught, that is to say a move away from prescriptive language teaching and the dominance of grammar-oriented approaches to teaching methods, the trend toward inclusion of less commonly taught languages can create tensions within foreign language departments. White (2006) found, in fact, that in addition to rather disparaging views of modern communicative language teaching methods, Faculty in French and Spanish at West Virginia University were concerned that changes in budgetary allocations and university mandates for the inclusion of these new languages might erode the funding and place of traditional programs within the department. In a sense, these faculty were concerned that by chasing governmental funding and each new "fad," foreign language programs were in danger of deprivileging the programs and languages on which they were founded and continue to rest. 
Foreign Language Departments: Phase Separation

As foreign language programs face the future, their place and role in universities is increasingly clouded. The long slide into educational essentialism, the changing choices of the student body, and the theoretical underpinnings on which foreign language education rest have created a climate in which foreign language programs have ceased to operate in unity. Rather, internal fissures have broadened into a chasm that seems to separate professors along many lines, including language affiliation, linguistics, literature, and language teaching. These cracks in the foundation of language departments disallow a united approach to arresting the erosion of language education and university funding for foreign language departments (Bernhhardt, 1997).

Compounding the problem created by a lack of unity within the departments is the longstanding belief that literature is the most important of all subjects taught in foreign language departments (Davis, Gorell, Kline, \& Hsieh, 1992; Foster, 1999). A survey, conducted by Norma Klayman (1978), suggested that although (1) developing basic language skills, (2) teaching of culture in the context of the foreign language, and (3) teaching literature in the original language were all part of the duties of a foreign language department, the third function trumped all others. Attitudes toward this role of the department were so 
strong that over $80 \%$ of all foreign language faculty opposed (1) teaching culture in the students' native language and (2) approving foreign language in translation courses as replacements for required foreign language classes (Klayman, 1978) .

Although Klayman's (1978) study is approaching its $30^{\text {th }}$ anniversary, there is little, if any, reason to doubt that attitudes among foreign language professors have changed. In fact, in an unpublished study that served as a precursor for this current project, White (2006) found that professors engaged in the teaching of literature were adamant in their belief in the primacy of literature in foreign language departments. One participant neatly summed up the overall responses of literature professors by stating that:

I think that the department's classes should continue to be literature-based. I don't see how you can teach the language and the culture of a country without studying its literature (White, 2006).

John Dewey (1967), perhaps America's pre-eminent educational philosopher, suggested that the importance of the past, represented in the symbols and signs created by humans is an important factor in differentiating humans from animals. 
Dewey (1967) recognized that humans, including literature professors, live "in a world where each occurrence is charged with echoes and reminiscences" of the past and where the reminders that represent these occurrences are "enduring symbols of life" (p. 1) that shape meaning and suggest possibilities. Within what appears to be a rather static view of history, the events of today are merely the echoes of the past. For this reason, literature professors champion great works of the past as the point of entry for understanding the world, its past, and its future promise.

Language learning for literature, therefore, assumes that the traditions of the past can be encountered and understood only through the symbolic representations, most artfully and articulately present in works of literature, produced by a culture. While Dewey (1967) is quick to underscore the importance of the aesthetic in education, he nonetheless abhors the dualisms inherent in privileging one aspect of culture or language over all others. He understands and eloquently expresses the idea that "rules and ideals embodied in the traditional code" must be reconciled with new knowledge and modern practical achievements (p. 262). Regarding language programs, a narrow conception of the role of language learning within the foreign language department tends to be dismissive of 
any role for any role for language learning that does not, at its fundamental level, ascribe dominance to literary works. Couched within this privileging of literature is the tendency toward phase separation within foreign language departments (Rodd, 2002). Briefly, this term refers to a separation of prestige and symbolic power within a foreign language department based on the discipline (Lariviere, 2002). In general, when phase separation is present within a foreign language department, the scholarly life and symbolic power of the program is housed in the upper-level literature courses while the language teaching courses are given over to teaching assistants, lecturers, or adjunct instructors, all of whom possess little power within the department. For their part, linguistic and Teaching English to Speakers of Other Languages (TESOL) professors who work within foreign language departments occupy a vague territory between the two extremes, never fully trusted by literature instructors and never fully accepted as equal partners in the department's mission.

In addition to the symbolism present in phase separation, more tangible differences exist as well. Lariviere (2002) suggests that the scholarly pursuits of the literature department claim the majority of the resources "in terms of hiring, resource allocation, and the like," leaving the language program adrift and in constant need of attention and funding ( $p$. 
246). Others (Bernhardt, 1997; and Foster, 1999) agree with this overall assessment of a bias toward literature in language programs. Bernhardt (1997), particularly, addresses what he considers the inherent injustices in the segregation of faculty into a two-tiered structure. He suggests that while it is not uncommon for the language sections within a foreign language department to generate $90 \%$ of a department's enrollment, the lower division courses rarely receive more than $10 \%$ of a department's resources (Bernhardt, 1997). This situation creates an atmosphere within the department that is not conducive to promoting a unified front in the battle for control of the foreign language program and even for continued existence. Rather, the discordant voices and constant questioning of roles leave foreign language programs vulnerable to attacks from within and without.

\section{Structural Issues in Foreign Language Education}

The phase separation common to foreign language departments suggests, among other things, that there is a lack of formal strategies and language policies both within the academic community and the country as a whole. Compared with other nations that have developed national and regional language policies, the United States lags far behind. Indeed, while popular intellectuals in the United States are perpetually 
involved in squabbles over language issues and English only legislation, other countries have established national language policies that privilege language education as an essential element of a school's curriculum and an integral part of lifelong success (Christian, 2005). Spain and the relationship between Spanish and the languages found in the Catalonian and Basque regions represent just one example of the advantages of coherent and defined language policy. The Spanish constitution recognizes the plurilingual nature of the country and allows each of its autonomous zones to designate official languages in addition to Spanish, the national official language (Huguet, 2004; Ferrer, 2000; and Branchadell, 1999). The liberal and progressive nature of language policy in other countries can also explain, at least partially, differences in the second language proficiency of Americans and the citizens of other nations. Statistics taken from recent studies suggest that over $50 \%$ of Europeans self-report fluency in a second, and sometimes third, language. In the United States, this figures stands at only about nine percent of the population (Christian, 2005). Although there are many reasons for these dramatic differences, the lack of a coherent and consistent national language policy and the persistent English Only movement are more often than not linked to the inability of Americans to value languages other than English (Christian, 2005; Schulz, 1999). 
Within the academic community, from whence governance and foreign language curriculum policy should emanate, there is little vision about what foreign instruction might resemble in the future (Swaffar, 1999; Nichols, 2000; and Maxwell \& Garrett, 2002). Nichols (2000) suggests that in the face of mounting uncertainty about the nature of language programs, administrators remained mired in outdated notions of the role of foreign languages in the academic community and are therefore slow to pursue changes that might make language learning a more viable element of the higher education curriculum. Others (Foster, 1999; Swaffar, 1999; and Bernhardt, 1997) agree with this overall assessment of language program administration and add that the continuing privileging of literary studies and the professors who teach in these programs has serious negative long-term consequences.

When coupled with structural issues in foreign language departments that prohibit self-evaluation and a changing of the guard, the lack of a coherent national policy that can guide foreign language instruction leaves foreign language programs adrift, fending for themselves in an academic world that is increasingly alien and which has little use for what it considers the outmoded rationale on which foreign language programs base their existence. Although hinted at on several occasions, it remains to be seen what role foreign language 
programs articulate for themselves within the context of higher education. The next section, therefore, explores in greater detail the role of foreign language education within higher learning.

The Role of Foreign Language Education in Universities

The defense of foreign language education has a long history in the literature. Primarily, this justification of the need and role of foreign language learning has entailed outlining the multitude of reasons why foreign languages should be studied. Indeed, Lantolf and Sunderman (2001) suggest that almost $10 \%$ of all articles published in The Modern Language Journal, from its first edition to 2001, focus on the importance and relevance of foreign language study in education. This represents almost 400 total articles and amounts to, in Lantolf and Sunderman's (2001) estimation, a clear and “general insecurity in the language teaching profession with regard to the contributions of FL [foreign language] study to the overall education of students" (p. 5).

In the early years of the discussion over the value and role of foreign language education in higher learning as well as society at large, Lantolf and Sunderman (2001) suggest that defenders of the language curriculum rested their case on mental disciplinarian notions that language study helps sharpened 
mental abilities. Examples of this defense can be seen in Purin's (1920) claim that a systematic study of language assists in the development of "close and orderly thought" while also promoting a more sophisticated "understanding of our mother tongue" ( $p .326)$. Likewise, Ogden (1921) suggested that foreign language learning increased a student's "capacity for abstract thought" (p. 362). Finally, Shelton (1923) suggested that the study of language prepared the masses for the rigors of democratic elections by fostering "the ability to think clearly and reason from cause to effect" (p. 108).

Although the idea that foreign language study enhances a variety of mental skills, including problem-solving, creativity, and overall cognitive functions remains to this day (Schulz, 1999), more often than not other reasons are given for promoting and defending foreign language instruction. Perhaps not surprisingly, Lantolf and Sunderman (2001) identify foreign language education's role in national defense and national security as one of the primary roles of contemporary foreign language education. Let us not assume, however, that this is a new trend, brought on by the events of september 11, 2001. Rather, the use of national defense and security as a rationale for increased language learning is a recursive theme that runs, like a thread, through the $20^{\text {th }}$ century. As an example, only a few years prior to the start of World War I, Wann (1941) 
suggested that national security required the citizenry of the United States "to know other nations as well as they know us" (p. 340). And, just on the eve of the war, Benesch (1941) advised that knowledge of foreign languages was required for the "security of the nation" (p. 275). Slightly more than 10 years following the close of World War II, another geo-political event shook the United States and brought about renewed calls for investment in foreign language education. Galloway (1983) notes that in the aftermath of the launch of Sputnik, the United States government began the Herculean task of facilitating language learning across the country. In promoting foreign language learning, the federal government expanded (1) the training of new language teaching specialists in the nation's colleges and universities as well as (2) increasing the number of language labs located in high schools across the country. Indeed, between the years of 1957 and 1961, the number of language labs in high schools, constructed from funds allocated by the National Defense and Education Act (NDEA) of 1958, grew from fewer than 100 to around 2,500 (Galloway, 1983). The investment in the infrastructure and personnel supporting language learning was accompanied by an increase in the number of language courses offered in the nation's schools. Galloway (1983) notes that by 1960 , over $70 \%$ of American high schools 
offered foreign language courses and that more than $80 \%$ of colleges and universities did so as well.

Yet another rationale for learning a foreign language is the utilitarian nature of language study. Within this general essentialist notion of the importance of language learning, there are several subsidiary reason, including (1) increased earning potential (Grosse, Tuman, \& Critz, 1998); (2) the need for business people, negotiators, and politicians who are capable of interacting in a myriad of languages and cultural settings (Unks, 1983; and Vogel, 2001); and (3) the need for knowing a foreign language to take part in the growing global intellectual world (Lantolf \& Sunderman, 2001). It is clear that many of these rationales for foreign language education were persuasive to George W. Bush as he articulated his National Security Language Initiative in the winter of 2006 . Liebowitz (2006) suggests that the program, described by Bush as "a plan to further strengthen national security and prosperity in the $21^{\text {st }}$ century through education, especially in developing foreignlanguage skills" was designed to promote national security, avoid gaps in intelligence such as those that contributed to the events of September 11, 2001, and advance the nation's capacity to "complete globally in business, diplomacy, scientific research, and other creative endeavors" (p. B10). 
The reasons for learning a foreign language that were listed above primarily came from individuals outside the language teaching profession and the collegiate environment. From within the walls of academe, Frantz (1996) suggests that seventeen values underpin the teaching of foreign languages on the nation's college campuses. These include, among others, gaining an understanding of the past, both linguistic and cultural; liberalizing one's experiences; and balancing content and skills rather than a competition between skills and content (See Appendix $G$ for the entire list). When asked the length of time required to acquire these skills, six percent of the respondents answered four years and more than one-half (60\%) answered two years (Frantz, 1996). The rest of the participants suggested that students could acquire these skills in less than two years (Frantz, 1996). It is important to note that Frantz' (1996) study was comprised of a questionnaire mailed to foreign language department chairs, division directors, and deans responsible for foreign language programs in the absence of departmental chairs and provided a list of values for the respondents to rate. Finally, limited space was given to the inclusion of other rationale underpinning foreign language education and no front-line language teachers or literature professors were included in the survey (Frantz, 1996). 
The absence of literature and foreign language teaching professionals from Frantz' (1996) survey is glaring and brings us to question whether the values articulated by administrators represent those held by professors. Indeed, there is substantial evidence to suggest that differences do exist and that long-standing professorial views on language privilege the canonical literature of a nation as the true representation of that society's crowning achievements (Foster, 1999, Swaffar, 2003). Flowing from this insistence of language for literature, many foreign language departments have become narrowly focused on the teaching of that single aspect of language, thereby excluding areas that privilege language for practical purposes (Swaffar, 2003; Foster, 1999).

An earlier study (Klayman, 1978), conducted in the late 1970 s and mentioned earlier in this chapter, confirms the narrow focus on literature. Klayman's (1978) study addressed foreign language faculty attitudes toward the importance of their field and the rationale underpinning foreign language learning. As previously stated, Klayman (1978) determined that foreign language faculty believed developing basic language skills, teaching of culture in the context of the foreign language, and teaching literature in the original language were all part of the duties of a foreign language department. The third role of language instruction, however, trumped all others. More 
recently, White (2006) confirmed and expanded these earlier findings. Principally, White (2006) found that literature professors in the foreign language departments continue to believe that literature should be privileged and that the best access to cultural awareness is through reading canonical works. It is clear then, that what is at question is not whether literature faculty believe that the acquisition of cultural competence and the attainment of self-liberalization are important, for indeed they do. Rather, the question becomes whether cultural concepts and understanding of self can be acquired through the reading of literature. Although this is a "truth" that is often assumed in the literature classroom, there is ample evidence to suggest that short of detailed and explicit study of cultural norms, students will fall short of becoming culturally aware (Wolfson, 1983/1984; Wolfson \& Manes, 1980). In these studies, focusing primarily on the speech act of complimenting in American English, Wolfson (1983/1984) discovered that many of the taken for granted cultural actions that native speakers perform are generated from social rules located well below the conscious level. Wolfson (1983/1984) then suggested that the only means to understand the foundations on which these actions are based is through systematic and conscious study of cultural and social norms. Therefore, while the study of literature might be an entrée into cultural 
studies, the reading of literature cannot, without detailed discussion and explanations of ideas, provide the global awareness that literature professors seem to seek.

Beyond these two studies (Klayman, 1978; Frantz, 1996) that purported to examine faculty attitudes toward foreign language education, I was unable to locate additional literature on the topic. The paucity of research that delves into faculty attitudes toward foreign language education takes on even greater significance when compared with the plethora of studies on student attitudes toward language study. Indeed, there have been a myriad of studies that sought to identify the attitudes of students of foreign language toward language education. Those studies have typically dealt with undergraduate attitudes toward the study of literature (Davis et al, 1992), student attitudes toward their own language efficacy as a function of language courses and teaching methods (Tse, 2000), student metacognitive beliefs that surround self-efficacy and learning styles (Graham, 2003), student perceptions of factors that contributed to failure in the language classroom (Graham, 2004), and how sociodemographic, psychological, and politicocultural forces intersect to create both positive and negative student attitudes toward language learning (Dewaele, 2005).

Returning to language professionals for just a moment, it is abundantly clear that even as university administrators and 
the federal government call on language departments to teach strategic languages that will foster economic competitiveness and national security, foreign language departments have been slow to develop these programs and have, in too many cases, continued to protect the status quo that privileges the literature of the traditional western languages over the changing needs and desires of national leaders, university administrators, and students. While the view that language learning provides a means to access great literature remains strong in foreign language departments (Foster, 1999), it represents the Maginot line in the defense of the foundations of foreign language education. That is to say, this foundation represents a defense so static and anachronistic that it cannot be altered to accommodate changes in the vision and role of contemporary higher education. It therefore risks not a direct frontal assault, but rather a swift flanking attack carried out by the more mobile and better placed academic departments more central to the university's core mission.

Finally, the absence of studies that focus on faculty attitudes toward foreign language learning is glaring because we are all too aware of the importance that attitudes have on shaping the beliefs, value systems, and behavior of individuals. Likewise, we are cognizant of the importance and seminal role that faculty play in university affairs. It is to this 
important element in this study that we now turn. In the next section, we will explore the means by which faculty acquire and express their attitudes toward their closely held academic beliefs and values. In doing so, we will rely heavily on Bandura's (1969/1986) and Bourdieu's (1983) theories as a basis for explaining how the values and attitudes are acquired and utilized within the field of education.

Field, Habitus, Social-Cognitive Theory and Faculty In recent years, some (Giroux, 2005; Bradley, 2005) have begun to question the dominance of faculty at colleges and universities across the country. On the one hand, Bradley (2005) suggests that both state and national legislatures are engaged in a systematic process of challenging the legitimacy of faculty control of higher education via the enactment of academic bills of rights that would increase government control and oversight in the traditionally faculty dominated areas of curriculum planning, teaching, hiring, and promotions. As an example, Fields (2005) cites critics of the Higher Education Act who fear that provisions in the bill represent a backdoor effort to erode the autonomy of universities while also diminishing faculty control of important decisions. Along a parallel path, Giroux (2005) intimates that the corporatization of higher education represents a more serious threat to faculty dominance 
in higher education. In terse prose, Giroux (2005) claims that the era of faculty dominance is long gone and that governance of universities has been given over to well-paid and well-connected bureaucrats who receive their marching orders from and report to bureaucratic boards of trustees. Compounding the problems associated with external board control of internal university affairs, Giroux (2005) suggests that faculty control of the university has been diluted by the rise of external governing boards and their increased insistence on bottom-line accountability and corporate management techniques that encourage outsourcing via the employment of increasing numbers of part-time and adjunct faculty, who ultimately temper faculty influence within academia.

Yet, even with these attacks on faculty influence and control at universities, the importance of their input and power can not be overlooked (Rosser, 2003; Kerr, 2001). Rosser (2003) suggests that faculty governance at universities is a tradition that remains strong at universities. Kerr (2001) also notes the importance of faculty and suggests that their influence on the administration of universities has long exceeded simple control over the courses offered and the content of specific programs of study. Kerr (2001) and Boyers (1990) both note that the faculty has achieved and maintained authority over admissions, course content, course approval, and graduation requirements. 
Although Kerr (2001) admits that the power wielded by American faculty is less than that possessed by earlier French professors in Paris, he remains nonetheless adamant in his belief that American faculty continues to play the major role in determining the programmatic and research areas that receive increased funding in American universities.

To confirm Kerr's (2001) thoughts on the importance of faculty within higher education, one has only to look at recent events at major American universities to understand that faculty have not lost their teeth and continue to play a crucial, if not dominant role in the administration of colleges and universities. Indeed, Carton (1995) reported that Yale, due to a faculty upheaval over constraints placed on the use of a $\$ 20$ million grant, returned the money to the benefactor. More recently, faculty unrest at Harvard led directly to the (forced) resignation of the school's president, Lawrence $H$. Summers (Wilson, Fain, Fogg, \& Selingo, 2006 ; Pluviose, 2006; and Peretz, 2006). In addition, McCormack (2004) provides examples from five universities, including Baylor, Central Washington University, the University of Southern Mississippi, Rensselaer Polytechnic University, and Bowie State University, where faculty influence either directly or indirectly led to the resignation of the institution's president. Finally, Lowery and Basinger (2002) suggest that Henry Moon, the former president of 


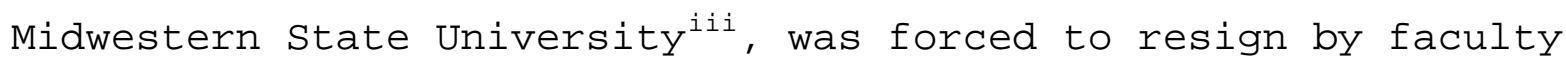
pressure and dissatisfaction with his vision for the university. These examples present evidence that university faculty influence within higher education continues to exert strong, if not outright, control over university affairs both inside and outside the classroom.

In acknowledging faculty control of the university, Ingersoll (1996) suggests that their control lies along two parallel lines. While the first, the autonomy of individual professors within their classrooms, does not address the principle questions of this research, the second, the faculty's control and influence over school policy, does. As faculty make decisions and help concretize policies that will move universities into the future, a prime area for research and consideration must be their attitudes toward their specific areas of academic achievement and the disciplines that surround them and make up the academic community. Even though this is an important area for research, there have been few studies that looked at the attitudes of faculty toward other programs and higher education in general. Those that have been conducted have concentrated on singular programs (Klayman, 1978) or on attitudes toward decision making processes in general (Ingersoll, 1996). 
Yet, to know the attitudes of faculty toward their program and those that surround them is an important, if not essential, step in understanding how universities might grow and undertake steps to create an integrated curriculum. As Dilthey (1976) suggests " $[\mathrm{W}] \mathrm{e}$ cannot understand ourselves and others except by projecting what we have actually experienced into every expression of our own and others' lives" (p. 176). This is to say, in fact, that individuals construct their own worldview through the lived and meaningful experiences in which they are socialized. Therefore, to understand an individual's actions, it is essential to reconstruct their lived experiences and relationships within a social setting. Social-cognitive theory offers one such means of understanding relationships between people, departments, and attitudes. This theory can help us understand how attitudes shape the beliefs and values that guide the actions of individual players within a given social system. With this in mind, we can easily understand how this study is, in many significant ways, predicated on Alfred Bandura's (1986) social-cognitive theory, a means of explaining an individual's behavior based on self-regulating control over their thoughts and actions.

The foundation of Bandura's theory rests squarely on his concept of a recursive triadic relationship between the environment, people, and behavior (Bandura, 1986; Wood \& 
Bandura, 1989). The educational settings and environment, as Bourdieu and Passerson (1977) reminds us, is no different from many others in which participants have divergent goals and diverse means of achieving specific ends. Social-cognitive theory allows the researcher to examine relationships of power and prestige within the educational setting and to determine the impact of beliefs and values in the decision making process (Thoits, 1995) because, as Bandura (1986) recognizes, individuals are proactive and "self-regulating" rather than passive. Within the triadic relationship, therefore, individuals exercise control over their actions and work to create environments in which their beliefs and values serve as the basis for the growth of the organism, whether it be social, personal, or professional (Pajares, 2003).

These theories lend themselves well to the concept of agency, which, as Foster (1986) suggests, is based on Bourdieu's notion of field and the problematization of human struggle in specific loci, including their professional environment (Harrison, Rainer, Hochwater, \& Thompson, 1997). Agency, in this respect, provides humans with the opportunity to reproduce the structures that are pleasing to them and with which they are comfortable (Lash, 1992). Martin (2004) recognizes that the notion of agency mandates that humans transcend passive interaction with their lives and engage in effective and 
substantial efforts to contribute to the creation of their local environments. From this overriding principle, Martin (2004) suggests two parallel lines along which humans work to develop and influence their worlds. One is a constructivist conception of individuals and the other is a view of humans situated within their sociocultural setting. In both of these complementary views of human agency, the individual's behavior is seen as an attempt to (re)create their local world in the image of their own personal beliefs and values.

Bourdieu's (1983) concepts of field and habitus allow us to understand agency as the game plan by which players attempt to influence the outcome of the game being played. While Bourdieu's theories are certainly not the only means of evaluating the actions of individuals within a defined space, Grenfell and James (1998) suggest that the use of Bourdieu's theories allow "insights and understandings not readily visible in other approaches" (p. 2), especially in the field of education where his work highlights how various groups attempt to reproduce the vision of the world that affirms the value system and beliefs that underlie their visions of the field. With this realization in mind, it becomes imperative for faculty from all departments, but particularly those situated in programs that are coming under increasing pressure to "rightsize," to understand not only the environment they inhabit but 
also the conceptual framework of their fellow denizens. Foreign language departments represent one such maligned program.

Therefore, if foreign language departments hope to operate effectively within the shifting landscape of the modern corporatized university, it behooves faculty and administration to become aware of the thoughts, attitudes, actions, and beliefs of fellow players; that is, the value systems and thoughts that undergird faculty attitudes toward foreign language education.

The Context of the Study: West Virginia University West Virginia University (WVU), the flagship university of the State of West Virginia, is a large public institution that enrolls approximately 26,000 students in a wide array of undergraduate and graduate programs. While WVU has 13 colleges and schools, the present study examines only three, the Eberly College of Arts and Sciences (ECAS), the College of Business and Economics (CB\&E), and the College of Engineering and Mineral Resources (CEMR). Enrollment trends at WVU, and more specifically within these three colleges, replicate national tendencies toward an increase in enrollment in professional programs and a decrease in enrollment in liberal arts courses, including foreign languages. Although the Eberly College of Arts and Sciences (ECAS) has maintained its position as the college within West Virginia University that produces the most 
credit hours, it is doing so with fewer and fewer students (See Table 2.2 for complete statistics). While data from the 1970-71 academic year show that the ECAS housed almost $40 \%$ of all students, by the 1998-99 academic year, this figure had slid to only $15 \%$ and continues to hover around this percentage today. In real terms, this represents a decline from over 6, 300 students in 1970-71 and from a high of 7,020 in 1980-81, to just over 4,000 students enrolled in liberal arts studies.

Likewise, the foreign language program, which in 1990-91 produced well over $11 \%$ of all credit hours within the Eberly College of Arts and Sciences, has seen its share of credit hour production decrease, and then stabilize over time at approximately $8 \%$. Although credit hour production and the number of students enrolled in foreign language classes are not perfectly equivalent, this figure is in line with national statistics for foreign language enrollment in college language courses (See Tables 2.3 and 2.4). It is therefore clear that over time, there has been significant erosion in the number of students enrolled in foreign language courses and the number of credit hours produced by the foreign language department. 
Table 2.2. Statistical Profile of West Virginia University Enrollment in Selected Years.

\begin{tabular}{|c|c|c|c|c|c|c|c|}
\hline \multirow[t]{2}{*}{ Year } & \multirow[t]{2}{*}{$\begin{array}{l}\text { WVU } \\
\text { Total }\end{array}$} & \multicolumn{3}{|c|}{$\begin{array}{l}\text { Enrollment by } \\
\text { Selected College }\end{array}$} & \multicolumn{3}{|c|}{$\begin{array}{l}\text { Percentage of } \\
\text { Enrollment by } \\
\text { Selected Colleges }\end{array}$} \\
\hline & & ECAS & CB\&E & CEMR & ECAS & CB\&E & CEMR \\
\hline $1970 / 71$ & 16,774 & 6,335 & 346 & 1,214 & $38.8 \%$ & $2.1 \%$ & $7.2 \%$ \\
\hline $1980 / 81$ & 21,220 & 7,020 & 1,711 & 2,219 & $33.1 \%$ & $8.1 \%$ & $10.5 \%$ \\
\hline 1991/1992 & 20,894 & 5,119 & 1,387 & 1,863 & $24.5 \%$ & $6.6 \%$ & $8.9 \%$ \\
\hline 1998/1999 & 22,338 & 3,401 & 1,058 & 2,138 & $15.3 \%$ & $4.8 \%$ & $9.6 \%$ \\
\hline $2005 / 2006$ & 26,051 & 4,075 & 1,176 & 2,749 & $15.6 \%$ & $4.5 \%$ & $10.5 \%$ \\
\hline $\begin{array}{l}\text { Table adap } \\
1980-81,1 \\
\text { ECAS Eber } \\
\text { CB\&E Coll } \\
\text { CEMR Coll }\end{array}$ & $\begin{array}{l}\text { ted fron } \\
991-92,1 \\
\text { ly Colle } \\
\text { ege of } \\
\text { ege of }\end{array}$ & $\begin{array}{l}\text { Statist } \\
98-99, \\
\text { e of Ar } \\
\text { Isiness } \\
\text { gineer }\end{array}$ & $\begin{array}{l}\text { Cal Pr } \\
\text { ind } 200 \\
\text { s and } \\
\text { and Eco } \\
\text { ig and }\end{array}$ & $\begin{array}{l}\text { files o } \\
\text { - } 06 \text { ) } \\
\text { ciences } \\
\text { lomics } \\
\text { lineral }\end{array}$ & Resourc & Virg & \\
\hline
\end{tabular}

Table 2.3. Statistical Profile of West Virginia University Enrollment in Selected Years and Selected Colleges.

\begin{tabular}{|c|c|c|c|c|c|c|c|}
\hline \multirow[t]{2}{*}{ Year } & \multirow[t]{2}{*}{$\begin{array}{l}\text { WVU } \\
\text { Total }\end{array}$} & \multicolumn{3}{|c|}{$\begin{array}{l}\text { Credit Hour Production by } \\
\text { Selected College }\end{array}$} & \multicolumn{3}{|c|}{$\begin{array}{c}\text { Percentage of credit Hour } \\
\text { Production by Selected } \\
\text { Colleges }\end{array}$} \\
\hline & & ECAS & CB\&E & CEMR & ECAS & CB\&E & CEMR \\
\hline $1970 / 71$ & 491,534 & 257,359 & 45,011 & 22,376 & $52.4 \%$ & $9.1 \%$ & $4.5 \%$ \\
\hline $1980 / 81$ & 540,166 & 237,133 & 69,677 & 36,572 & $44.0 \%$ & $12.9 \%$ & $6.8 \%$ \\
\hline $1991 / 1992$ & 678,880 & 308,027 & 48,003 & 31,164 & $45.4 \%$ & $7.1 \%$ & $4.6 \%$ \\
\hline $1998 / 1999$ & 569,624 & 281,146 & 46,087 & 43,389 & $49.4 \%$ & $8.1 \%$ & $7.6 \%$ \\
\hline
\end{tabular}


Table 2.4. Foreign Language Credit Hour Production

\begin{tabular}{|c|c|c|c|c|c|}
\hline Year & $\begin{array}{l}\text { Credit Hour } \\
\text { Production WVU }\end{array}$ & $\begin{array}{l}\text { Credit Hour } \\
\text { Production A\&S }\end{array}$ & $\begin{array}{l}\text { Credit Hour } \\
\text { Production } \\
\text { Foreign } \\
\text { Languages }\end{array}$ & $\begin{array}{c}\text { Foreign } \\
\text { Language } \\
\text { Percentage of } \\
\text { WVU Total }\end{array}$ & $\begin{array}{c}\text { Foreign } \\
\text { Language } \\
\text { Percentage of } \\
\text { A\&S Total }\end{array}$ \\
\hline $1970 / 71$ & 491,534 & 257,359 & 14,672 & $2.9 \%$ & $5.7 \%$ \\
\hline $1980 / 81$ & $54 \odot, 166$ & 237,133 & 15,460 & $2.8 \%$ & $6.5 \%$ \\
\hline $1991 / 92$ & 678,880 & 308,027 & 35,480 & $5.2 \%$ & $11.5 \%$ \\
\hline $1998 / 99$ & 569,624 & 281,146 & 24,559 & $4.3 \%$ & $8.7 \%$ \\
\hline
\end{tabular}

This decline in student numbers and credit hours has been encouraged by internal and external forces that seek an exactness in learning and skills acquisition that conforms to increased societal calls for improved education (Apple, 1986/1990/1996; Eisner, 2002). This movement is visible in the increased use of accreditation to prove academic quality, especially in the professional schools. As Wergin (2005) notes, "specialized accreditors such as the Association to Advance Collegiate Schools of Business (AACSB) and the Accreditation Board for Engineering and Technology (ABET) have for the past decade or so prescribed standards" and courses for engineering and business schools falling under their jurisdiction (p. 37).

Although there is some evidence in recent standards revisions that both $A B E T$ and $A A S C B$ are turning toward 
accreditation standards that value "measurable outcomes," vestiges of prescribed curricula remain and privilege courses within the professional schools at the expense of liberal arts programs. This process is visible in two distinct areas, one concerning admissions standards and the other degree requirements. Advising documents provided by the CB\&E's Advising Center show that prior to admissions to a degree program with the CB\&E, students must complete a minimum of 15 semester hours of basic business courses. Once admitted, degree requirements for each separate major require a minimum of 49 semester hours. By ramping up of the number of courses required for admission to and graduation from the college of Business and Economics, courses within the ECAS are lessened in importance, thus contributing to the decline in the credit hour production and importance of the college.

These requirements, and similar ones in other colleges, can also be seen a contributing factor to a downward trend in the number and scope of courses required to satisfy WVU's General Education Curriculum (GEC) ${ }^{\text {iv }}$. In 1970, the number of credit hours needed to satisfy the GEC stood at approximately 56 . Of these, 36 hours were taken from three clusters and the rest from required courses in English (6 hours), Physical Education (2 hours), and Foreign Languages (6-12 hours depending on placement). Today, the West Virginia University Undergraduate 
Catalog for 2005 - 2007 indicates that between 41 and 43 credit hours are required to fulfill this academic requirement. Of these, however, up to nine hours can be taken within the student's major, effectively reducing the GEC to between 32 and 34 credit hours. Additionally, in some academic and degree programs, no foreign language courses are required to satisfy the university's overall curriculum.

Turning to the CEMR, the situation and influence that outside accrediting agencies have on the curriculum is different, but points to a more ominous future for liberal arts programs. In the past, professional accrediting standards and engineering curricula often mandated that students complete over 140 credit hours before being granted a degree. These hours came from both engineering courses and classes required for the GEC. Today, special permission has been granted to many engineering programs, including the ones housed within the CEMR, to reduce the number of hours required for graduation by decreasing the number of courses required from the GEC. At WVU, only seven GEC courses, or approximately 21 credit hours, are required of engineering majors. It would be unfair to suggest that these students do not enroll in additional ECAS courses because engineering students are required to fulfill additional requirements in mathematics and science, programs that are housed within the ECAS, to fulfill degree plans. However, the 
courses are narrowly focused and do not allow students to elect foreign languages, history, or other courses from the humanities tradition.

The foregoing arguments have presented evidence that the rise of the professional schools and the prescribed curricula developed by external accrediting agencies is an important force in the decline of enrollment in foreign language and other liberal arts programs. Additionally, the ability of business departments and engineering programs to apply for and receive funding from governmental and industrial sources have made these programs more central to the university, especially in times when state funding for higher education has decreased. It is therefore important to understand how the faculty in these programs view education and more specifically, what role they assign to foreign languages in their students' plans of study. Without a basic understanding of the educational values that these faculty possess, foreign language programs are essentially blind and therefore unable to successfully navigate their way through the changing landscape of American higher education.

Summary and Rationale for the Current Study

This chapter has provided an overview of the history of foreign language education in American higher education, current and historical foreign language enrollment trends, and a brief 
discussion of several factors that influence foreign language departments in American universities. As was seen, foreign language enrollment has varied over time as national and international events focused attention on the need for speakers of other languages. The research has also shown that with the advent of the new corporate model of higher education and its adherence to bottom line principles, foreign language and other non-revenue producing programs have come under increased scrutiny as language that focuses on fiscal responsibility has replaced language about ideal education. This chapter examined social-cognitive theory as an example of how attitudes influence behavior within a specific social or professional context. Finally, this chapter concluded with evidence that the lack of research on faculty attitudes toward foreign language education represents a powerful argument for undertaking this study. Likewise, it is equally important to uncover faculty attitudes determined by their socio-cognitive beliefs and values toward education in general and foreign language study specifically. This exploratory study will begin to uncover the attitudes of faculty from the Eberly College of Arts and Sciences, the College of Business and Economics, and the College of Engineering and Mineral Resources toward the role and purpose of foreign language education at West Virginia University. In so doing, it will open avenues for dialog and discover 
commonalities and differences among faculty that might be used for the creation of strategic alliances and increased interdepartmental cooperation.

Changes in higher education have arrived with such rapidity that many of the taken-for-granted notions that provided a sense of comfort and place to generations of college and university faculty are not longer valid. The torrent of change has left professors in liberal arts and non-professional studies alienated from the venture-capital, entrepreneur-minded universities that dot the landscape of the nation. In many significant ways, these changes have left faculty feeling disconnected from the mission of the university and wondering how long the humanities can survive as an integral part of the university curriculum. 


\section{CHAPTER THREE: METHODOLOGY}

\section{Introduction}

The purpose of this study was to explore the perspectives of West Virginia University faculty from the Eberly College of Arts and Sciences (ECAS), College of Business and Economics (CB\&E), and College of Engineering and Mineral Resources (CEMR) toward foreign language learning within the context of American higher education. Along with this central question, the research addressed three subsidiary questions, including (1) the current/historical state of foreign language education at WVU; (2) the understanding of the role and purpose that faculty from the various colleges have concerning foreign language learning at West Virginia University; (3) the benefits that skills and knowledge learned in a foreign language classroom have for students from each in each individual academic area; (4) whether changes in accreditation and certification requirements have altered the role and content of the traditional liberal core and general education classes; and (5) whether changes in the focus of foreign language study might provide links across diverse content areas?

With these immediate questions in mind, the overall goal of this research was to provide a textured and in depth account of 
beliefs toward foreign language at a single university. It is hoped that in uncovering attitudes toward foreign language learning in particular and liberal arts education in general, the findings can help the Foreign Language Department better understand their historic and contemporary place within the university academic structure as well as assist in building connections and creating dialog across non-aligned academic departments.

As is clear from the literature review, foreign language departments, as well as all liberal arts, have come under intense scrutiny and have been required to down-size as other areas of the university develop more quickly and profitably. With this in mind, foreign language programs can no longer rely on outdated philosophies of learning that espouse Cardinal Newman's (2003) philosophy that true education conduces to the end of enlarging one's mind. Rather, they must embrace the new "corporate university" model that has taken over and find ways to reinvigorate their programs while seeking strategic alliances within the university community.

\section{Statement of the Research Problem}

Foreign language departments have been under pressure from various quarters to change their way of teaching, to heal internal rifts, to cooperate more fully with other academic 
departments, and to downsize in face of the trend of smaller enrollments. These pressures, when coupled with a hesitancy to look beyond the borders of their own programs and curriculum have caused foreign language departments to be isolated from potential allies located in areas of the university that are rapidly growing in both number of students and in resources allocated (Bernhardt,1997). Although this situation is evident from even a cursory review of literature, the author of this study was unable to find any research that explores faculty attitudes toward foreign language education within the context of American higher education and more specifically, (1) the current/historical state of foreign language education at WVU; (2) the understanding of the role and purpose that faculty from the various colleges have concerning foreign language learning at West Virginia University; (3) the benefits that skills and knowledge learned in a foreign language classroom have for students from each in each individual academic area; (4) whether changes in accreditation and certification requirements have altered the role and content of the traditional liberal core and general education classes; and (5) whether changes in the focus of foreign language study might provide links across diverse content areas?

Given this lack of completeness with regard to the literature and studies on faculty attitudes toward foreign 
language education, this study sought to provide insights and mutual understanding that can be used to establish strategic alliances between foreign language departments and other academic programs on campus. This was accomplished via the exploration of faculty attitudes regarding the questions listed above (and below) and the provision of a textured and rich account of the data uncovered through interviews that employed open-ended questions concerning faculty beliefs about what constitutes an appropriate education for students enrolled in diverse programs.

\section{Statement of the Research Questions}

The purpose of this study was to determine the attitudes of West Virginia University (WVU) faculty from the Eberly College of Arts and Sciences (ECAS), College of Business and Economics (CB\&E), and College of Engineering and Mineral Resources (CEMR) toward foreign language learning in the context of higher education. In addition to this overarching question, five ancillary questions were posed. These included:

1. What is the historical/current state of foreign language education at WVU?

2. What is the faculty's understanding of the role and purpose of foreign language learning at WVU? 
3. What benefits do the skills and knowledge learned in a foreign language classroom have for students from your academic area?

4. How have changes in accreditation and certification requirements altered the role and content of the traditional liberal core and general education classes?

5. How might a change in the focus of foreign language study toward practical applications of language use, encourage links across diverse content areas?

Table 3.1 provides a matrix establishing how interview questions as well as the analysis of West Virginia University statistical profiles and Academic Bulletins served to answer each of these questions. For its part, Table 3.2 links individual questions from interview protocol with the research question that it addressed.

Table 3.1. Research Questions and Means of Data Collection.

\begin{tabular}{lccc}
\hline Question Number & Interviews & WVU Statistical & WVU Academic \\
Profiles & $\begin{array}{c}\text { Accreditation } \\
\text { Bulletins }\end{array}$ \\
\hline Question One & $\mathrm{X}$ & $\mathrm{X}$ & $\mathrm{X}$ \\
Question Two & $\mathrm{X}$ & & \\
Question Three & $\mathrm{X}$ & $\mathrm{X}$ & \\
Question Four & $\mathrm{X}$ & $\mathrm{X}$ & $\mathrm{X}$ \\
Question Five & $\mathrm{X}$ & & \\
\hline
\end{tabular}


Table 3.2. Research Questions Aligned with Interview Protocol.

1. What is the

historical/current state of foreign language education at WVU?
9. University administrators often set agendas for the future of their universities. In your mind, how important is foreign language education to university administrators and to the future of the university?

Follow up: How does the current state of foreign language education at the university compare to the past?
2. What is the understanding that faculty have toward the role and purpose of foreign language learning at west Virginia University?
5. I want to explore your ideas on why foreign language education is a traditional part of higher education. So, in your estimation, what is the purpose of foreign language learning?

7. With your answer to the previous question in mind, what skills does the WVU foreign language program teach their students?
3. What benefits do the skills and knowledge learned in a foreign language classroom have for students from your academic area?
11. What role does foreign language education have in the education of students from your academic college?

12. We talked about general skills that foreign language learning imparts to students. What are some specific skills that foreign language learning might provide to students enrolled in your program?
4. How have changes in accreditation and certification requirements altered the role and content of the traditional liberal core and general education classes?
13. Can you speak to how accreditation standards have changed over the past 10 to15 years? What impact has this had on the curriculum in your program?

14. What role do professional accrediting agencies have in determining the curriculum in your program?
5. How might an increase in applied foreign language study provide a link across diverse content areas?
10. What are some potential curricular links between the foreign language department and your program/department/college?

Research Design

The intent of this research was to critically evaluate the attitudes that underpin professorial beliefs about foreign 
language education in the higher education context and to examine how these attitudes are affected by collective beliefs held by faculty who hail from diverse academic and professional backgrounds. Given that little, or no research, has been conducted in this area, this study constitutes a vital means of gaining an in depth understanding of how faculty articulate their beliefs concerning foreign language education and how these unconscious attitudes affect their decisions concerning the academic core and student advising.

Data uncovered during interviews and the thorough inspection of university documents produced a compelling interpretation of these attitudes and serves, I hope, as a bridge on which future discussions can be carried out. Additionally, the use of several data sources, including interviews of faculty from three separate colleges within west Virginia University, statistical profiles of the university, and course bulletins and degree requirement documents, provided triangulation for the study thereby resulting in a study that accurately reflects the idiosyncratic nature of this qualitative study .

\section{Qualitative Research Design}

Qualitative research methods are, first and foremost, research methods that allow for the discovery of what people 
know, do, think, and feel by observing and interacting with study participants and the evaluation of relevant documents (Patton, 2002). Yet, qualitative research is not a limiting term. Rather, it is an umbrella category that includes several forms of inquiry that help explain the "meaning that people have constructed" in their daily personal and professional lives (Merriam, 1998). Although qualitative research encompasses a broad range of possibilities, Merriam (1998) outlines several major characteristics associated with these studies and which require the researcher to:

1. understand that importance must be placed on how participants perceive their world and on how the researcher perceives the participants

2. use several data sources, including interviews and document analysis in order to ensure triangulation

3. engage in fieldwork

4. provide a richly descriptive explanation of the results while focusing on holistic and comprehensive meaning

5. be flexible while allowing for an emerging research design . 
In addition to these overriding characteristics of qualitative research methods, Corbin (1990) suggests several reasons why researcher may wish to avail themselves of a qualitative design structure. These include:

1. the nature of the research question being studied

2. the desire to explore areas in which little or no previous research has been conducted

3. the desire to gain new insights into questions that have been previously addressed via the use of either qualitative or other research methods

4. the need to provide details that are difficult to convey with quantitative research methods

The choice for a qualitative design in this study was based on the fact that little previous research has focused on the attitudinal differences among faculty concerning foreign language learning at institutions of higher education. As an exploratory study that addresses beliefs about foreign languages that might be hidden below the level of conscious thought, the researcher feels that the use of guided questions, asked during face-to-face interviews, provides the best opportunity for uncovering the richness of the question and the attitudes that lie behind actions. 
The use of semi-structured interviews to collect data has proved useful for exploring participant experiences, beliefs, attitudes, and knowledge (Malterud, 2001). In addition to the aforementioned benefits of interviews, Fontana and Frey (2000) described interviews as "one of the most powerful ways in which we try to understand our fellow human beings" (p. 645). Finally, Hollway and Jefferson (2000) offer the suggestion that interviews allow for the construction of meaning within the process of self-reflection.

In this study, interviews consisted of open-ended questions, each lasting approximately 45 minutes, that were audiotaped, transcribed, and analyzed using grounded theory, an approach that allows for the thematic analysis of data in an effort to uncover the significance of experiences (Boyatzis, 1998; Strauss \& Corbin, 1998; and Schwandt, 1997). Prior to beginning the interview process, participants were read a statement of informed consent and told that they could halt the interview at any time without jeopardizing their positions at WVU.

All interviews were audiotaped and transcribed in verbatim. Transcripts from the interviews were analyzed for recurring themes and categories. Analysis of the data was repeated until the researcher had achieved the saturation point and no new themes emerged. It should be noted, however, that claims of 
saturation include a good measure of faith (Cutcliffe \& McKenna, 2002) and rely heavily on the researcher's own understanding of recurrence of themes and potential theory-laden responses (Patton, 1990; Lincoln \& Guba, 1985). The decision to identify the saturation point, therefore, suggests that the researcher will have continually compared new data to old and is confident that no new themes will appear (Cutcliffe \& McKenna, 2002).

\section{Limitation of Qualitative Research}

Patton (2002) and Merriam (1990) suggest that several potential problems plague the use of qualitative research. These include:

1. the possibility of subjectivity that limits reliability and validity

2. the presence of sensitivity and bias that the research can bring to the study

3. the lack of generalizability in qualitative research studies

To combat the first of these limitations, the researcher structured how data were collected and managed and ensured that the same interview protocol was used with each participant. Additionally, the interview protocol was piloted to a group of 
six individuals who were asked to provide comments on the clarity of the questions and the overall framework of the protocol. Additionally, the presence and analysis of other documents provided a neutral backdrop against which the interpretation of interviews could be compared. While it is impossible to isolate and remove all personal biases from the research design, the researcher has included, later in this chapter, a statement of personal experiences that relate to the field of foreign language education and institutions of higher education. Finally, the researcher readily acknowledges that the results of this study will not be generalizable beyond the confines of the three colleges selected from West Virginia University's academic community. The idiosyncratic nature of this study does not lend itself well to use by other institutions who might wish to explore their own faculty attitudes toward foreign language learning in higher education. However, it must be noted that the researcher's purpose was not to produce generalizable results, but rather to study only this particular institution so as to gain a clearer view of faculty attitudes toward foreign language education within this particular context. It might also be noted that other researchers could use the study design as well as the result from the interview as a starting point from which they could 
explore faculty attitudes toward foreign language education at their particular institutions of higher education.

Participant Selection and IRB Approval

Although Patton (1990) and Baum (2000) suggest that there are no hard and fast rules for sample sizes, the aim of qualitative research is to gain an in depth understanding of the phenomenon under study. To capture the richness of data and a better view of the texture of the responses, this study employed purposeful sampling in the recruitment of participants. This type of sampling:

1. selects participants according to criteria developed by the researcher while also allowing for unfolding theorizing (Miles \& Huberman, 1994)

2. is based on the assumption that the researcher wishes to interview those individuals who are best able to provide relevant and detailed information about the phenomenon being investigated (Merriam, 1990).

3. is used when researchers wish to capture the peculiarities of a given context (Patton, 2002; Merriam, 1990) 
Prior to conducting the interviews, the researcher obtained approval for this study (granted on January 11, 2007, see Appendix F) and then selected potential participants according to the following criteria:

1. employment in one of the three colleges under study

2. possession of tenure at the time of the interviews

3. minimum of 10 years of employment at WVU

At the conclusion of this process, the researcher emailed selected faculty with a brief description of the study and an invitation to participate (Appendix H). Faculty who agreed to participate in this study were offered the chance to identify a suitable location for the interview. All faculty chose their university office space for the conversations.

of the 21 faculty identified and contacted, seven either failed to respond to the invitation to participate or rejected the opportunity to discuss their perspectives on foreign language education. of these, five were from the college of Engineering and Mineral Resources (CEMR) and two were from the Eberly College of Arts and Sciences (ECAS). Generally, faculty from the CEMR who declined the invitation suggested, in their responses, that foreign language programs have little impact on engineering, resulting in their inability to discuss the 
questions with a reasonable amount of authority. The two members of the ECAS who did not wish to participate did so because of their research agendas and their impending retirements.

\section{Data Collection Procedures}

As noted previously, this study seeks to determine the attitudes of West Virginia University (WVU) faculty from the Eberly College of Arts and Sciences (ECAS), the College of Business and Economics CB\&E), and the College of Engineering and Mineral Resources (CEMR) toward foreign language learning in the context of higher education as well as the ancillary questions (1) the current/historical state of foreign language education at WVU; (2) the understanding of the role and purpose that faculty from the various colleges have concerning foreign language learning at West Virginia University; (3) the benefits that skills and knowledge learned in a foreign language classroom have for students from each in each individual academic area; (4) whether changes in accreditation and certification requirements have altered the role and content of the traditional liberal core and general education classes; and (5) whether changes in the focus of foreign language study might provide links across diverse content areas? 
To accurately and satisfactorily address these questions using a qualitative research design, Patton (2002) and Merriam (1990) suggest that multiple data collection techniques, chosen from among open-ended interviews, direct observations, and written documents, be employed. This study relied on an initial analysis of university documents (See Appendix B for a list of documents reviewed) that assisted the researcher in establishing an appropriate list of questions for the Interview Protocol (See Appendix A for the complete Interview Protocol). This preliminary document evaluation phase was followed by in depth interviews that will use open-ended questions to probe faculty concerning their beliefs about higher education and their perceptions toward the role of foreign language learning in their academic disciplines.

\section{Data Organization and Analysis}

Data obtained from the interviews was continuously and repeatedly analyzed so that the use of an emergent design that provides the best opportunity for a rich and textured understanding of the question could be assured. All data are stored in a secure location and all identifying information has been removed so that anonymity and confidentiality is assured. All interviews were audiotaped and transcribed in verbatim. Transcripts from the interviews were analyzed for recurring 
themes and categories. Analysis of the data was repeated until the researcher achieved the saturation point and no new themes emerged. It should be noted, however, that claims of saturation include a good measure of faith (Cutcliffe \& McKenna, 2002) and rely heavily on the researcher's own understanding of recurrence of themes and potential theory-laden responses (Patton, 1990; Lincoln \& Guba, 1985). The decision to identify the saturation point, therefore, suggests that the researcher has continually compared new data to old and is confident that no new themes will appear (Cutcliffe \& McKenna, 2002).

\section{Reliability and Internal Validity}

Reliability refers to the degree to which a study's findings can be reproduced (Patton, 2002; Merriam, 1990). Yet, when conducting qualitative research, it is not currently possible to measure reliability in the traditional quantitative sense (Patton, 2002). Therefore, the objective of this research must be to measure reliability and validity within the context of the present study. In this case, the reliability of the study is ensured by the construction of an audit trail that provides for the authentication of the data collection process via an in depth account of how the data were collected, how categories were derived, and how the process was altered as the research evolved (Merriam, 1990). 
Internal validity, when contrasted to reliability, refers to the degree to which the findings of a study match reality (Merriam, 1990). An essential element of internal validity, therefore, is the use of triangulation to confirm the analysis of interview data. In this sense, triangulation refers to the use of multiple data sources, investigations, or methods to confirm the findings that emerge from a study (Merriam, 1990). In this study, the investigator used two methods of data collection, including guided interviews and the review of university produced documents, which allowed for a holistic and multi-dimensional analysis of data (Merriam, 1990).

\section{Relevant Past Experiences}

At this time, I am serving as the Interim Coordinator of the Basic French Language Program at West Virginia University. I am also employed as a Graduate Teaching Assistant within the department and am assigned to teach French language classes as well as Second Language Acquisition and Language Teaching Methods courses. I am also an Ed.D. student in Curriculum and Instruction in West Virginia University's College of Human Resources and Education. I have previously earned a Bachelor of Arts degree in History from the University of Virginia and a Master of Arts degree in Foreign Languages (French and Teaching English as a Second Language) from West Virginia University. 
Prior to returning to West Virginia University to pursue a doctoral degree, I worked, either as an instructor or program coordinator, in language instruction for over 17 years. These previous experiences include a two-year stint at Bluefield State College, a historical black college located in Bluefield, West Virginia and a ten-year tenure as director of the Intensive English Language Institute at Midwestern State University.

I have presented more than 10 papers and workshops dealing with English as a Second Language (ESL) instruction, international programs, and curriculum theory and have copublished one article that synthesized responses to a call for the establishment of job descriptions in ESL teaching. For additional personal information, please see Appendix C, a copy of my current curriculum vitae.

\section{Statement of Personal Context}

I have been associated with foreign language instruction for well over 17 years. Service in this area has come as both a Graduate Teaching Assistant and a regular full-time employee in a mid-sized state university in Texas. As a long time teacher in ESL, I have often perceived a lack of respect for instructors who teach only "language" and have complained vociferously that written language, a fairly recent development, should not be the primary focus of foreign language instruction in higher 
education. Coupled with my experiences as a director of an ESL program that was essentially a small business located within the organization structure of a university, I became acutely aware that instruction in languages must meet the needs of clients and not remain hostage to what I consider an outmoded view of the liberal arts tradition.

With this in mind, I must acknowledge that my selection of a research topic and the attitudes that I bring to the research question influence my beliefs and perceptions concerning the appropriate role of foreign language programs at universities. 


\section{CHAPTER FOUR: RESULTS}

\section{Introduction}

The purpose of the study was to determine the perspectives of West Virginia University (WVU) faculty from the Eberly College of Arts and Sciences (ECAS), the College of Business and Economics (CB\&E), and the College of Engineering and Mineral Resources (CEMR) toward foreign language learning in the context of higher education. As an extension of this basic question, I addressed five subsidiary areas including (1) the current/historical state of foreign language education at WVU; (2) the understanding of the role and purpose that faculty from the various colleges have concerning foreign language learning at West Virginia University; (3) the benefits that skills and knowledge learned in a foreign language classroom have for students from each in each individual academic area; (4) whether changes in accreditation and certification requirements have altered the role and content of the traditional liberal core and general education classes; and (5) whether changes in the focus of foreign language study might provide links across diverse content areas? 
Under the influence of the guiding question presented in the interview protocol (Appendix A), the 12 faculty members (See Appendix $G$ for a list of participant pseudonyms and their college affiliation) who participated in this study centered their responses on four major recurring themes. These included (1) the reasons for engaging in the study of a foreign language, (2) perceptions of the problems that challenge foreign language education, (3) the potential for cross-curricular links between university programs and the Foreign Language Department, and (4) the purpose of foreign language programs within the context of higher learning. In the next four sections of this chapter, each of these themes will be treated with an overview of the conversations that introduces the participants' attitudes and views toward foreign language education within the context of higher learning at West Virginia University. In an effort to ensure confidentiality, each of the participants will be identified by the college in which they work and by a pseudonym intended only to identify their gender.

\section{Reasons for Foreign Language Study}

Participants identified two major reasons for engaging in the study of foreign languages. The first concerned the skills, including the ability to understand cultural differences, that the study of languages can bring to students. The second reason 
was more practical and centered on the ability of a foreign language class to either prepare students for the rigors of living abroad or indeed to help engineering or business students gain their first-choice employment. Although additional reasons, including links between language study and increased cognitive abilities, travel, and the thought that the study of a foreign language improves the understanding of one's native language, underpinning the foreign language rationale appeared during the conversations, none were sufficiently ubiquitous to merit more than a casual mention in this section.

Participant responses regarding the skills that engaging in the study of a foreign language can help students gain must be considered in reference to Frantz (1996) study on this question. Frantz (1996) identified 17 values associated with learning a foreign language (See Appendix $\mathrm{H}$ for a complete list of these 17 values). These included such seminal areas as understanding others, cultural literacy, and self-liberalization, all aspects of foreign language learning that reside squarely within the humanistic traditions of self-improvement and enlightenment. More recently, in the wake of increased global competition for market share and international political machinations following the terrorist attacks of September 11, 2001, foreign language education has been championed as a means of reclaiming American business' dominant place in commerce and industry as well as a 
way to protect the United States from additional surprise attacks (Liebowitz, 2006). When combined, therefore, the number of reasons given for studying a foreign language reaches 19 and includes both humanistic and practical value grounds for engaging in the difficult task of acquiring a foreign language. When questioned about the role and purpose of foreign language education, faculty from the Eberly College of Arts and Sciences (ECAS), College of Business and Economics (CB\&E), and College of Engineering and Mineral Resources (CEMR) interpreted the question as inquiring into the reasons students should engage in language study. Further, the participants expressed ideas similar to the ones listed in Frantz' (1996) study as well as the notions underpinning the National Security Language Initiative (Table 4.1 offers a complete list of the skills professors associated with foreign language education). First and foremost among the reasons mentioned were the skills that foreign language learning can provide students. Indeed, many participants noted that one of the primary purposes of foreign language study is to offer students the knowledge needed to unlock the mysteries of other cultures, thereby helping individuals conduct themselves in culturally appropriate ways when in foreign countries. Indeed, all 12 participants mentioned this notion as the primary reason for studying a foreign language within higher education. As an example, 
Martha, an ECAS professor with more than 30 years service to the university, suggested that:

the main reason for learning a foreign language is to understand the culture of the country, or countries where that language is spoken. Learning a foreign language should be able to help you get a grasp of the differences between your home and theirs. I mean, to be able to be a good traveler and a welcome guest in their land. (Martha, ECAS)

One of the underlying concerns that pushed participants to champion foreign language learning as a means to understanding culture was their belief that American students live apart from the rest of the world and therefore suffer a cultural isolation that diminishes their capacity to understand others. Judy, another ECAS professor, suggested as much when she noted that Americans, given the hegemony of the English language and the cultural dominance of the United States, have become complacent in the country's successes and have therefore lost touch with the importance of "otherness." Judy then suggested that foreign language study can help: 
Americans reach beyond our own borders and diminish the insular nature of our people because all people need to be in touch with others and they need to know more than one language to be real citizens of the world. You know, to be able to know what is outside the borders of their small communities. Foreign language study can help expose people to other cultures and make them aware of what is out there. Make them aware of other people and cultures and reduce their fear of the unknown. (Judy, ECAS)

Participants from other academic areas also expressed the notion that learning a foreign language can assist students in the acquisition of cross-cultural understanding. Yet, in addition to theses self-liberalizing effects of foreign effects of language study, professors within the CB\&E suggested that understanding other cultures has practical value in the modern business world. Ted, a CB\&E professor with more than 20 years experience at WVU, noted that:

with the globalization of the economy, things have changed in the business world. It is absolutely necessary for students to gain an understanding of other cultures if they want to negotiate successfully with people from those cultures. (Ted, CB\&E) 
Tony, another professor from the CB\&E, also suggested that learning a foreign language, or at least the cultural norms of the people who speak the language, has enormous practical implications. His beliefs were based partly on the experiences of a former student who was employed as an efficiency expert in a factory located in an Eastern European country. After diligently examining the working of the factory, the expert proposed a series of changes intended to improve the efficiency of the plant. However, after a few months, no improvements were apparent. Upon re-examination, the efficiency expert found that the alternative modes of work that he suggested conflicted with the underlying culture of the people and contributed to a worker slowdown instead of improved efficiency. Tony, after telling this story, shared that he believes:

understanding the language can really help you understand the way people think. I mean, language and thought, for me, are so intertwined. If you know the language and the way people think and approach problems, you can get inside their heads and maybe get an advantage in negotiations. (Tony, CB\&E)

Engineering professors, like their counterparts in the CB\&E, were adamant in their belief that the study of the culture 
of a country or people can open doors usually closed to Americans. Often, however, the importance of understanding the culture hinged on its value to "get jobs done" and to make the far away locations in which engineers often work more tolerable. Bob, closing in our $4 \odot$ years of service to the College of Engineering and Mineral Resources, acknowledged "a great and obvious advantage" to learning a foreign language and especially the culture attributed to that language. He noted that in his opinion:

almost all engineering work done in the world is done in English, so the actual use of a foreign language in the field may be limited. But, when the work day is over or when you are having trouble making yourself understood, cultural understanding is vitally important. Plus, you know that many times, a young engineer's first assignment is overseas. If they can understand the culture and get by, they will have a better chance at succeeding, both professionally and socially. (Bob, CEMR)

While it is clear that differences in the rationale underpinning the belief in the importance of cultural understanding exist, the notion that studying a foreign language can contribute to understanding diverse cultures is widespread 
in the three academic colleges studied. Beyond this core value, however, participants noted a wide range of other reasons for studying a foreign language. While none of these values had the pervasive support of language study for cultural understanding, one additional practical-value rationale underpinning the study of foreign language did stand out when comparing the responses of all the participants. Whereas only one professor from the ECAS indicated that studying a foreign language held significant potential to increase employability, two professors from the CB\&E and three professors from the CEMR indicated that the presence of foreign language courses on a student's transcripts could be viewed as a noteworthy plus as employers reviewed job applications .

Tony, a self-professed proponent of foreign language study from the CB\&E, noted that in his belief:

everyone is now talking about the global economy. In reality, this global thing has been around for many years. But, it seems that many people outside of business and a few other areas are just coming to understand the significance of globalization. So, students in our programs, accounting and marketing and the others, who have a foreign language on their transcripts have a great chance of getter the best job offers or at least their first 
choice because firms are looking for people who can go abroad and be reasonably comfortable, especially in their first real assignments. (Tony, CB\&E)

Participants suggested that the same concept holds true in engineering. Bob noted that as engineering has became a global profession, engineering firms are seeking qualified personnel who can work in other countries. He then suggested that:

students probably won't get fluent in a language in four semesters of study, but at least they will have that on their transcripts. And that can help them make their résumés more attractive to potential employers. (Bob, CEMR)

One final noteworthy theme that emerged in the conversations with several participants was the thought that the study of a foreign language can help students gain a better understanding of their own language as well as improving their overall cognitive functions. Indeed, Robert, a professor from the CB\&E, noted that he has "a personal theory that foreign languages help you improve your thinking skills and your knowledge of your own language, especially in the areas of logic" (Robert, CB\&E). Elaborating on these ideas, Robert added that: 
many of my colleagues in other areas feel that students who come to the university today don't really know much about English. Because of this, they think, and I tend to agree with them, that studying the grammar of a foreign language can really enhance a student's understanding of his own language. You know, things like nouns, verbs, and the like. (Robert, CEMR)

The concept that learning a second language provides dividends for literacy and comprehension of students' native language is not new and has some support within the second language acquisition and foreign language teaching literature. During the mid-1960s, Brega and Newell (1967) suggested that the results of their qualitative and quantitative study provided evidence to support the notion that foreign language study increased the cognitive capacity of high school students. More recently, Armstrong and Rogers (1997) as well as Merisuo-Storm (2006) suggested that beginning foreign language studies in the early years of formal education fosters the development of basic skills and promotes cognitive growth. 
Table 4.1. Skills Attributable to Foreign Language Education.

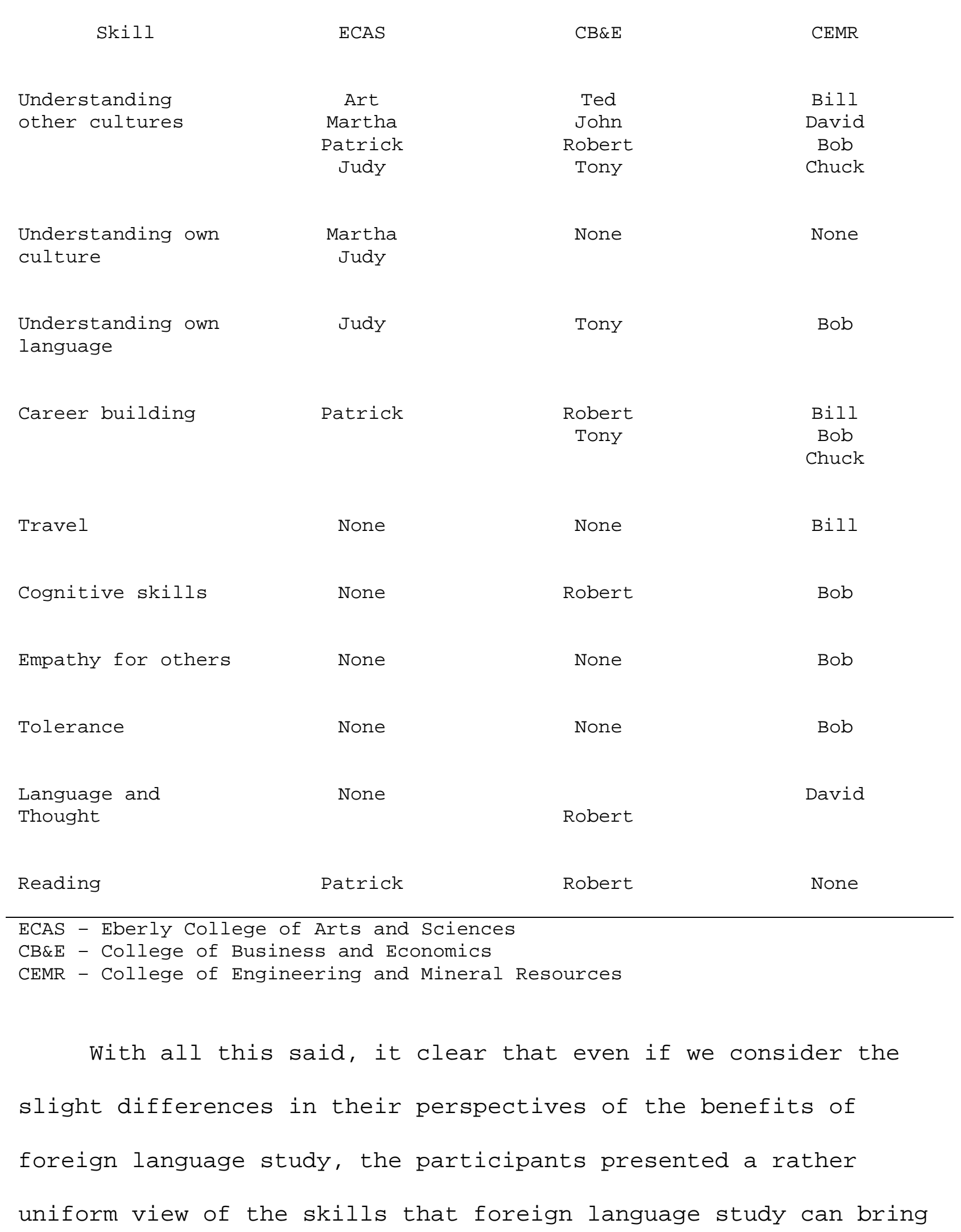


to university students. Yet, even with the advantages that the study of a foreign language can offer students, participants were hesitant to suggest that foreign language study, as it is currently operationalized at the university level, can help students gain these skills. Rather, they tended to suggest that the focus on apractical language skills and the limited exposure students have to the language precludes the development of the skills they deemed so important.

\section{Perception of Problems}

Although many students engage in foreign language learning, only a few learners obtain skills beyond the novice level. The failure of their students to achieve proficiency in a second language haunts foreign language departments and is a constant and contentious point that leads to endless questioning of language teaching methods, student motivation, the need for the foreign language requirement, and the factors that contribute to student failure to achieve fluency (Sigsbee, 2002; Germano, 2004). In commenting on this touchy issue, Germano (2004) noted that the three truths of foreign language education - you will learn to read it, you will learn to speak it, and you will learn to write - are far removed from the reality of what actually transpires in foreign language classrooms at the university. Germano (2004) also suggested that contrary to the shiny 
brochures and sparkling mission statements produced by foreign language departments that offer the hope of learning a language in a few short years, foreign language students rarely exit these programs with more than rudimentary skills in the target language.

In this study, the majority of the participants suggested that foreign language departments are falling short of the goal of producing competent speakers of the language who possess the cultural awareness necessary to interact with native speakers of the foreign language. In addressing this perceived problem, participants were quick to point out internal and external factors that contribute to the lack of foreign language success. The first area of concern consists of two internal challenges, the lack of unity within the foreign language department at WVU and the notion of what knowing a language means, that the Foreign Language Department must address if it is to recover its place within the university. The second area, outside the control of many foreign language departments, deals with accreditation and the lack of student motivation for the learning of foreign languages.

Addressing the internal crisis, one participant bluntly stated that "language education at WVU, for what it's worth in my opinion, is in a state of disrepair" (Art, ECAS). Following up, he concluded that: 
the administration gives the department a very low ranking in its hierarchy of academic priorities, primarily because those people over there can't get their own house in order. (Art, ECAS)

Also commenting on the internal challenges that the foreign language department at WVU has faced in recent years, John, a professor in the CB\&E, noted that:

the Foreign Language Department has some problems that can't be easily explained. I mean, didn't they just have to get a new Chair from outside the department. From English, I think. That tells me that there are some things going on over there that need to be looked into. (John, CB\&E )

More often that not, however, participants focused on the internal curriculum and content of the foreign language classes and their idea that the study of culture and practical oral skills are devalued within language departments, a problem that haunts foreign language programs because students prefer the more practical oral skills to reading and writing skills. 
Patrick, a professor at WVU for almost 40 years, suggested that in his experience:

foreign language departments, like the one here, provide reading-oriented courses that don't help much with oral proficiency. That really hurts the language program because students aren't really interested in reading. They want to learn to speak and understand so that when they travel, they will feel comfortable. (Patrick, ECAS)

Martha echoed this point of view and further suggested that foreign language classes are:

geared toward specialists and much of the recipient population is simply trying to satisfy a requirement, that I might add they find onerous, or just sitting in the class hoping to be able to speak a few words when they are done. (Martha, ECAS)

Outside the ECAS, Ted, a longtime professor in the CB\&E, noted that the lack of focus on communication strategies discourages many business majors from enrolling in these classes. More specifically, he suggested that in his opinion, these classes "don't tend to focus on commerce, interchange, or 
really communication and they don't bring a lot to the table for business majors" (Ted, CB\&E).

In addition to questions and concerns about the content of the language programs, some participants openly wondered whether it is realistic to expect significant language acquisition in the amount of time devoted to language study at the university. Tony, a participant from the CB\&E, suggested that:

four semesters of language study provides practically nothing of practical value to our students. Our students want to understand culture and to be able to speak a few words but they don't get any help from the foreign language classes they take. (Tony, CB\&E).

Many of these concerns have been echoed by David Maxwell whose first initiative, upon coming to the presidency of Drake University, was to eliminate the foreign language department from the university's academic structure (Schneider, 2001). Maxwell's arguments for closure were not based on financial constraints or lack of student enrollment, but rather on the quality and relevancy of the product being offered students (Schneider, 2001). Maxwell's argument, articulated to the University's Board of Trustees, was that the insistence on the study of literature and grammar in foreign language programs had 
created a "national malaise" from which foreign language programs have not been able to escape (Schneider, 2001). He further suggested that students who are truly interested in learning a foreign language should forego the academic classroom and board a plane for a country in which the language is spoken. Maxwell's proposal was bolstered by the fact that he had been a longtime professor of Russian within the foreign language department at Drake. From his vantage point, he observed that foreign language programs had become ineffective and out-oftouch with the desires of most university students. Indeed, like many of the participants in this study, Maxwell, suggested that internal constraints on the curriculum, in favor of literature, were the product of an out-of-date notion of language study, especially in contemporary education where students are more interested in acquiring the skills that will allow them to work in professional fields in the target country (Schneider, 2001).

Additionally, Swaffar (2003) has suggested that foreign language courses, especially those above the introductory sequence, are tied more closely to the preferences and specialization of professors than to a notion of student needs or what constitutes a curriculum that will prepare students for the next class or life outside academe. Discussions of language course content surfaced in this study as well. Although no one 
overtly questioned the overall quality of the language courses offered by WVU's Foreign Language Department, several participants suggested that the scope of those courses do not provide adequate coverage for students from their area. This perspective was primarily voiced by CB\&E participants who believe that foreign language preparation should be an important component in their student's plans of study. As an example, Robert noted that:

language classes don't really focus on the things that we, in business, find useful. Our students want to know about commerce, trade, and economics. Those ideas aren't really, from what I know, gone over much in foreign language classes. (Robert, CB\&E)

Judy, a self-professed "firm believer" in the promise inherent in foreign language learning, suggested that like many programs, the Foreign Language Department attempts to prepared students for an academic life in their own discipline. She noted that:

the preparation of specialists in our fields, whatever they may be, is an important part of what all academic units do. But, in [name of department], when we look outside our own area, we wish that other programs would have some 
practical-based instruction. Maybe it's not fair, but we'd like other areas to do what we don't. We want the Foreign Language Department to teach some practical skills to students who won't be majors in their department. (Judy, ECAS )

Art also addressed the issue of practical courses. He mentioned that within [name of department], there is general agreement that the possibility of practical [name of discipline] classes, aligned with needs of business majors, could provide a solid and productive basis for interdepartmental exchange. Yet, he was quick to acknowledge that:

first of all, we don't have these practical classes. And, there is also the problem of restricted course options in business and engineering. Their degree plans are set well in advance and don't allow a lot of options, a lot of the classes that we would like to offer and that we think would be beneficial. (Art, ECAS)

Art's comments touched upon the notion of increasingly crowded curricula that disallow student choice and crossdisciplinary study. Indeed, increased precision in education, placed on professional programs, such as business and 
engineering, by external accrediting agencies, have worked to create set plans of study that allow few options outside the colleges and departments in which students are enrolled.

Outside accrediting agencies, including the Accreditation Board for Engineering and Technology (ABET) and the Association to Advance Collegiate Schools of Business (AACSB) have recently moved away from input-based standards for accreditation that were highly prescriptive. However, many of the changes in the standards affect internal components of the professional degree programs more than options for electives and other courses outside the professional programs. In this way, instead of creating a wide-range of options for students, choices have been limited to courses inside engineering and, to a lesser degree, business programs.

Table 4.2. Factors Diminishing the Effectiveness of FLE.

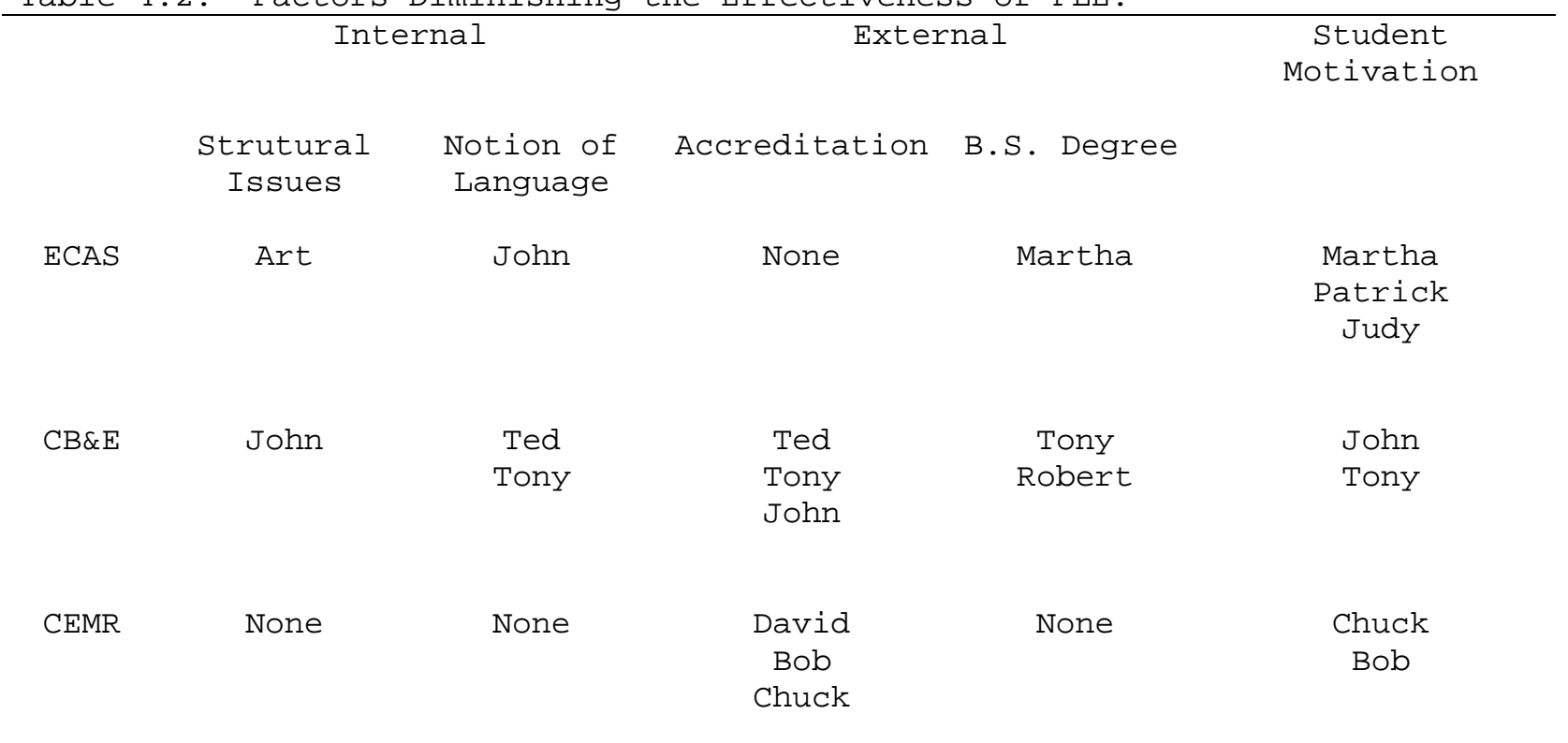


Many of the participants in this study noted that the skills that can be learned through the study of a foreign language require more than four semesters to acquire. However, given programmatic requirements imposed by the various departments, many students, especially those enrolled in professional and technical programs, have little room in their plans of studies for electives. The crowding of the curriculum, as it were, stems from accreditation standards that seek to address the nation's concern with the quality of higher education. Indeed, many recent studies (Rose \& Ward, 2006; Davenport, 2001; and Zionts, Scurry, \& Zionts, 2006) suggest that the public fears that the lack of transparency within higher education, or what Rose and Ward (2006) call the "Black Box Culture of higher education," hides endemic problems. Further, Newman, Courtier, and Scurry (2004) note that there is a growing uneasiness in the public that translates into their fear that higher education is not providing students with the skills needed to compete in the global economy. Issuing from these concerns, the government has begun to look more closely at higher education and at accreditation and exit testing as two means of improving quality and assuring accountability for the tremendous sum of money spent on higher learning. 
The influence of external accrediting bodies as the guarantors of quality within higher education cannot be ignored in any discussion of academic requirements for professional and technical programs. Equally important, however, are recent trends in accreditation standards suggest that the face of accreditation has changed from an input-oriented approach that focused on ratios of instructors who possess terminal degrees and the number of credit hours required for graduation, to an output-oriented approach that takes into account the mission of the institution as well the skills that graduates possess at the time of graduation and several years hence (Wergin, 2005; Davenport, 2001; and Zionts, et. al., 2006).

Given the importance of programmatic accreditation in professional schools and the corresponding lack of importance to academic units housed in the liberal arts, it is perhaps not surprising that no ECAS participants in this study professed to know anything about accreditation beyond the fact that it “happens occasionally and is usually a problem that has to be dealt with" (Art, ECAS). Even with this in mind, the lack of discussion on accreditation among faculty from ECAS was glaring because of the manner in which issues surrounding accreditation dominated conversations with participants from CB\&E and CEMR. Participants in these areas noted that the aforementioned changes in accreditation standards and objectives have provided 
some flexibility in the way in which programs meet the agency standards. Yet, they also suggested that the majority of this flexibility is found in course distributions within the colleges and individual departments rather than across curricular and programmatic boundaries.

In his discussion on accreditation, Tony concentrated on the history of accreditation within the business school. He noted that the old accrediting standards determined a school's status based on pre-determined criteria applicable to all institutions regardless of size or stated mission. He termed this "accreditation by the numbers" and suggested that ratios, including student:faculty, number of terminally qualified faculty:number of MBA faculty, and the number of full-time faculty:number of adjunct faculty, were the essential questions raised during each new round of program accreditation. Tony also noted that this type of "bean counting accreditation" soon became "dysfunctional" because of the cost of employing tenuretrack professors teaching in prescribed student to teacher ratios. In place of this system, AACSB implemented an accreditation program that focuses on the institution's mission and which replaced prescriptive requirements with general aims that each business school has to meet, according to its own plan . 
When discussing this same history, John, a CB\&E professor intimately familiar with the accreditation process, suggested that:

about 10 years ago, the pendulum in higher education had swung too far toward specificity. There was no room for any electives and no margin for error in the curriculum. In light of rising costs, these standards become overbearing and something had to change. What we have today is something a little less onerous. It allows us to tell AACSB how we meet the goals of accreditation rather than them telling us how to do it. (John, CB\&E)

Participants from the CB\&E were also quick to point out that the new standards preserve a place for liberal arts studies by mandating that students in the business program take only one-half their total courses from the business school. All other classes, or approximately 64 credit hours, are required to be taken from liberal arts. John noted that:

our accrediting agency is careful not to let students take more than one-half their classes in the major. They realize, and I agree, that there is more to an education than job training. We have to balance job training and the 
other skills, interpersonal skills, so that our students will thrive in the business world. (John, CB\&E)

Even with these safeguards against a "too technical" education, Ted noted that the curriculum remains "crowded" with little room for electives. He suggested that:

although our accrediting agency is careful not to let students take too many classes in their field, their plans of study are still pretty crowded. With all the math courses that they have to take over in the Arts and Sciences program, they don't have a lot of room for other stuff. In fact, I think that most of our students only have about three or four what we call free electives. That is, electives that can (pause), must be taken from outside our college. (Ted, CB\&E)

Like their accreditation counterparts in business, the Accreditation Board for Engineering and Technology (ABET) has also moved toward an output-basis of accreditation. This move has allowed individual programs the opportunity to address the standards vis-à-vis their overall mission. David, a longtime engineer who is very familiar with accreditation practices, suggested that the changes that occurred in the late 1990s, like 
the ones in business, moved the accreditation process from one that insisted on "bean counting to a process that was more flexible and which considered the realities present in engineering schools" (David, CEMR).

This move away from deterministic guidelines has allowed engineering colleges to satisfy traditional liberal arts requirements with programs and activities that are internal to engineering departments. A primary example of this trend that directly affects the tradition of foreign language education is $\mathrm{ABET}^{\prime} \mathrm{s}$ third criterion for program accreditation. This standard, dealing with student outcomes and assessment, suggests that engineering programs must demonstrate that their students receive "the broad education necessary to understand the impact of engineering solutions in a global economic, environmental, and social context." The means of accomplishing this objective, however, are left to the individual programs. At WVU, participants noted that engineering departments satisfy this objective not through coursework in foreign languages but rather through interpersonal exchanges within the engineering classroom. Chuck noted that:

the CEMR has a large percentage of international students and faculty, probably larger than any other program on campus. Through group and team projects, interaction with 
faculty, and just sitting in the classroom with students from other places, our students get a good dose of multicultural exposure. We build these experiences into our classes and curriculum and ABET accepts them as meeting the goal of ensuring a global dimension to our curriculum. (Chuck, CEMR)

Bob concurred with these remarks and added that the few classes required from WVU General Education Curriculum (GEC), especially the three-hour credit that satisfies Objective Nine (Non-Western Culture), also serve to ensure that the requirements set by $A B E T$ are met. From this perspective, students in engineering are able to obtain practical experience in dealing with others as well as an introduction, through a single course in the ECAS, to concepts necessary for understanding the global environment.

Overall, the move toward outcome-based accreditation standards was intended to provide flexibility in the ways that professional programs could meet accreditation standards and objectives. However, the participants in this study suggested that the plasticity allowed by the new norms inform questions that center on which classes students can take within professional programs rather that encouraging students to value self-liberalizing courses offered by the ECAS. Ultimately, therefore, accreditation's earlier move toward specificity and 
precision in education and its more recent trend toward allowing programs the flexibility to devise their own means of satisfying general objectives have served to pinch the number of elective courses required of students, thereby reducing the possibilities of cross-curricular alliances that expand the range of courses students can take.

Yet, even if these cross-curricular options were available to students, participants suggested that many students lack the motivation necessary to engage in either short-or long-term foreign language study. Many participants noted that this unwillingness to study languages stems from fear of failure to gain good grades in language classes as well as a fear of language study in general. Tony and Chuck, although hailing from two different colleges, both suggested that students in business and engineering are faced with difficult degree plans that require careful selection of elective courses. Because of the prevailing notion in the CB\&E and CEMR that foreign language courses are difficult and tend to lower students' GPAs, many of the students in these colleges seek courses in which superior grades are easy to obtain.

Chuck, a long-time advisor to engineering students, suggested that: 
our students have difficult degree plans and honestly, they are looking for easy grades from their electives. Because of several issues, our students don't think that foreign language classes are easy or that they can expect to get good grades in them. So, they take their electives in science and more often in math. These are easy classes for engineers and help get their GPAs up. (Chuck, CEMR)

Judy also noted an undercurrent of fear among students who have to take a foreign language course as part of their degree requirements. While sympathetic to foreign languages and the benefits it can bring students, she stated that in her belief:

the majority of students that I advise are afraid of language classes. I don't know why, but the language requirement hangs over their heads like a dead weight. So, students in those classes are usually only there because of the requirement. Otherwise, they would choose something that they feel would better fit their program of studies or something that they think they might be able to use later on in their lives. (Judy, ECAS)

Significantly, these fears have given rise to the increased 
use of the Bachelor of Science (BS) degree because of its lack of a language requirement. Bob suggested that many of the students he advises can choose between the Bachelor of Arts (BA) and the Bachelor of Science degree. He noted that he believes students opt for the BS because of the lack of language courses. Indeed, the elimination of a language requirement for the BS degree has also allowed students to take additional technical courses while eliminating the need for foreign language study. For a majority of its history, WVU had required students who wished to obtain the BS degree to enroll in both foreign language courses and additional science and math classes. However, 10 years ago, the foreign language requirement was dropped, allowing students to forego language study in favor of increased science-, math-, and technology-based courses. While a number of issued played into this decision, including reducing the overall number of courses required for graduation, student complaints about the practical value of language education were also part of the calculus leading to this decision (Bill, Bob, and Tony). Although Tony suggested that the elimination of the foreign language requirement for BS degree students was an error on the part of the administration, he felt that he understood the logic underpinning the decision. He suggested that: 
first and foremost, it was a question of hours. With the foreign language and other science requirements, our students were taking at least five years to graduate. So, from that point-of-view, getting rid of some of the clutter from the curriculum seemed reasonable. Then, you also have motivation factors. A lot of these students didn't and still don't want to take a language class. They are afraid of these classes and feel a lot more comfortable in math classes. That's where their motivation lies. (Tony, CB\&E)

Fear of language study plays an important and detrimental role in the willingness of students to engage in foreign language study. Participants suggested that students often seek a means to forego language study, an area in which they feel considerable anxiety, for courses in math, science, and other technical fields that lower their affective filter and provide courses that they feel to be more relevant to their academic majors. In both the ECAS and the CB\&E, these feelings have increasingly pushed students toward the BS degree in their fields of study, thereby further restricting curricular choice.

From this discussion, it was clear that the university curriculum has been squeezed from several directions, including notions of what constitutes the meaning of language learning, the changing nature of accreditation standards, and the 
motivation that students have for engaging in or avoiding language study. Questions that surround the constriction of the curriculum go beyond, however, the effects on a single program. As programs of study become more detailed and less amenable to interdisciplinary movement, the ability of all programs to forge cross-curricular links has been narrowed. The modern multiversity has engendered, in fact, the establishment of semiautonomous colleges that serve the intellectual and extracurricular needs of their students without extensive thought to how their programs fit into the larger academic puzzle. Yet, even in this climate, participants suggested that the possibility of some, albeit limited, curricular links between foreign languages and their colleges and programs were possible, if tailored to the specific needs of their students.

\section{Cross-Curricular Links}

Not withstanding the challenges to cross-disciplinarian studies that accreditation and internal degree requirements pose, faculty from all three colleges, the Eberly College of Arts and Sciences (ECAS), the College of Business and Economics (CB\&E), and the College of Engineering and Mineral Resources (CEMR), looked favorably upon the possibility of academic links between their programs and the Foreign Language Department at West Virginia University (WVU). These potential connections 
were in two principal areas. The first included the creation of cultural awareness classes, taught in English, which would enable students from all three colleges to gain a better understanding of the world beyond the borders of the United States. These non-language specific courses would require that faculty from the foreign language department team teach courses that mixed the cultures and survival skills of several world regions into one or two courses. Faculty from the three colleges studied felt that the Foreign Language Department is uniquely qualified to engage in the teaching of courses of this type because of their broad understanding of the culture, business and social, of the countries where Spanish, German, French, Chinese, and other languages are spoken. The second area that promises broad and productive links between the Foreign Language Department and other academic areas is study abroad. Participants in this study felt that foreign language faculty, given their language skills and understanding of the foreign cultures, are uniquely suited to leading or co-leading study abroad programs for students from Arts and Sciences, Business, and Engineering.

It is significant that many participants in this study expressed the same views toward the insular nature of the American people and the need to discard xenophobic tendencies. At the same time, however, the participants were fearful that 
concentration on one language, for many of their students, would fail to meet their long-term needs. Simply put, they expressed the view that in a global society, students have little knowledge about where they will be in 10 years or what their language needs will be. To combat this problem, many participants suggested, as above, that the language department offer a one semester class or a two-semester sequence that treats a variety of cultures and survival language skills. In addressing the first possible area for curricular integration, Martha suggested that:

Americans are in serious need, especially this generation, of broadened understanding of others. And, while I am not convinced that learning a foreign language in the language classroom ensures that students will get this new perspective on life, I do believe that a culture class, teaching lots of different cultures in one class, would really help, especially if it were taught in English. And, I think that the professors in foreign languages might probably have the best insights into how this class could be handled and what to teach. I think that many students in [name of program] would take the class and benefit greatly from it. (Martha, ECAS) 
In a similar fashion, Judy noted that she feels that "the people in this country are hostile to a multilingual environment" (ECAS). At the same time, however, she suggested that:

to be citizens of the world, people need to know more than one language so that they can know what is outside the borders of their small community. More importantly, maybe, is just knowing what is out of their sight. You know, cultural differences. It is here that I think the foreign language department could really provide some good services and good classes. (Judy, ECAS)

Chuck offered that such a program:

would be incredibly valuable to students from our college. Many students would take this class because, for one, I would encourage it, and secondly, because they know that they will probably have an international assignment early in their careers. Getting to know how to get along with others would be really valuable to them and they would understand the value of a class like that. (Chuck, CEMR) 
Finally, Ted noted that the "stuff of business has less to do with literature than with an awareness of business and social culture" (Ted). In completing this thought, he added that:

the faculty in the Foreign Language Department, even if they have their degrees in literature and the such, probably know more about the culture of a country than we do. They would be really helpful in a class that talks about the social and business climate of a country, and where many of these beliefs come from, than anyone else on campus. (Ted, CB\&E)

Table 4.3. Potential Cross-Curricular Linkages

Link

Coursework

Study Abroad
ECAS

Martha Judy

Martha Judy
CB\&E

Chuck

Ted

Tony

Ted John Robert Tony
CEMR

David Chuck

Chuck

Similarly, many participants noted the importance of study abroad experiences for students from all colleges. This is especially true in light of West Virginia University's 2010 Plan: Building the Foundations for Academic Excellence. Goal 
3: Enhance the Educational Environment for Student Learning of this strategic plan has built-in objectives that view education as a process of increasing global awareness and students' abilities to understand their place in the worldwide network of economics, culture, and politics. With this in mind, faculty were quick to suggest that educational endeavors in foreign lands are an excellent means to accomplish this goal and to provide experiences for students that go beyond classroom learning. Yet, these same participants were equally quick to point out that many professors in their programs do not have the language or cultural skills required to deal effectively with unexpected occurrences in the foreign country and suggested that cooperation with the Foreign Language Department would be a way to build bridges and to provide a valuable service to the university and to students from a variety of academic programs. Judy seemed to be intimately aware of the outline of the strategic plan and offered the thought that the university, through this initiative, is encouraging faculty to seek out opportunities for international exchanges and study abroad experiences. She noted that:

we don't currently have a lot of study abroad opportunities in [name of department] but that doesn't mean we aren't on the lookout for them. The university is pushing these 
programs and we need to get on board. The new strategic plan has language that speaks directly to the need for internationalization of the campus and for me, the best way to do that is to get our students going abroad. Of course, most of our faculty had foreign language classes years ago and even then it was mostly for reading. So, I think that we could work with foreign language faculty to develop some programs. They could help us out with the language and culture and we could help them out with students. (Judy, ECAS)

While only one participant from the ECAS mentioned the possibility of study abroad as a natural link between their programs and the Foreign Language Department, all the participants from the CB\&E were aware of this important, yet latent, potential. It should be noted, however, that the CB\&E has worked diligently over the past 10 years to develop in-house study abroad programs. At this time, the CB\&E offers programs in China, Italy, Germany, and a "Developing Markets" program that has visited Cuba, the Czech Republic, and Poland. Yet, even with this record of success, the CB\&E is seeking additional study abroad options for its students. It was within this context that several participants mentioned the potential of links between the CB\&E and Foreign Language Department. Tony, 
an adamant supporter of both language study and foreign travel, suggested that:

the level of our students' lack of understanding about foreign language, culture is astounding. It bothers me to think that our future business leaders have no clue about other languages, other cultures. This is startling and can be combated, at least a little, by study abroad programs. Right now, we take students to several places around the world, Germany, China, and Italy. But, only in a few of those programs do we work with the Foreign Language Department. Just as often, we work with [name of professor] from the [name of department] or someone else who can speak the language and who is interested. If the people in foreign languages were interested, we could all do a lot more. And that would really help our students. (Tony, CB\&E)

Chuck, a participant from the CEMR, also suggested that there is "a fair amount of interest in study abroad programs within our college" (Chuck). He suggested, however, that much of this interest comes: 
from our students who are also in the Honors college. I think that there are some scholarships, actually a fair amount of money, that are available for study abroad. If we could work out something with foreign languages, we could recruit a lot of students into these summer programs. of course, the courses couldn't only be in language. There would probably have to be some technical content to them as well. (Chuck, CEMR)

Study abroad opportunities have, in recent years, taken on an increased importance in colleges and universities across the country. As students seek competitive advantages upon entry into the job market, they feel that foreign experiences, provided by short- and long-term study in a foreign land, enhances their résumés. Participants in this study were clearly aware of the importance that students place of these programs and the need for links between the Foreign Language Department and their programs. However, the study abroad programs envisioned by participants go beyond language courses readily available to all students enrolled at WVU. Rather, they were specialized classes that would combine the study of business and social culture within a single program. These classes, as suggested by the participants, would help students who are unaware of the location of future foreign assignments better 
understand the intricacies of foreign cultures and allow them to operate more effectively in their business and social

interactions. Likewise, many of these same participants suggested that foreign study, co-organized by their own programs and the Foreign Language Department would have tremendous appeal to students for whom the curriculum in their professional programs is restricted, especially during the Fall and Spring Semesters.

The Purpose of Foreign Language Study

One of the main objectives in undertaking this study was to uncover the viewpoints of faculty toward the underlying purpose of foreign language education within the context of higher learning. As the interviews progressed, it became increasingly evident that the participants were not ready to discuss the philosophy of education and the relationship that language study has to the meaning of education. Rather, as mentioned earlier, the participants interpreted this question more narrowly as the skills that foreign language study was previously meant to teach or the skills that it can provide in contemporary society. Even in the face of follow up questions that insisted on the philosophical role of foreign language learning within the university context, participants responded by suggesting that: 
foreign language learning was always about teaching Ph.D. students to read in the language. Years ago, all students had to pass a reading exam, usually in German or French and sometimes in Spanish or Italian. Today, most works of literature are translated and most of the important journals are in English, so this reason for studying a foreign language is gone. (Patrick, ECAs)

Participants from the professional schools, business and engineering, interpreted this question even more narrowly by focusing not only on the skills that learning a language can impart to students, but also on the essentialist nature of having a foreign language experience on a student's academic transcript. Chuck noted that:

when firms recruit, they want to see a foreign language or a foreign experience on the applicant's transcript. Without this, they will probably not hire the student, even if everything else looks good. (Chuck, CB\&E)

In this manner, foreign language study is made just another box that must be checked off prior to graduation. In essence, learning a language has been transformed from an experience in self-liberalization to another requirement to be met before one 
can enter the job market. Although I had hoped to delve more deeply into this question, I am forced to acknowledge Swaffar's (2003) conclusion that foreign language programs present no clear vision or unifying purpose to a higher education system that has become increasingly professionalized and vocationalized. Nonetheless, I was surprised by the lack of concern for the philosophical underpinnings on which our educational system rests and the narrow interpretation of the questions posed to participants.

\section{Summary and Conclusion}

This chapter provided an overview of the responses of the participants in this study. As seen above, participant view toward the skills and advantages that foreign language education can provide students does not differ significantly with those suggested by the review of literature. That is to say that the study of languages can help students gain insights into the culture of a language while also assisting students in coming to an understanding of their own culture and language. Participants also suggested that they believe the Foreign Language Department's insistence on a literature-based curriculum hinders the potential for cross-curricular exchanges and weakens the department's standing within the university. Participants also suggested that in spite of these problems and 
the ones posed by restricted curricula, there are several possible links, including course proposals and study abroad experiences that could be explored. 


\section{CHAPTER FIVE: SUMMARY AND DISCUSSION}

Introduction

The purpose of this study was to determine the perspective of West Virginia University (WVU) faculty from the Eberly College of Arts and Sciences (ECAS), the College of Business and Economics (CB\&E), and the College of Engineering and Mineral Resources (CEMR) toward foreign language learning in the context of higher education. As an extension of this basic question, I addressed five subsidiary areas including (1) the current/historical state of foreign language education at WVU; (2) the understanding of the role and purpose that faculty from the various colleges have concerning foreign language learning at West Virginia University; (3) the benefits that skills and knowledge learned in a foreign language classroom have for students from each in each individual academic area; (4) whether changes in accreditation and certification requirements have altered the role and content of the traditional liberal core and general education classes; and (5) whether changes in the focus of foreign language study might provide links across diverse content areas?

Through the use of semi-structured interviews, faculty participants from the three colleges offered their perspectives 
on foreign language learning within higher education. The analysis of the transcripts suggested that four important themes emerged during the course of these conversations. These included (1) the reasons for engaging in the study of a foreign language, (2) perceptions of the problems that challenge foreign language education, (3) the potential for cross-curricular links between university programs and the Foreign Language Department, and (4) the purpose of foreign language programs within the context of higher learning.

Overall, participants were reasonably consistent in their beliefs about the skills that learning a foreign language can provide to university-level students. Moreover, the reasons suggested by the participants were similar to those found in academic literature promoting the learning of foreign languages for the cultural awareness that it can bring to students who have been relatively isolated within the boundaries of the United States. However, participants did suggest other rationalities for engaging in foreign language studies. From the perspectives of participants from the CB\&E and the CEMR, learning a foreign language, or more specifically the cultures associated with foreign languages, possesses practical value in two areas. First, the understanding of diverse cultures helps ensure that business people and engineers are comfortable in the foreign cultures in which they will likely be posted as part of 
their early career assignments. Equally important to many participants was the value that a foreign language element on academic transcripts presents. Participants from the CB\&E as well as the CEMR suggested that the presence of a foreign language class, or sequence of courses, on students' academic records has become a quasi-prerequisite for employment. Faculty from these colleges noted that the global nature of these fields necessitates some exposure to foreign cultures and languages prior to entry into the professional world.

Yet, even given this importance, participants were concerned that the type of courses provided by the Foreign Language Department at West Virginia University are not meeting the specific needs of students from all three colleges studied. Participants felt that a change in focus toward the teaching of culture rather than language skills would provide greater overall benefit to students from all colleges, but especially the professional schools. Participants suggested that their concerns stem from two areas, one internal to the foreign language department and the other external. First, faculty from the three colleges believe that the teaching of language skills for literature and the study of literature dominate the curriculum within the Foreign Language Department. In light of this focus on essentially only one aspect of language, participants felt that foreign language study was not meeting 
the needs of students from the professional schools. They reasoned, in fact, that the narrow focus on one language and the lack of study of world cultures presented obstacles rather than potential in the study of languages. Externally, participants noted that changes in accreditation standards, again within the professional schools, have altered the nature of accreditation. As accrediting agencies moved away from input criteria for evaluating programs, they allowed institutions and individual departments to demonstrate how the accreditation objectives were met in light of the mission and goals of the institution rather than standards applicable to all institutions. This modification of accreditation principles has allowed the programs to meet standards with extracurricular activities, classes, and student-faculty interaction that tend to limit the need for contact with other academic departments, including foreign languages.

Even though these challenges were clearly on the minds of participants, faculty from the EBAC, CB\&E, and CEMR were optimistic about potential programmatic links with the Foreign Language Department at West Virginia University. First, participants noted that the development of a comparative world culture class, or two semester sequence of courses, would be beneficial to students in all three colleges. As noted above, participants in the CB\&E and CEMR were mindful of the future 
careers of their graduates and linked student understanding of cultures to success in their chosen professions as well as to gaining their first-choice employment. Similarly, participants suggested that increased study abroad, sponsored or facilitated by the Foreign Language Department, holds significant potential for cross-departmental links. Participants noted that faculty from the Foreign Language Department are uniquely qualified to lead or co-coordinate these program because of their understanding of the languages and cultures associated with the countries in which the study experiences would take place. However, participants suggested that while the study of language should be a component of the study abroad experience, other more practical skills, including cultural awareness and contentspecific courses, should also be included.

It should also be noted that while a primary consideration in undertaking this study was to gain a better understanding of faculty thoughts on the underlying philosophical purpose of foreign language study within the university, participants did not speak directly to this question. Rather, when queried about the role and purpose of foreign language study, they were content to speak to the skills that engaging in the study of languages can help students acquire. The absence of discussion concerning this central point, however, is suggestive in itself. The lack of insights and understanding of the purpose of foreign 
language study within the university indicates, among other things, that the academic community is fractured along disciplinary lines and considers education as a narrowly defined and program specific phenomenon.

Finally, on a more personal level, I noted in chapter 3 that I bring a number of biases to this project. These can be attributed to the many years that I have spent in foreign language education as a student, teacher, and administrator and to perspectives on language learning garnered through these experiences. Indeed, my understanding of language learning is deeply embedded in my personal history, revealed in the Lens Papers attached to this document (See Appendix D), and has led to the beliefs that I find true. At the same time, however, I understand that my personal truth is only one of many possible worldviews and does not represent a reality that can be forced on others. Further, while I was aware of my personal lens prior to engaging in the work associated with this project, I found, as I listened to participants discuss the state of the field that has been a significant part of my professional life and an instrumental agent in my personal formation, a sense of betrayal by those charged with carrying foreign language and general education forward. Themes of complacency, missed opportunities, taken-for-granted attitudes, and isolationism ran through the stories of participants like an unwanted thread running through 
the fabric of foreign language learning. Equally important and just as powerful, the concept of educational essentialism was also omnipresent in this academic story. Whether aware of the underlying meaning of their comments or not, participants often suggested that education has been reduced to essential elements on which "good learning" and "good programs" must be based.

This conceptualization of what it means to be educated differs significantly from my personal beliefs. While I understand that accommodations to the reality of education must be made and that foreign language programs must embrace practical learning, I am a product of self-liberalizing aspects of education and believe strongly in the promise that education possesses. Given this background, I can only wonder how my perceptions and the resulting conclusions might be different from those of a person who does not share my worldviews or my faith in the potentuating effects of foreign language learning.

\section{Discussion}

Theoretically, this study was underpinned by the models and theories of Bandura (1969/1986) and Bourdieu (1983). The constructs that form the backbone of these works emphasize the importance of place and social intercourse on the actions and beliefs of participants. Clearly, the perspectives of faculty participants in this study suggest that they are significantly 
influenced by the milieu in which they conduct their daily lives as well as their educational and personal backgrounds. Additionally, these perspectives indicate that the importance of a particular form of education is constructed through unspoken judgments and assessments that stem from a combination of current context and personal histories.

Although the context of this study is West Virginia University, a large multi-faceted institution located in a rural state, the results suggest that many of the attitudes uncovered in this study are consistent with those suggested in current literature and are common among faculty at many American universities. Modern American multiversities have increasingly adopted a for-profit and vocational bias in their educational practices. Although this phenomenon has been widely reported, other concepts, educational essentialism and alternative means of education, couched within this view of education, have received far less attention. Yet, it is clear in the results of this study that the move towards educational essentialism has engendered the desire for and creation of alternative means of preparing students for the rigors and expectations of employers.

Although this line of questioning was not an original component of the study, the emergent design approach that is inherent in qualitative methods allows for the evaluation of the type of unanticipated data found in this study. Indeed, while 
participants were answering questions concerning (1) potential curricular links between their programs and the Foreign Language Department and (2) the role that accrediting agencies play in determining curriculum changes, they were going beyond the boundaries of these questions and entering into new and unexplored territory. In fact, participants, especially from the CB\&E and the CEMR, seemed to be keenly aware of and interested in alternatives to the traditional notions of foreign language and general education programs that might serve to better prepare their students for entry into and success in their career fields.

Stemming from their experiences and their perspective regarding what foreign language study can provide students, most of the participants suggested that the traditional notion of foreign language study, the learning of the language to read literature or journal articles in the original, was no longer a justifiable rationale for language study. Rather, during interviews, faculty from the three colleges were almost unanimous in their agreement that cultural skills trumped literature skills as a basis for learning a foreign language. Indeed, discussions centering on the value of cultural studies and the tailoring of programs to meet the needs of the various colleges was, along with the theme of accreditation, the most common topic that emerged during the interviews process. As 
noted above, participants suggested that the lack of certainty of future job placement and the realization that business and engineering have become global professions make the learning of a single language a disadvantage to many students.

This understanding of the future careers of students led participants from the CB\&E and the CEMR to suggest that learning cultural awareness skills, through comparative world culture classes, is an idea whose time has come. They reasoned that the creation of students who understand and can function in a variety of cultures trumps the learning of a single language and single culture, regardless of the depths of appreciation of that country and language. In a sense, the practical value of learning a single language has been reduced as the global economy and changes in employment patterns force individuals to function in diverse cultural spheres as they move along their career paths.

Coupled with changes in the practical and everyday use of language, participants, especially those from the professional schools, appeared certain that the existence of a language element on students' transcripts has become a pre-requisite for entry into the professional world. All but one of the participants from the professional schools, the CB\&E and the CEMR, suggested that students who take a foreign language are more likely to gain employment in their first-choice-firm than 
students who do not have this experience. Participants noted that the probable cause of this phenomenon was that graduates from the business school and engineering program are more likely than not to have international postings early in their professional careers. They also noted that in spite of the fact that most international business, whether in accounting or engineering, is transacted in English, the knowledge of foreign culture, as evidenced by language study, indicates that these employees will be capable of and comfortable with living in a foreign land.

The reduction of the study of languages to an essential, yet peripheral role in the education of students from professional schools renders language study a field that adds value to these majors rather an area that possesses worth on its own. In a sense, the choice to engage in the difficult task of acquiring a second language adds a necessary accoutrement to the student's credential and creates a neatly packaged product that seems, on the surface at least, to promise a broad understanding of the cultural differences found in the world. More importantly, perhaps, the acceptable contents of these packages appear to well known, leading to the establishment of criteria that must be met regardless of whether the underlying value of these prerequisites are present. 
Ivan Illich (1970) refers to this phenomenon as the process of ritualization of progress and society. In essence, he claims that the meaning of education as an emancipatory vehicle has been swept aside by the need to create a product that possesses value in the marketplace. Illich (1970) suggests that the creation of this value is contingent upon the emergence of acceptable codes of conduct and the codification of the requirements necessary for entry into the workplace. The ritualized and highly codified criteria are then bundled into acceptable packages and sold to the public as neatly wrapped and approved merchandise. These processes, of course, simply contribute to the essentialist nature of education that has been on the rise since the publication of the Flexner Report in the early years of the twentieth century. The ritualization of education has, in fact, tended toward certification by the numbers rather than an attempt to determine whether the educational calculus is correct.

The second area of interest that emerged during the course of this study concerned the factors that have contributed to this rather circumscribed and essentialist notion of the advantages that learning a foreign language can bring to students. Participants suggested that challenges to the centrality and role of foreign language learning emanate from internal and external forces. Inside of foreign language 
departments, participants suggested that faculty attitudes toward what it means to know a foreign language have created distance between the needs of professional programs and the foreign language curriculum. Additionally, internal conflict within the Foreign Language Department at West Virginia University has not allowed the department to reach out to other academic areas in an effort to forge meaningful crossdepartmental relationships. Finally, external constraints, namely the rise of program-specific accreditation, have contributed to the specificity of programs of study that limits the scope of classes in which students in professional programs can enroll.

The participants' thoughts on the internal constraints facing the Foreign Language Department are consistent with concepts found in the review of literature. Nichols (2000) and Swaffar (1999) suggested that the privileging of literature in the foreign language department has created situations in which these departments have become self-servicing with the study of language centering on the future study of literature rather than on the needs of the majority of students and other academic programs within the university structure. Additionally, internal conflicts associated with phase separation (Lariviere, 2000) and the dominance of Spanish (Welles, 2004; Nichols, 2000) have created tensions in foreign language departments that are 
apparent to other academic disciplines. Indeed, two participants (Art, ECAS and John, CB\&E) suggested that the Foreign Language Department at WVU is in a state of disrepair and that the university administration has no confidence it is ability for self-healing. There can be little doubt that these feelings discourage attempts on the part of other academic areas to engage in co-coordinated programs and cross-curricular exchanges .

Outside constraints also contribute to the substantial challenges facing the Foreign Language Department. Participants in the professional schools, business and engineering, suggested that even in light of recent changes in accreditation standards, the curriculum of their programs has been significantly restricted in recent years. Indeed, the majority of the flexibility created by an increased emphasis on student outcomes rather than input processes is internal to the individual programs and departments. This means, in essence, that engineering and business programs now have the ability to redistribute course requirements within their colleges while limiting the number of courses from other academic areas. More importantly, perhaps, is the ability of these programs to reconcile accreditation standards dealing with cross-cultural awareness and global understanding with courses and extracurricular activities housed solely within their colleges. By 
allowing interaction with international faculty and students to satisfy the requirement that engineering programs produce globally aware students, foreign language departments, the traditional locus of this knowledge, have been left in a diminished role with regard to the curriculum of these programs.

In spite of these challenges, the majority of participants suggested that curricular alliances and cross-discipline coordination between their academic programs and the Foreign Language Department were not only possible but also highly desirable. On the surface, the suggestion that foreign language education has little to offer professional programs and the notion of curricular links might seem contradictory. However, at a deeper level, these seeming inconsistencies suggest that foreign language learning still has a place within higher education. Participants suggested, however, that this role differs significantly from the self-assigned role given to foreign language study by literature faculty within the Foreign Language Department. Rather than emphasizing the prevailing notion, held by many foreign language faculty, of language study for literature (Swaffar, 2003; Foster, 1999; and Klayman, 1978), participants promoted the study of diverse cultures and the understanding of others that a comparative culture course can bring to students. 
Participants related the need for culture over language to the realities of the academic requirements of their programs, and the nature of employment for their graduates. Indeed, almost all participants, whether from the ECAS, CB\&E, or CEMR, suggested that the academic programs in their areas of study are restricted in the number of electives that students can take. Additionally, student use of the Bachelor of Science (BS) degree in all three colleges has eliminated the need for foreign language study by allowing students to enroll in other, primarily technical courses, to satisfy their General Education Curriculum (GEC) requirements. Participants from the CB\&E as well as the CEMR also noted that their graduates will most likely be employed in countries that speak languages not taught at WVU and that their careers will take them to several worldwide locations in which different languages are spoken. According to the participants, these two realities make learning a single language a disadvantage to the student and suggest that a culture or introduction to world languages course would be better suited to their needs. Additionally, participants from the professional schools noted that their students are aware of this need and would most likely find tremendous benefit in such a culture course. Finally, participants from all three colleges recognized that foreign language faculty possess a unique set of skills, related to cultural understanding and language ability, 
that enables them to be significant contributors to the education of all university students in on-campus and study abroad experiences.

As attractive as this push for comparative culture courses might be, it hides a naïve approach to understanding the relationship between language and culture. In a very real sense, participants suggested an atomistic view of the complex relationship between behavior and linguistic background. That is, participants conflated the building blocks of culture (basic beliefs, values, and behaviors) with language rather than with the context in which these elements are embedded. In fact, it appears that participants were convinced that the study of language represents what Robinson-Stuart and Nocon (1996) refer to as the "magic carpet ride to another culture" that is achieved as a primary by-product of language study. Today, however, we know that the connection between language and culture is not always present in the foreign language classroom. Brown (2007) notes that in fact, many students acquire foreign language skills "with little or no sense of the depth of cultural norms and patterns of the people who speak the language" (p. 194). Therefore, caution must be taken to avoid entering into a causal relationship between the study of language and the acquisition of cultural skills. 
Faculty should not, however, be overly chastised for this construction of the meaning of culture and its relationship to language. All too often, multicultural classes and campus-wide multicultural initiatives promote this intertwined relationship by insisting on the study of large macro trends associated with language or national groups rather than on individual cultures that can encompass several languages or which are distinct from other speakers of the same language. Although his approach to teaching culture, labeled the "heroes and holidays" syllabus, has been much maligned by multicultural experts (King, 2001; Moodley, 2007), it remains dominant in the minds of those who are not language and culture experts.

In spite of the misunderstanding of the relationship between language and culture, tools are available to make the teaching of cultural awareness an important element of foreign language classrooms. Using approaches developed by Byram and Feng (2005), DeCapua and Wintergerst (2004), and Wright (2000), foreign language faculty have the opportunity to unteach stereotypes that are prevalent in the thoughts of many students and faculty. More importantly, faculty can begin to teach the skills that will allow students to move from the simple recognition of cultural components to the higher order cognitive skills that include analysis, synthesis, and evaluation of information. In this manner, foreign language programs can 
meet, and in fact surpass, the expectations of professional colleges by providing students not only knowledge of individual cultures but also the skills needed to adapt to unknown cultures that they might encounter.

Finally, as noted briefly earlier in the discussion, participants did not, when presented the opportunity, delve into the underlying philosophical rationale for inclusion of foreign language study in the higher education curriculum. This lack of commentary points to a taken-for-granted attitude about the contents and scope of higher learning. In this view, foreign language programs are a part of the higher education curriculum because (1) they have always been there and (2) they represent an academic unit that must be present for an institution of higher learning to call itself a university. Indeed, it appears that for many of the participants, the absence of a foreign language department would call into question the very nature of the university. That is to say, universities have become defined by a pre-determined list of programs necessary for their own existence.

Yet, today this form of tautological reasoning is increasingly under attack. Throughout the university, this study suggests that there is a significant decrease in the sense of a university as a single community of professors and learners possessing a common soul and a united mission (Newman, 2003; 
Kerr, 2001; and Illich, 1970). In essence, this means that universities are tending more toward the concept of semiautonomous colleges lumped together under an umbrella structure provided by a centralized administration than the traditional notion describe above. Likewise, in the era of accountability and departmental relevance based on centrality to the university, foreign language departments are being cut from leading universities because of their inability to adapt to the changing educational landscape (Schneider, 2001). The failure, therefore, of university faculty at WVU to assign a purpose to foreign language education is suggestive of systemic problems that bode ill for the future of foreign language education at the university.

As a whole, the perspectives of the faculty who participated in this study suggest that changes in the educational goals of academic departments are creating an educational context in which the curricular system and rationale of individual programs is becoming increasingly closed, impermeable to outside influences and the need to couch their educational goals within larger university initiatives. The ability to engage in alternative conceptualizations of what it means to be educated bodes poorly for programs situated on the periphery of core academic units and is suggestive of larger macro-trends that influence all levels of public education in 
the United States. More importantly, however, the results have exposed the complexities of relationships within the modern university and suggest that foreign language departments must embrace the evolving nature of higher learning if they wish to remain in the academic structure of the modern American multiversity.

\section{Reconceptualizing the Foreign Language Department}

In spite of the aforementioned problems and the challenges that foreign language education faces, participants in this study suggested that the Foreign Language Department has a role in the mission of the university and the education of its students. To be sure, this role is perhaps not the one imagined or preferred by foreign language professors because it places foreign language learning on the periphery of the core academic units. More radically, the implications stemming from this relocation of foreign language programs point to the necessity of developing an ecology of foreign language education that is capable of sustaining and accepting multiple perspectives on the meaning of language learning within the context of higher education. The establishment of a new space and guidelines for interaction across programmatic boundaries amounts to no less than a fundamental reconceptualization of university-based foreign language departments and emphasizes the need to forego 
the taken-for-granted binary division between the study of language for literature and the study of language for practical use that often exists within foreign language departments.

There is little doubt that the summons to reform the mission of foreign language programs inherent in this reconceptualization will be difficult, at best. History and tradition within foreign language programs have privileged literature-based studies over the teaching of language skills for practical use. Indeed, for most of the history of higher education in the United States, the social and intellectual environment of higher learning provided the sub-context on which the privileging of literature and language skills for reading and writing was based. This cloistering of the intellectual pursuits and philosophical raison d'être of the department into upper level literature courses created an obvious distinction in the mission of various faculty and produced curricula that focused on the production of fellow intellectuals devoted to the study of language for reading. Today, however, the pendulum of education has swung in favor of skills-based learning and now privileges practical skills and job-training curricula. There must be, as a consequence, a bridging of the divide that separates the language and literature curricula so that language learning and language teaching can regain meaning within the academic community. 
This is not to say, however, that literature has lost its place in higher education. Rather, it is simply to suggest that literature-based studies and the self-servicing language learning for literature can no longer form the backbone on which foreign language programs are based. In the contemporary university, room must be made in the curriculum for the study of practical language skills that can assist students in their primary areas of study, including business and engineering. This amounts to an accommodation to the realities of the world outside the walls of academe and to the encroachment of accountability inside the halls of higher education.

The reconceptualization of this new outward looking foreign language department is partly based on theoretical underpinnings provided by Mikail Bakhtin (1973) and more particularly his emphasis on the importance of dialogical processes. Centering this discussion on Bakhtin's (1973) concepts of centripetal (inward pushing) and centrifugal (outward pushing) forces, notions borrowed from the field of physics, we understand that foreign language programs were traditionally and typically fashioned by centripetal forces that mandated an inward looking curriculum that satisfied the needs of the department as well as the few students who wished to become specialists in their chosen literary field. Swaffar (1997/2003) and Bernhardt (1997) call this inward looking curriculum "self-servicing" in that 
students enrolled in the language portion of these programs gain the skills necessary to cope with the reading and writing assignments typical of upper level courses taught in the department. This model of language programs, traditional to many foreign language departments, creates a closed system in which the study of a language begets the study of literature in the original rather than an outreach to other disciplines and means of conceptualizing language use.

If foreign language programs are to recover their place in higher education, they will be required to bring centrifugal forces to bear on their curricula. That is, they will have to look outward while engaging others in the dialogical processes that will create inter-disciplinary links and provide new meaning to their programs. In this manner, the traditional and largely artificial boundaries between language for literature and language for practical use will be broken down and a new means of understanding the foreign language department's role in higher education will be developed from the organic relationships engendered in this dynamic and dialogical relationship.

While this reconceptualization of the foreign language department might not be palatable to many in foreign language education, there are precedents in other academic areas that can inform the discussion and provide a frame of reference for 
foreign language educators. Daniel Williams (2000) offers one such model, developed for Leisure Studies, that foreign language departments could use as a starting point to redefine their mission and to recover their place within the academic community. As it pertains to foreign language education, the model (See Figure 5.1) consists of three concentric levels, each relating to the others as well as to the world beyond higher education. Within this framework, the foreign language department must contemplate its mission within its own boundaries as well as in its relationship to others, including specialized educational programs and the larger community that represents the stakeholders for higher learning.

Within the first level, labeled the Philosophical Zone, foreign language departments must raise and answer questions concerning what it means to know a language. Rather than the taken-for-granted literary focus common to university foreign language departments, the questioning at the epistemological level must be answered by myriad of language professionals, including literary theorists, literature professors, linguists, cultural experts, and language teaching professionals. This synthesis of ideas will assist foreign language departments in coming to a broader understanding of "language." While discussion at this level remains philosophical, it embraces dialogical processes by virtue of the use of a variety of ways 
of viewing language at its fundamental level. Concomitant with this internal dialog is an understanding of broader educational and societal entities that act as informers and consumers of the foreign language curriculum. While these external forces do not enter into the conversations regarding the nature and meaning of language, language learning, linguistics, and cultural symbolism, echoes of their thoughts and concerns can be heard and inform a portion of the dialog being held between members of the department.

As we move away from the center, external forces are engaged at the next level of the framework. The Philosophical Zone and the outer realms of the framework meet in the Transitional Zone, an area that provides the space for language experts to engage their curricular partners from outside the foreign language department in conversations that will inform discussions on the needs of students who seek practical language skills for various purposes. Conversations within this space require that all participants abandon their own taken-forgranted notions of education and work toward the establishment of curricula that recognizes the variety of purposes for which language can be used in society. Further, it is within this zone that foreign language experts and their counterparts from other academic areas bring their unique points of view to bear to birth several curricula that meet the needs of students from 
many academic programs as well as external clients that might use the services of university graduates.

Although the dialog that occurs within this level remains geared toward the creation of programs that meet the needs of academic units and their clients, it is nonetheless apparent that voices from outside academe influence the discussion and are important informers in the development of curricular initiatives. In essence, the inclusion of many voices in this conversation points to the necessity to create a triadic relationship among foreign language experts, other academic departments, and outside clients that can be used to develop programs that are sufficiently broad in scope to build the language and cultural skills required by a multitude of constituents.

The outer-most zone of the Incomplete Framework for Reconceptualizing Foreign Language Departments consists of the classes and programs intended to teach the skills identified by curricular partners, both internal and external to the university, needed to satisfy the demands of various clients. These skills, each equally valid and meaningful, emanate from the conversations generated within the middle area and reflect the current and future considerations of potential clients for language, business, engineering, education, and other majors within higher education. While tempting to classify the 
teaching of skills as purely vocational education, it must be noted that the design of these courses stems from the convergence of the philosophical meaning of language and its practical uses. This should result in an understanding that many ways of conceptualizing language exist and that while each must be treated differently, each must be treated with respect.

Also, it is essential to understand that this framework is couched within the larger societal structure. Indeed, it clearly situates education at the intersection of public policy, societal perceptions, and political machinations. While some have argued that higher education has become increasingly privatized, universities and colleges remain entrenched within the public sphere and help shape the future of the nation. If foreign language departments continue to eschew their public function by not helping students gain the skills deemed necessary for economic and political regeneration, an already weary public will eventually renege on its promise of funding and doom foreign language programs to obsolescence in higher education. I believe that reconceptulizing foreign language education along the lines suggested by this framework can help language departments come to a better understanding of their mission within society and education.

The boundaries of this incomplete framework are permeable and require the interaction of a variety of specialists who 
engage in dialog for the future based on respect for each subfield that forms the foundation of a unified foreign language department. Within this dialogical process, the framework provides the opportunity for departments to pose the questions needed for serious self-evaluation and to complete a redefinition of their place in higher education that is fundamental to the reconceptualization of the foreign language department. Indeed, it is my belief that without this programwide evaluation of what it means to know a foreign language and concessions to practical aspects of language study, foreign language programs face an uncertain future within higher education .

Finally, this model suggests the need for bi-directional communication among multiple layers of educators and the clients that higher education serves. There can be little doubt that the effective foreign language department will draw upon a wide body of interdisciplinary fields, including literary studies, linguistics, pedagogy, and cultural studies, to create programs capable of meeting student needs and recovering its place within the academy. This notion of the modern foreign language program rejects a circumscribed language learning agenda that devalues any one aspect of language teaching, including the teaching of literature. Rather, the goal is to embrace a myriad of rationales for language learning that accept differences and 
which accommodate the realities of the multiversity and modern society. Only through acceptance that there are many reasons, Figure 5.1. Incomplete Framework for Reconceptualizing Foreign Language Departments.

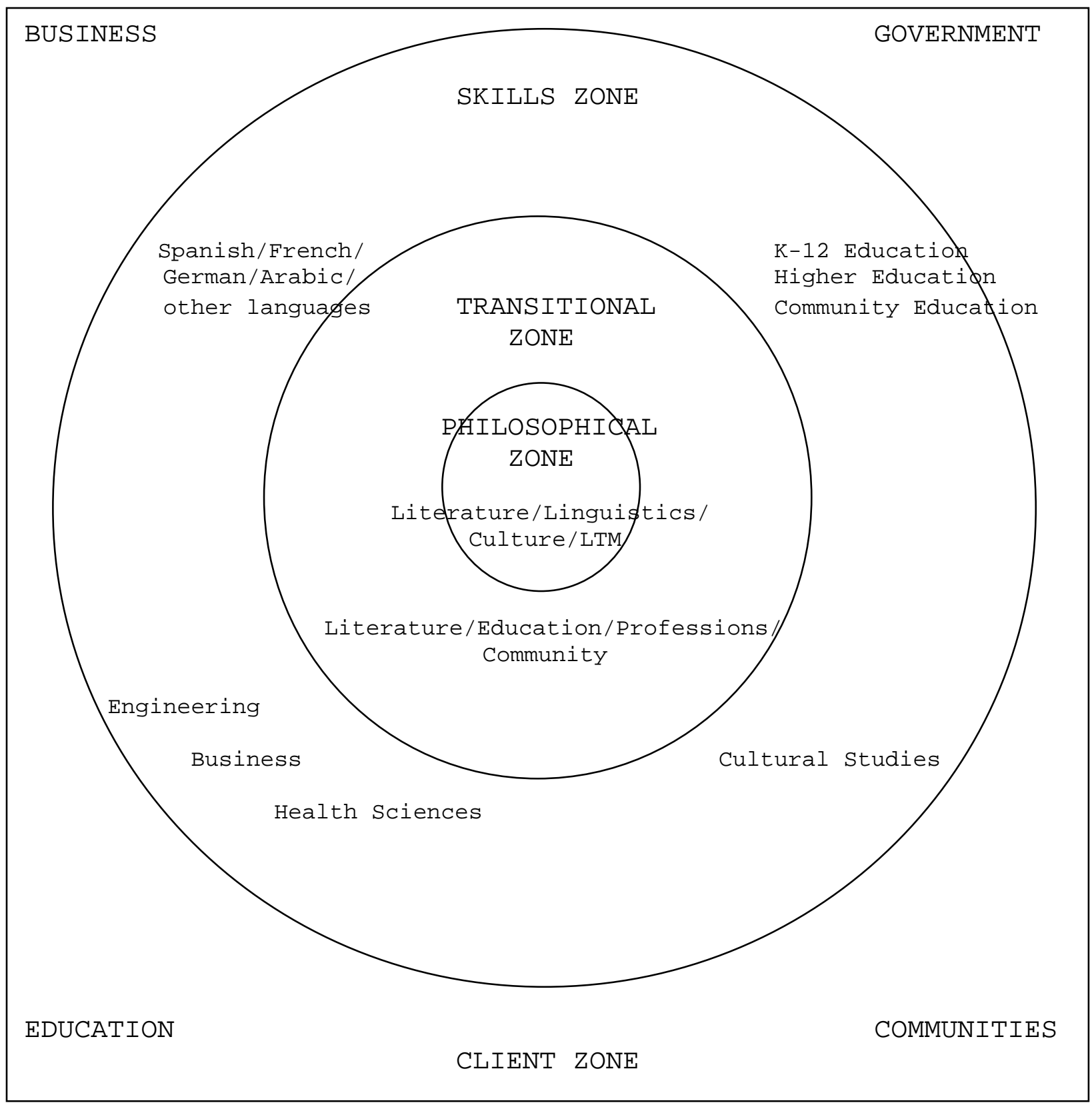


all equally valid, that individuals engage in the difficult task of second language learning can this dialog be productive and birth a foreign language department that reconceptualizes itself, thereby creating and recovering its space within higher education .

\section{Implications for Foreign Language Departments}

The results of this study suggest several implications for the Foreign Language Department at West Virginia. Perhaps first on this list is the re-evaluation and reconceptualization, along the lines suggested by the Incomplete Framework for Reconceptualizing Foreign Language Departments, of the purpose of studying a foreign language. As was noted in the review of literature, many reasons have been given for the promotion of studying a foreign language. From inside the foreign language department, the longstanding belief that underpins language study has been the need to learn a language to read literature in the original. Yet, in contemporary higher education, this role has been challenged by several factors and has ceased to provide a sustainable raison d'être for language study. With this in mind, the implication are clear and amount to no less than the need for a department wide critical self-evaluation of the purpose of studying a language and to the understanding that what it means to know a language is significantly more 
complicated that possessing the ability to read and write in the language.

Further, the rationale for language study currently offered by foreign language departments differs greatly from the rationale for language study given by members of the academic community who inhabit areas outside the Foreign Language Department. From the vantage point of the participants in this study, foreign language learning should instill a sense of cultural awareness in students for whom learning a specific language is neither possible given curriculum requirements nor preferable given expectations of future employment. Although I suggested that participant views of the relationship between language and culture do not accurately represent the complexity of cultural issues, the sincerity of participant requests for comparative culture courses can not be denied. Indeed, participants in this study suggested, rather strongly, that the Foreign Language Department at WVU should work toward the establishment of survey courses that will provide an introduction to several key languages and the social and business cultures associated with countries in which these languages are spoken. According to participants, especially those from the CB\&E and CEMR, this type of course or course sequence would not only provide tremendous benefits for their students, but it would also be popular. By tailoring courses to 
the needs of non-foreign language majors, the foreign language department can expand its course offerings and provide services to other departments that are valued as important additions to their students' education and understanding of their place in the world.

To accomplish the creation of this type of class, a teamteaching strategy, bringing professors from several internal sub-departments together, would be required. Therefore, the conceptualization of this type of class would require clear and strong leadership within the department that would question artificial internal boundaries and the necessity to teach all courses in the target language. While Klayman (1978) suggests that teaching courses in the students' native language goes against many of the principles that language professionals hold dear, it would allow for greater access to the courses by a variety of students and would help craft linkages across academic disciplines, thereby creating a new space for foreign language learning.

Similarly, participants suggested that foreign language faculty are uniquely capable of co-coordinating study abroad programs for students from professional schools and the ECAS. Although these programs might not be literature or language based, students from professional schools would benefit greatly from the experiences of studying and learning abroad and might 
be compelled to enroll in a language course upon their return to the United States. While this type of program coordination might force foreign language faculty to the role of counselor, guide, or informed participant in the study abroad context, the centrality of professional $v$. foreign language programs has been well established. For the most part, foreign language programs exist on the fringes of university hierarchies and must accept and use this situation if they are to continue to be a part of higher education.

Yet, even this fringe existence is being questioned and threatened by efforts to dislodge university-based foreign language programs from the academic hierarchy. As mentioned above, the efforts of David Maxwell to remove the foreign language program from Drake University do not bode well for these programs. While the reasons behind Maxwell's challenge to foreign language education stem from accountability issues tied to the quality of programs and lack of student success, a complementary financial accountability movement also threatens programs that have been lost their centrality to the university. Coplin (2006) suggests that the outsourcing of many of these programs can provide quality academic courses with no cost to the academic community and no decline in the quality of university graduates. These efforts, geared toward two levels of accountability, are not, however, the only threat to the role 
of foreign language programs. As university departments seek alternative experiences for their students, they are increasingly examining study abroad options that satisfy the cultural awareness and globalization objectives of their curricula or accreditation standards. Many of these programs are sponsored and facilitated by university-based offices of International Programs. These offices, sensing the opportunity to invigorate their own programs, are actively seeking close relationships with a variety of university departments with whom they share common interests.

It is perhaps more important and more interesting that the relationship between foreign language departments and international offices have become strained over the past decade. Each program sees the other as their primary on-campus competition for internationalization and study abroad programming. While faculty in foreign language programs question whether study abroad experiences designed or endorsed by international offices are sufficiently rigorous, international offices often question whether foreign language faculty are open to any study abroad options that do not include their own faculty-led programs. Although the relationship between these departments is interesting and laden with unseen undercurrents, the purpose of this study was not to delve into this issue. From this discussion, however, two equally clear 
issues emerge. First, is it evident that offices of international programs have been interested in developing programs with a variety of university departments and have benefited from close working relationships with these academic programs as well as external, for profit, study abroad agencies that provide a myriad of language, culture, and content study abroad opportunities. Secondly, it is equally plain that foreign language programs should plan and promote study abroad options that are compelling to students and which consider the nature of foreign study and the reasons that students wish to travel and study abroad.

If foreign language departments wish to become re-engaged in university-sponsored foreign study, they will have to alter their conception of foreign study by abandoning the notion that study abroad programs should concern language study alone. Additionally, these departments will have to seek funding for exploring study abroad possibilities as well as for granting release time for faculty who coordinate these programs. In an academic environment that has moved toward accountability-based evaluation of performance and centrality, the quest for such funding will no doubt be difficult. Yet, if the foreign language department can form a united front with schools of business and the engineering, as well as other programs, the possibility of being granted funding increases significantly. 
Further, by couching these requests in reference to strategic plans for increasing student awareness of the outside world, the foreign language department and its new allies will increase their options and opportunities for study abroad funding.

Foreign language departments can work closely with international offices to encourage university administrators to allow a "study abroad scholarship fee" to be assessed to each student. Money from this fund would be used solely for student scholarships. As such, no administrative overhead would be allowed to be taken from this fund. This concept is not new in the world of academe. Approximately 10 years ago, the State of Texas allowed universities to unilaterally assess a fee of $\$ 1.00$ per student for each semester of enrollment, including summer terms. The legislative action also allowed universities to raise this fee to $\$ 3.00$ per student if a student-supported referendum passed during regular university-wide elections. Although none of this money is directly assessable by foreign language departments, the potential for increased study abroad participation points to possible long-term benefits for foreign language departments because of their faculty's unique position as the campus' language and cultural experts.

Increasing student fees is never an easy task. However, in this case, the fact that all monies collected from the fee go directly to students eased the passage of the legislation in 
Texas. Additionally, West Virginia University's Strategic Plan mentions the necessity to produce globally aware graduates. Playing on this theme, study abroad programs, supported at least in part by student contributions, enable the university to increase study abroad participation without the accompanying high costs traditionally associated with these programs. In this sense, the scholarship fee presents a win-win situation for the university by increasing students' international exposure with little cost to the university.

Participants in this study were cognizant of the fact that when students from their programs enroll in foreign language classes, their concerns for specific communicative abilities are not addressed. While this might not be surprising in lower level (100-200) courses, the problem also exists at the intermediate level where language is supposed to be taught through diverse content. As Swaffar (2003) noted, there has been a tendency in foreign language departments to offer classes based on instructor interests rather than the needs of students from within and outside the foreign language program. Moreover, all language courses above the first two years of instruction have been traditionally provided by tenure-track or long-term lecturers whose primary interests lie in the content areas they studied and researched in their graduate programs. The combination of these two factors has contributed to the 
provision of courses at the intermediate level of language study that purport to teach language through content but which focus rather narrowly on the content of the course and which ultimately discourage students from other academic areas from engaging in intermediate or advanced foreign language study.

Studies on student attrition rates within foreign language departments suggest that the abrupt change from the study of language for communication to the study of content with little regard for language use is a primary consideration for students who choose to drop out of language study (Graham, 2004). Given the importance of these mid-level classes in providing a platform for language acquisition as well as being a primary means of encouraging language learners to continue their studies, foreign language departments should focus more attention on these courses. The first step in improving these courses is the articulation of a philosophy of language learning that embraces all aspects of language and which acts as a guide in the development of classes. This would ensure that the courses offered students provide for their needs rather than simply attesting to the interests of the faculty who teach these courses. A second step would be to engage outside academic departments in a dialog that leads to the offering of classes that interest students from a variety of disciplines. Finally, foreign language departments should staff these mid-level 
courses with qualified language teachers who are aware of current teaching methodology and who possess the desire to teach language through content.

The findings from this project also lead to another important implication for foreign language study and education in general. It appears that foreign language programs are at an important junction in their history and are at risk of being shuffled to a side-track from whence recovery of place is impossible. The ubiquitous call, from the participants in this study, for cultural understanding courses in place of purely language oriented classes questions whether these faculty desire language or sociology/anthropology courses. Indeed, if the cultural component of language study trumps language itself, it is a rather short jump to the abandonment of language programs in favor of existing academic departments that might seem better suited to the provision of courses that contain the desired cultural content. To combat this possible movement away from language study, foreign language departments should actively seek the establishment of university policy that re-instates the foreign language requirement for all academic programs regardless of the degree being sought. At the same time, however, this project suggests that the content and scope of these required courses should be altered from the current 
understanding of language teaching to one that embraces a variety of rationales for undertaking language study.

A final implication gleaned from the data collected for this study treats the lack of outreach from the Foreign Language Department to other academic areas. Too often, participants noted that they were unaware of programs offered by the Foreign Language Department or that they would be very interested in discussing possible coordinated efforts if faculty in the foreign language department would demonstrate the smallest interest. Although Swaffar (1999) suggests that foreign language departments have traditionally exhibited isolationist tendencies, the challenges that face foreign language programs are unprecedented in nature and require foregoing traditional taken-for-granted attitudes in favor of outreach efforts that can redefine the role of the foreign language program while also preserving its place in higher education. Without a new effort at creating a space within academe, foreign language programs risk not only increased isolation, but also eventually banishment from the university.

A Word of Optimism, Maybe

Although the picture of the place of foreign language education that has been painted in this study is fairly pessimistic, it is important to note that a certain air of 
optimism is also present in these pages. The results of this study suggest that the majority of faculty interviewed believe that foreign language departments have a place within higher education and more specifically at West Virginia University. While this place might be redefined as being on the periphery of the central academic structure, the Foreign Language Department can establish a niche area that will render it vitally important to the university's professional programs while also continuing to engage in the teaching of language skills, language teaching methods, linguistics, and other disciplines that are a part of the foreign language program. Indeed, the foreign language faculty are looked upon as professionals in a field about which few people outside foreign languages are capable of functioning effectively. This storehouse of good will and respect should be used to forge new relationships based not on outdated paradigms but rather on the reality of what foreign language study can bring to the modern multiversity.

Standing against this backdrop of good will and positive feelings toward the importance of language learning and language professors is the reality of the current state of foreign language learning within the university. While participants suggested their eagerness to advise their students into foreign language classes, especially those that provide significant cultural content, few students from outside the Eberly College 
of Arts and Sciences participate in foreign language learning. Indeed, a report generated by West Virginia University's Office of Admissions and Records shows that of all the credit hours produced by students from the College of Business and Economics (CB\&E), only $1.4 \%$ were taken from the university's foreign language offerings (See Table 5.1 for additional information on foreign language enrollment by college). At less than one percent, the rate of foreign language enrollment for students from the College of Engineering and Mineral Resources (CEMR) was even lower and suggestive of systemic problems and concerns. Overall, these low levels of enrollment in foreign language courses confirm the participant's perspectives on the lack of importance for foreign language education as it is currently constructed. Parallel to this idea, the low enrollments also suggest that in spite of professed favorable attitudes toward the possibility of curricular links with foreign language programs, faculty from the CB\&E and the CEMR are unwilling to forcefully recommend foreign language classes to their students. Although there are no doubt many reasons behind the low enrollment trend, including the one mentioned above, it is quite possible that restrictions resulting from accreditation standards have allowed the professional programs to more carefully control student coursework which ultimately results in 
their ability to manage credit hour production and funding for their programs.

Despite the current state of language education nationwide, there can be room for tempered optimism within the halls of foreign language departments. Armed with an understanding of the wishes of other programs, foreign language departments can work toward creating curricula that focus on these needs and which will be attractive to students who might not normally want to engage in language study. While the recovery of space within higher education might be difficult to achieve, I strongly suggest that without an effort in this direction and without a reconceptualization of what it means to teach and learn languages, the fate of the Foreign Language Department will lie in the hands of departmental outsiders who will evaluate the program in terms unfavorable to the continuation of foreign language learning within the university.

Table 5.1. Foreign Language Enrollment Percentages by College.

$\begin{array}{cc}\text { College } & \begin{array}{c}\text { Percentage of } \\ \text { Hours Produc } \\ \text { Foreign Lang }\end{array} \\ \text { ECAS } & 9.7 \% \\ \text { CB\&E } & 1.4 \% \\ \text { CEMR } & 0.096 \%\end{array}$




\section{Suggestions for Further Research}

One of the criticisms of qualitative research is its tendency to produce results that are not considered generalizable (Patton, 2002; Merriam 1990). Although the questions raised within this study are generalizable to other institutions of higher education and the emerging nature of the modern multiversity, the present study is no different in that it is suggestive only of faculty perspectives on foreign language learning at West Virginia University (WVU). More particularly, it presents only the understanding of foreign language education and the perspectives and attitudes toward this question of faculty members from three colleges (Eberly College of Arts and Sciences, College of Business and Economics, and College of Engineering and Mineral Resources) within WVU's academic structure. With this consideration in mind, as well as questions discovered during the course of the research, there are several areas that are suggestive of the need for further research. These include the following:

1. An additional qualitative study of all the academic colleges housed within WVU's academic structure.

2. A quantitative study that uses the suggestions provided by this research project to delve into the attitudes and 
beliefs of the entire WVU faculty population toward the questions addressed within this study.

3. An additional study of other universities (peer, private, and other state-assisted institutions) to determine if the attitudes of professors at WVU are similar to the attitudes found at other institutions of higher education.

4. A study addressing the questions posed within this study to administrators at the level of Dean and above.

5. Additional theoretical work on the Incomplete Framework for Recovering Meaning.

6. An additional study that would allow foreign language faculty to express their thoughts on the content of the current project.

7. An additional study that delves into the philosophy that underpins the inclusion of foreign language programs within higher education. 


\section{REFERENCES}

Aggeler, W. (1950). The Army Language School - An Appraisal. The Modern Language Journal, 34,3, 189-195.

Apple, M. (1986). Teachers and Texts. New York: Routledge.

Apple, M. (1990). Ideology and Curriculum. New York: Routledge.

Apple, M. (1996). Cultural Politics and Education. New York: Teachers College Press.

Armstrong, P., \& Rogers, J. (1997). Basic skills revisited: The effects of foreign language instruction on reading, math and language arts. Learning Languages, 2,3, 20-31.

Ashford, Ellie (2004). NCLB's Unfunded Arts Programs Seek Refuge. Education Digest, 70,2, 22-26.

Bakhtin, M. (1973). Problems of Dostoevsky's Poetics. Ann Arbor: Ardis.

Bagnato, K. (2005). 'Year of Languages' Seeks to Broaden Cultural Horizons. Community College Week, 17,16, 15-15.

Bandura, A. (1969). Principles of behavior modification. NY: Hold, Rinehard, and Winston.

Bandura, A. (1976). Social Learning Theory. Englewood Cliffs, NJ: Prentice Hall.

Bandura, A. (1981). Social Cognitive Theory of Mass Communication. Media Psychology, 3,3, 265-299.

Bandura, A. (1986). Social Foundations of Thought and Action: A Social Cognitive Theory. Englewood Cliffs, $\mathrm{NJ}$ : Prentice-Hall.

Bandura, A. (2001). Social Cognitive Theory of Mass Communication. Media Psychology, 3, 3, 265-299.

Benesch, A. (1941). The case for modern foreign languages. The Modern Language Journal, 25, 273-279. 
Bernhardt, E. (1997). Victim Narratives or Victimizing Narratives? Discussions of the Reinvention of Language Departments and Language Programs. ADFL Bulletin, 29, 1, 13-19.

Bourdieu, P., (1983). The Field of Cultural Production, or: The Economic World Reversed, Poetics, 12, 311-356.

Bourdieu, P., (1984). Distinction: A Social Critique of Judgement of Taste, London: Routledge and Kegan Paul.

Bourdieu, P., (1990). The Logic of Practice. Stanford: Stanford University Press.

Bourdieu, P., (1993). The Field of Cultural Production: Essays on Art and Literature. Cambridge: Polity Press.

Bourdieu, P., (1996). The Rules of Art: Genesis and Structure of the Literary Field. Cambridge: Polity Press.

Bourdieu, P., (1998). Practical Reason: On the Theory of Action, Stanford: Stanford University Press.

Bourdieu, P. (2002). Distinction: A Social Critique of the Judgement of Taste. Cambridge, MA: Harvard University Press.

Bourdieu, P., \& Nice, R. (1977). Outline of a Theory of Practice. Cambridge: Cambridge University Press.

Bourdieu, P., \& Passeron, J. (1977). Reproduction in education, society and culture. London: Sage Publications.

Boyatzis, R. (1998). Transforming Qualitative Information: Thematic analysis and code development. Thousand Oaks, CA: Sage.

Boyers, E. (1990). Scholarship Reconsidered: Priorities of the Professoriate. San Francisco: Jossey-Bass.

Bradley, G. (2005). Bills Challenge Faculty Control over Curriculum. Academe, 91,4, 9-10.

Branchadell, A. (1999). Language policy in Catalonia: Making liberalism 2 come true. Language \& Communication, $19,4,289-304$. 
Brega, E., \& Newell, J. (1967). High-school performance of FLES and non-FLES students. The Modern Language Journal, 51, 408-411.

Britten, N., \& Lincoln, Y. (1994). Handbook of qualitative research. London: Sage.

Brod, R., \& Huber, B. (1996). Foreign Language Enrollments in United States Institutions of Higher Education Fall 1995. ADFL Bulletin, 27,2, 57-84.

Brown, H. (2007). Principles of Language Learning and Teaching, $5^{\text {th }}$ ed. White Plains, NY: Pearson Education.

Byram, M., \& Feng, A. (2005). Teaching and researching intercultural competence. In E. Hinkel (Ed.), Handbook of research in second language teaching and learning ( $\mathrm{pp}$. 911930). Mahwah, NJ: Lawrence Erlbaum Associates.

Cage, M. (1991, June 26). 30 States Cut Higher-Education Budgets by an Average of 3.9\% in Fiscal 1990-91. Chronicle of Higher Education, p.A1-A2.

Canale, M., \& Swain, M. (1980). Theoretical Bases of Communicative Approaches to Second Language Teaching and Testing. Applied Linguistics, 1, 1-47.

Carton, B. (1995). Yale, unwilling to cede faculty control, decides to return $\$ 20$ million gift. Wall street Journal, 225,51, B2-B2.

Chomsky, N. (1957). Syntactic Structures. The Hague: Mouton and Company.

Chomsky, N. (1959). Review of Verbal Behavior by B. F. Skinner. Language, 35, 26-58.

Christian, D. (2005). Fostering Foreign Language Proficiency: what the U. S. Can Learn From Other Countries. Phi Delta Kappan, 87, 3, 226-228.

Clowes, D., \& Levin, B. (1989). Community, Technical, and Junior Colleges: Are They Leaving Higher Education? Journal of Higher Education, 60,3, 349-355.

Cohen, A. (1998). The Shaping of American Higher Education. San Francisco: Jossey-Bass Publishers. 
Coughlin, E. (1992, August 12). Sociologists confront questions about field's vitality and direction. The Chronicle of Higher Education, p.A6-A9.

Coplin, W. (2006, January 27). 7 Ways Colleges Can Cut Costs in Their Classrooms. Chronicle of Higher Education, p. B15B17.

Creswell, J. (2002). Research Design: Quantitative, Qualitative and Mixed Method Approaches. Thousand Oaks, CA: Sage.

Cuff, D. (1987). The Optional Academy. Journal of Architectural Education, 40,2, 13-14.

Cutcliffe, J., \& McKenna, H. (2002). When do we know what we know? Considering the truth of research findings and the craft of the qualitative research. International Journal of Nursing Studies, 39,6, 611-618.

Damrosch, D. (2000, November 17). Mentors and Tormentors in Doctoral Education. Chronicle of Higher Education, p. B24B25.

Davenport, C. (2001). How Frequently Should Accreditation Standards Change? New Directions for Higher Education, $113,67-82$.

Davis, J., Gorell, L., Kline, R., \& Hsieh, G. (1992). Readers and Foreign Languages: A Survey of Undergraduate Attitudes toward the Study of Literature. The Modern Language Journal, 76,3, 320-332.

DeCapua, A., \& Wintergerst, A. (2004). Crossing cultures in the language classroom. Ann Arbor: The University of Michigan Press.

Dewaele, J. (2005). Sociodemographic, Psychgological and Politicocultural Correlates in Flemish Students' Attitudes towards French and English. Journal of Multilingual \& Multicultural Development, 26,2, 118-137.

Dilthey, Wilhelm (1976). Selected Writings, translated by H. P. Richman. Cambridge: Cambridge University Press. 
DiMaggio, Paul (1979). On Pierre Bourdieu. American Journal of Sociology, Vol. 84,6, 1460-1474.

Douglas, P. (1954). Conant's Concept of University Administration. The Journal of Higher Education, 15, 2, $59-64+112-113$.

Dulay, H., \& Burt, M. (1974). Natural sequences in child second language acquisition. Language, 24, 37-53.

Eisner, E. (2002). The Educational Imagination. Columbus, $\mathrm{OH}$ : Merrill Prentice Hall.

Ezzy, D. (2002). Qualitative Analysis: Practice and innovation. Crows Nest, NSW: Allen and Unwin.

Feise, E. (1930). Aims and values of foreign language study. Modern Language Journal, 14, 631-638.

Ferrer, Feran (2000). Languages, Minorities and Education in Spain: the case of Catalonia. Comparative Education, 36, 2, 187-197.

Fontana, F., \& Frey, J. (2000). The interview: From structural questions to negotiated text. In N. K. Denzis \& Y. S. Lincoln (Eds.), Handbook of qualitative research (pp. 645672). Thousand Oaks, CA: Sage.

Foster, D. (1999). Making the Languages Department Indispensable to the University Community. ADFL Bulletin, $30,2,19-21$.

Foster, S. (1986). Reading Pierre Bourdieu. Cultural Anthropology, 1,1, 103-110.

Frank, D., \& Gabler, J. (2006). Restructuring the University: Worldwide Shifts in Academia in the $20^{\text {th }}$ Century: Stanford, CA: Stanford University Press.

Frantz, A. (1996). Seventeen Values of Foreign Language Study. ADFL Bulletin, 28,1, 44-49.

Galloway, V. (1983). Foreign languages in the schools: Through the looking glass. The Modern Language Journal, 67, 432455 . 
Gay-Crosier, R. (1987). Reshaping Foreign Language Programs: Implications for Department Chairs. ADFL Bulletin, 19,1, 3-7.

Germano, W. (2004, June 11). Parlez-Vous Anything? Chronicle of Higher Education, p.B16-B18.

Giroux, H. (2005). Academic Entrepreneurs: The Corporate Takeover of Higher Education. Tikkun, 20,2, 18-28.

Graham, B. (2006, January 6). Foreign-Language Learning Promoted. Washington Post, p. A4.

Graham, S. (2003). Learner's metacognitive beliefs. Research in Education, 70, 9-20.

Graham, S. (2004). Giving up on Modern Foreign Languages? Students' Perceptions of Learning French. The Modern Language Journal, 88,2, 171-191.

Graham, S. (2004). Giving up on Modern Foreign Languages? Students' Perceptions of Learning French. The Modern Language Journal, 88,2, 171-191.

Grenfell, M. (2004). Pierre Bourdieu: Agent Provocateur. NY: Continuum Press.

Grenfell, M. \& James, D. (1998). Bourdieu and Education: Acts of Practical Theory. Lewes: Falmer Press.

Grosse, C., Tuman, W., \& Critz, M. (1998). The Economic Utility of Foreign Language Study. The Modern Language Journal, $82,4,457-472$.

Grubb, W., \& Lazeron, M. (2005). Vocationalism in Higher Education: The Triumph of the Educational Gospel. The Journal of Higher Education, 76,1, 1-25.

Harrison, A., Rainer, R., Hochwarter, W., \& Thompson, K. (1997). Testing the Self-Efficacy-Performance Linkage of SocialCognitive Theory. The Journal of Social Psychology, 137,1, $79-87$.

Heller, S. (1992, January 29). Some professors see politics in Minnesota's plan to close their department. Chronicle of Higher Education, p.A20-A22. 
Hines, M. (2003). Foreign Language Curriculum Concerns in Times of Conflict. The Delta Kappa Gamma Bulletin, 70,1 15-21.

Hoff, P., \& Pinkerton, M. (1999). Reconfiguring Language Departments: Friendly or Hostile Takeover? ADFL Bulletin, $30,2,52-54$.

Hohendahl, P. (1998). The Fate of German Studies after the End of the Cold War. ADFL Bulletin, 29,2, 18-21.

Hollway, W., \& Jefferson, T. (2000). Doing qualitative research differently: Free association narrative and the interview method. London: Sage.

Huguet, Ngel (2004). Bilingual education in Spain: Current situation and future perspectives. Cultura y Educacion, $16,4,399-418$.

Hutchins, R. M., (2005). The Higher Learning in America. New Brunswick: Transaction Publishers.

Hymes, D. (1972). On Communicative Competence. In J. Pride \& J. Holmes (Eds.), Sociolinguistics. Harmondsworth, England: Penguin Books.

Hymes, D. (2000). The emergence of sociolinguistics: A response to Samarin. Journal of Sociolinguistics, 4,2, $312-315$.

Ingersoll, R. (1996). Teachers' Decision-Making Power and School Conflict. Sociology of Education, 69,2, 159-176.

Jacob, E. (1990). Alternative approaches for studying naturally occurring human behavior and thought in special education research. The Journal of Special Education, 24,2, 195-211.

Kerr, Clark (2001). The Uses of the University. Cambridge, MA: Harvard University Press.

King, J. (2001). Approaches to multicultural reform. In J. Banks \& C. A. McGee-Banks (Eds.), Multicultural education: Issues and Perspectives (pp. 225-246). New York: Wiley and Sons.

Kliebard, H. (1995). The Struggle for the American Curriculum. NY: Routledge. 
Klayman, N. (1978). Views of the Foreign Language Requirement in Higher Education. The Modern Language Journal, 62,5/6, 235-238.

Krashen, S. (1982). Principles and Practice in Second Language Acquisition. New York: Pergamon Press.

Lantolf, J., \& Sunderman, G. (2001). The Struggle for a Place in the Sun: Rationalizing Foreign Language Study in the Twentieth Century. The Modern Language Journal, 85, 1, 525.

Lariviere, R. (2002). Language Curriculum in Universities: What and How. The Modern Language Journal, 86, 244-246.

Lash, S. (1992). Structure, Agency, and Practical Knowledge. Contemporary Sociology, 21,2, 155-156.

Liebowitz, R. (2006, March 24). The Foreign-Language Challenge. Chronicle of Higher Education, p.B10-B11, 2p.

Lincoln, Y., \& Guba, E. (1985). Naturalistic Inquiry. Beverly Hills, CA: Sage.

Long, D., \& Long, R. (2001). Toward the Promotion of Foreign Language Study and Global Understanding. Education, 105, 4, pp. 366-368.

Lowery, C., \& Bassinger, J. (2002). Peer Review. Chronicle of Higher Education, 48,43, p. A7-A7.

Lunsford, T. \& Lunsford, F. (1995). The Research Sample, Part I: Sampling. Journal of Prosthetics and Orthotics, 7, 3, $105-112$.

Lyall, K., \& Sell, K. (2006). The True Genius of America at Risk: Are We Losing Our Public Universities to De Facto Privatization? West Port, CT: Praeger Publishers.

Malterud, K. (2001). Qualitative research: Standards, challenges, and guidelines. Lancet, 358,9280, 483-489.

Marks, A. (1999). Really Useful Knowledge: The New Vocationalism in Higher Education and Its Consequences for Mature Students. British Journal of Educational Studies, $47,2,157-169$. 
Martin, J. (2004). Self-Regulated Learning, Social Cognitive Theory, and Agency. Educational Psychologist, 39,2, 135145.

Maxwell, J. (1996). Using qualitative research to develop causal explanations. Harvard University: Harvard Project on Schooling and Children.

Maxwell, D., \& Garrett, N. (2002). Meeting National Needs: The Challenge to Language Learning in Higher Education. Change, 3, p. 23-28.

McCormack, Eugene(2005, March 25). Voting on the President. Chronicle of Higher Education, p. A12-A12.

Merisuou-Storm, T. (2006). Pupils' attitudes toward foreignlanguage learning and the development of literacy skills in bilingual education. Teaching and Teacher Education, 23,2, $226-235$.

Merriam, S. B. (1998). Qualitative research and case study applications in education. San Francisco: Jossey-Bass.

Monaghan, P. (1993, January 6). Beleaguered Classicists Debate Strategies for Survival. Chronicle of Higher Education, p. A8-A10.

Moodley, R. (2007). (Re)placing multiculturalism in psychotherapy and counseling. British Journal of Guidance and Counseling, 35, 1, 1-22.

Newman, J. H. (2003). The Idea of a University. Notre Dame, IN: University of Notre Dame Press.

Nichols, G. (2000). Spanish and the Multilingual Department: ways to Use the Rising Tide, ADFL Bulletin, 31,2, 39-43.

Nisbet, R. (1974). The Sociology of Emile Durkheim. NY: oxford University Press.

Ogden, R. (1921). The future of modern language in the high school. Modern Language Journal, 5, 353-364.

Pajares, F. (2003). Self-Efficacy Beliefs, Motivation, and Achievement in Writing: A Review of the Literature. Reading \& Writing Quarterly, 19,2 139-158. 
Palaigeorgiou, G. E., Siozos, P.D., Konstantakis, N.I., \& Tsoukalas, I.A. (2005). A computer attitude scale for computer science freshmen and its educational implications. Journal of Computer Assisted Learning, 21,5, 330-342.

Patton, M. (1990). Qualitative Evaluation and Research Methods. London: Sage.

Patton, M. (2002). Qualitative Research \& Evaluation Methods. Thousand Oaks, CA: Sage Publications.

Peretz, M. (2006). Summer's End. New Republic, 234,8, 38-38.

Pluviose, D. (2006). Rifts Between Harvard President and Faculty Lead to Resignation. Diverse: Issues in Higher Education, 23, 2, 16-18.

Purin, C. (1920). The importance of foreign language study in the general scheme of American education. The Modern Language Journal, 4, 325-330.

Rhoades, G., \& Slaughter, S. (1997). Academic Capitalism, Managed Professionals, and Supply-Side Higher Education. Social Text, 51, 9-38.

Robinson-Stuart, G., \& Nocon, H. (1996). Second culture acquisition: Ethnography in the foreign language classroom. Modern Language Journal, 80, 431-449.

Rodd, L. (2002). Language Curricula in Universities: The Case of Japanese, a "More Commonly Taught Less Commonly Taught Language." The Modern Language Journal, 86, 249-251.

Rosser, V. (2003). Historical Overview of Faculty Governance in Higher Education. In M. Miller \& J. Caplow (Eds.), Policy and University Faculty Governance. Greenwich, CN: Information Age Publishing.

Rottschaefer, W. (1991). Some Philosophical Implications of Bandura's Social Cognitive Theory of Human Agency. American Psychologist, 46, 2, 153-155.

Rudolph, F. (1977). Curriculum: A History of the American Undergraduate Course of Study Since 1636. San Francisco: Jossey-Bass Publishers. 
Savignon, S. (1972). Communicative Competence: An Experiement in Foreign Language Teaching. Philadelphia: Center for Curriculum Development.

Savignon, S. (1983). Communicative Competence: Theory and Practice. Reading, MA: Addison-Wesley.

Schulz, R. (1999). Foreign Language Instruction and Curriculum. Education Digest, 64, 7, 29.

Schwandt, T. (1997). Qualitative Inquiry. London: Sage.

Schneider, A. (2001, March 9). A University Plans to Promote Languages by Killing Its Languages Department. Chronicle of Higher Education, p.A14-A15.

Shelton, W. (1923). Modern language and citizenship. The Modern Language Journal, 8, 103-109.

Shrum, J. \& Glisan, E. (2005). Teacher's Handbook: Contextualized Language Instruction. Boston: Thomson Heinle.

Simon, P. (1981). The Tongue-Tied American. New York: Continuum Press.

Slaughter, S., \& Rhoades, G. (1996). The Emergence of a Competitiveness Research and Development Policy Coalition and Commercialization of Academic Sciences and Technology. Science, Technology, and Human Values, 21,3, 303-339.

Sleeper, J. (2001, April 13). Harvard's New Leader, Global Capitalism, and the Liberal Arts. Chronicle of Higher Education, p. B20-B21.

Stavans, I. (2005, August 29). The Challenges Facing Spanish Departments. Chronicle of Higher Education, p. B6-B7.

Stimpson, C. (2004, June 18). Reclaiming the Mission of Graduate Education. Chronicle of Higher Education, p.B6B9.

Straus, A., \& Corbin, J. (1998). Basics of Qualitative Research: Techniques and procedures for developing grounded theory. London: Sage. 
Swaffar, J. (1999). The Case for Foreign Languages as a Discipline. ADFL Bulletin, 30,3, 6-12.

Swaffar, J. (2003). Foreign Languages: A Discipline in Crisis. ADFL Bulletin, 35, 1, 20-24.

Terrell, T. (1977). A Natural Approach to Second Language Acquisition and Learning. Modern Language Journal, 61, $325-337$.

Thelin, J. (2004). A History of American Higher Education. Baltimore: The Johns Hopkins University Press.

Thoits, P. (1995). Social Psychology: The Interplay between Sociology and Psychology. Social Forces, 73,4, 1231-1243.

Tse, L. (2000). Student Perceptions of Foreign Language Study: A Qualitative Analysis of Foreign Language Autobiographies. The Modern Language Journal, 84,1, 69-84.

Unks, G. (1983). The Perils of a Single-Language Policy. Educational Leadership, 41,1, 18-22.

Vogel, T. (2001). Internationalization, Interculturality, and the Role of Foreign Languages in Higher Education. Higher Education in Europe, 26, 3, 381-389.

Wann, H. (1941). Youth problems and the study of modern foreign languages. The Modern Language Journal, 20, 333-340.

Welles, E. (2002). Foreign Language Enrollment Numbers: Some (Mis)interpretations Explained. Modern Language Journal, $86,2,253-255$.

Welles, E. (2004). Foreign Language Enrollments in United States Institutions of Higher Education Fall 2002. ADFL Bulletin, 35,2-3, 7-26.

Wergin, J. (2005). Higher Education: Waking Up to the Importance of Accreditation. Change (May/June), 35-41.

Werner, H. (2006). Foreign language teaching: a modern building on historical foundations. International Journal of Applied Linguistics, 16,1, 2-15.

White, W. (2006). Dinosaurs in Our Midst. Unpublished Manuscript, West Virginia University. 
Wiggins, G. (1998). Educative Assessment. San Francisco: Jossey-Bass .

Willis, E. (2005, September 9). The Pernicious Concept of 'Balance'. Chronicle of Higher Education, p. B11-B11.

Williams, D. (2000). Anatomy of the Academy: Dissecting the Past, Resecting the Future. Journal of Leisure Research, $32,1,180-185$.

Wilson, R., Fain, P., Fogg, P., \& Selingo, J. (2006, March 3). The Power of Professors. Chronicle of Higher Education, A10-A13.

Wolfson, N. (1983). An empirically based analysis of complimenting in American English. In N. Wolfson \& E. Judd (Eds.), Sociolinguistics and language acquisition (pp. 8295). Rowley, MA: Newbury House.

Wolfson, N. (1984). "Pretty is as pretty does": A speech act view of sex roles. Applied Linguistics, 5,3, 236-244.

Wolfson, N. \& Manes, J. (1980). The compliment as a social strategy. Paper in Linguistics, 13,3, 391-410.

Wood, R., \& Bandura, A. (1989). Social Cognitive Theory of Organizational Management. Academy of Management Review, $14,3,361-384$.

Wright, D. (2000). Culture as information and culture as affective process: A comparative study. Foreign Language Annals, 33, 330-341.

Zehev, T. (2006). The Triad Research University or a Post $20^{\text {th }}$ Century Research University Model. Higher Education Policy, 19,3, 287-298.

Zionts, L., Shellady, S., \& Zionts, P. (2006). Teachers' Perceptions of Professional Standards: Their Importance and Ease of Implementation. Preventing School Failure, $50,3,5-12$. 


\section{Appendix A}

Interview Protocol 
Interview Protocol - Script for Study

Good morning, good afternoon, good evening, thank you for participating in this research study. The purpose of the study is to explore faculty perspectives on foreign language study at universities, particularly at WVU. This study is being conducted in connection with my dissertation and doctoral degree in education. I would like to audiotape this interview in order to accurately represent what you say; may I have your permission to tape this interview? Before we begin I want to make sure you understand the following:

- Your responses will be kept anonymous or confidential; at no time will your name be revealed during reporting.

- Your name will not be attached to either the tape or notes from this interview, or to transcribed data.

- Your participation is entirely voluntary, you can choose to stop the interview at any time and you do not have to answer every question.

- Your class standing, grades, or job status will not be affected by your refusal to participate or to withdraw from the study.

Thank you again for your willingness to participate in this study.

The first of questions deals primarily with your background and experiences.

1. Could you please describe your current academic position at West Virginia University?

2. How long have you been employed here?

3. What is your educational background?

4. As a part of your program of studies for your undergraduate or graduate degree did you take a foreign language class? Did you enjoy the class? Why or why not? 
Let's move on to foreign language education and your thoughts on its role in higher learning.

5. I want to explore your ideas on why foreign language education is a traditional part of higher education? So, in your estimation, what is the purpose of foreign language learning?

6. What skills can learning a foreign language impart to students?

7. With your answer the previous question in mind, what skills does the WVU foreign language program teach their students?

As for the administration, we know that their views often differ slightly from faculty. So the next questions address your ideas on how the administration might view foreign language learning. Of course, you might consider your answer purely speculative, but with your experience here, I am sure that your thoughts are underpinned by more than just speculation.

8. Foreign language departments and classes have been a traditional part of higher education. Today, as foreign language enrollment declines, these programs are under pressure to downsize or in drastic cases to be removed from the university. In your mind, what role, if any, do foreign language programs play in the university curriculum?

9. University administrators often set agendas for the future of their universities. In your mind, how important is foreign language to university administrators and to the future of the university?

Moving on, I would like for use to discuss how foreign language programs can meet the needs of the university by connecting with other programs and academic areas.

10. What are some potential curricular links between the foreign language department and your program/department/college?

11. What role does foreign language education have in the education of students from your academic college? 
12. We talked about general skills that foreign language learning imparts to students. Now, let's discuss students from your academic area? What are some specific skills that foreign language learning might provide to students enrolled in your program?

Finally, accreditation is a word that many people don't like to hear. But, it is a reality at universities. Let's talk briefly about the influence that accreditation has on the curriculum in your area.

13. Can you speak to how accreditation standards have changed over the past 10 or 15 years? What impact has this had on the curriculum in your program?

14. What role do professional or general accrediting agencies have in determining the curriculum in your program?

15. Finally, I would like to thank you for your responses and ask whether there is anything that you would like to add or to clarify before we end the interview. 


\section{Appendix B}

Documents Reviewed 


\section{West Virginia University Statistical Profiles}

West Virginia University Statistical Profiles $1998-1999,29^{\text {th }}$ Edition. Morgantown, WV: West Virginia University Press.

West Virginia University Statistical Profiles $1995-1996,26^{\text {th }}$ Edition. Morgantown, WV: West Virginia University Press.

West Virginia University Statistical Profiles 1989-1990, 20 ${ }^{\text {th }}$ Edition. Morgantown, WV: West Virginia University Press.

West Virginia University Statistical Profiles $1985-86,16^{\text {th }}$ Edition. Morgantown, WV: West Virginia University Press.

West Virginia University Statistical Profiles $1980-1981,11^{\text {th }}$ Edition. Morgantown, WV: West Virginia University Press.

West Virginia University Statistical Profiles $1974-1975,5^{\text {th }}$ Edition. Morgantown, WV: West Virginia University Press.

West Virginia University Statistical Profiles 1970-1971.

Morgantown, WV: West Virginia University Press.

\section{Annual Reports of the College of Arts and Sciences}

Annual Report, 1981-1982: College of Arts and Sciences, West Virginia University. Morgantown, WV: West Virginia University Press.

Annual Report, 1977-1978: College of Arts and Sciences, west Virginia University. Morgantown, WV: West Virginia University Press.

Annual Report, 1976-1977: College of Arts and Sciences, west Virginia University. Morgantown, WV: West Virginia University Press. 


\section{West Virginia University Undergraduate Catalogs}

1999-2001 West Virginia University Undergraduate Catalog. Morgantown, WV: West Virginia University Press.

1995-1997 West Virginia University Undergraduate Catalog. Morgantown, WV: West Virginia University Press.

1985-1986 West Virginia University Undergraduate Catalog. Morgantown, WV: West Virginia University Press.

1980-1981 West Virginia University Undergraduate Catalog. Morgantown, WV: West Virginia University Press.

1970-1971 West Virginia University Undergraduate Catalog. Morgantown, WV: West Virginia University Press.

1960-1961 West Virginia University Undergraduate Catalog. Morgantown, WV: West Virginia University Press. 


\section{Appendix C}

Curriculum Vitae, William L. White 


\author{
William L. White \\ 3466-3 University Avenue - Morgantown, WV 26505 \\ 304-290-0336 (H) 304-293-5121, ext. 5529 (0) \\ e-mail: bill.white@mail.wvu.edu
}

\title{
EDUCATION
}

West Virginia University Doctor of Education (Ed.D) - Curriculum and Instruction

May, 2007

Dissertation: Faculty Perspectives on the Role of Foreign Language Education at WVU

Coursework in Foundations and Theory

C\&I689 Cultural Diversity in the Classroom

C\&I701 Curriculum Development

C\&I707 Theories, Models, and Research of Teaching

C\&I708 Contemporary Determinants of Curriculum

C\&I709 Curriculum Theories

C\&I791B Curriculum Evaluation

EDP700 Psychological Foundations of Learning

SCFD640 History of Education

The philosophy, theory, and foundations of education were inherent components in all of these courses and provided a historical and contemporary understanding of the state of education in the United States.

Coursework in Teaching Strategies

C\&I687 Advanced Teaching Strategies

LANG392 Seminar in ESL Methods

LANG421 Language Teaching Methods

LANG621 Teaching Foreign Languages - College

EDP740 Principles of Instruction

Coursework in Research

EDP612 Introduction to Research

EDP613 Statistical Methods 1

EDP614 Statistical Methods 2

EDP710 Seminar in Educational Research

SCFD615 Qualitative Research Methods

West Virginia University Morgantown, WV Master of Arts - Foreign Languages (TESOL and French)

May, 1992

French and Teaching English as a Second Language

Thesis: Cross Cultural Differences in the Speech Act of objecting

University of Virginia

Charlottesville, VA

Bachelor of Arts - History

January, 1985 
L'Université d'Avignon

One Year Educational Program

Avignon, France

September, 1990 - June, 1991

\section{EXPERIENCE}

\section{West Virginia University}

Interim Coordinator, Basic French Language Program

August, 2006 - Present

Coordinate all aspects of the Basic French Language Program, including providing orientation and language teaching methods short course for new Graduate Teaching Assistants (GTA), scheduling courses, providing continuing teaching training through weekly meetings with GTAs, conducting classroom observations, and assuring assessment quality.

Graduate Teaching Assistant, Foreign Language Department August, 2004 - Present

Graduate Courses Taught

LANG69๑ French Teaching Practicum

Undergraduate Language Methods/Acquisition Taught

LANG 322 Second Language Acquisition

LANG 421 Language Teaching Methods for K-12 Teachers

Undergraduate French Course Taught

FRCH 102 Second Semester, Elementary French Language

FRCH 203 First Semester, Intermediate French Language

FRCH 204 Second Semester, Intermediate French Language

Online Courses Taught

FRCH 293 Virtual Vendée (web-based French Language and Culture Course)

\section{Midwestern State University}

Director, Intensive English Language Institute

September, 1994 - August, 2004

Directed all aspects of the Institute, including maintenance of the budget, overseeing curricular matters, hiring instructors, recruiting students, and scheduling classes. 
Midwestern State University

Director, International Programs

June, 1996 - August, 2001

Directed all aspects of the university's international initiatives, including acting as the institution's DSO and RSO, providing orientation programming for new and continuing students, reviewing student service requirement such as insurance policies, and conceptualizing and implementing exchange programs for students and faculty.

\section{Bellevue High School}

Teacher, French Language

August 1998 - June 1999

Taught advanced French to high school students. Participated in administrative functions and extracurricular activities associated with the French program.

\section{OTHER INFORMATION}

\section{Awards:}

Dissertation Research Grant. College of Human Resources and Education, West Virginia University (2007)

Second Annual McBride Award for Study in France. Foreign Language Department, West Virginia University (1990 - 1991)

\section{Scholarship:}

\section{Publications and Papers Submitted}

White, W. \& Turner, D. (1997). Developing a full-time job description in a growing IEP. TESOL Matters, 7, 1, p. 16.

White, w. (in press). Self-Alienation: The language of discontent. Curriculum and Teaching Dialogue.

White, W. (2006). Dinosaurs in our Midst: The uncertain future of foreign language education. Manuscript submitted for publication.

White, W. (2007). Reconceputalizing the Foreign Language Department: A dialogical approach to change. Manuscript submitted for publication.

White, W. (2007). Integral Curriculum Theory and Practice. Manuscript submitted for publication. 


\section{Presentations}

White, W. (2006, October). Recovering conversations about curriculum. Paper presented at the annual meeting of the American Association of Teaching and Curriculum, Charlotte, NC.

White, W. (2006, october). Reclaiming the In-Between in the Theory-Practice Divide. Paper presented at the annual meeting of the American Association of Teaching and Curriculum, Charlotte, NC.

White, W. (2001, November). Beyond Language Instruction in the ESL Classroom. Paper presented at the annual meeting of TexTESOL, Austin, TX.

White, W. (1999, November). Facilitating the Internationalization of the College Campus. Paper presented at the Fall meeting of the Texas International Education Consortium Operating Council, Austin, TX.

White, W. (1999, June). The College Experience. Paper presented at the annual Orientation Meeting for NCN Japan, Wichita Falls, TX.

White, W. (1997, November). Materials Design: The Lifeblood of the ESL Instruction. Paper presented at the annual meeting of TeXTESOL, Austin, TX.

White, W. (1996). Recycling the News: Creative Activities that Spark Student Interest. Paper presented at the annual meeting of TexTESOL, Dallas, TX.

White, W. (1996, March). Travel Brochures: Facilitators of Group Interaction and Much More. Paper presented at the annual meeting of TESOL International, Chicago, IL.

White, W. (1996, March). Teaching in the Monolingual Classroom. Paper presented at the annual meeting of TESOL International, Chicago, IL.

White, W. (1992, October). Group Work: Adding Another Dimension to the Second Language Classroom. Paper presented at the annual meeting of New River Foreign Language Association. Bluefield, WV.

\section{Presentations Submitted}

White, W. (2007). Recreating the Foreign Language Department. Presentation proposal submitted to annual meeting of the American Association of Teaching and Curriculum, Cleveland, $\mathrm{OH}$.

White, W. (2007). Behind the Curriculum Mask. Presentation proposal submitted to annual meeting of the American Association of Teaching and Curriculum, Cleveland, $\mathrm{OH}$.

White, W. (2007)Dinosaurs in our Midst: Challenges to foreign language education. Presentation proposal submitted to annual meeting of the American Association of Teaching and Curriculum, Cleveland, $\mathrm{OH}$.

White, W. (2007). Whose Curriculum is it Anyway?. Presentation proposal submitted to annual meeting of the American Association of Teaching and Curriculum, Cleveland, $\mathrm{OH}$. 


\section{Languages:}

English, Native Speaker

French, Near Native

Italian, Novice

Professional Development Programs:

NAFSA's Marketing and Recruiting Seminar

San Francisco, CA

December, 1999

NAFSA's Study Abroad Professional Development Program

Arlington, TX

March, 1998

NAFSA's Intensive English Program Professional Development Program Richlands, TX

April, 1998 


\title{
Appendix D
}

\author{
Lens Paper of William L. White
}


First and foremost, I believe that we are all products of our upbringings. Whether we ultimately decide to modify the views imprinted on us by our caregivers or whether we accept them wholesale and reproduce them in our own world is, obviously, another question. As we grow from childhood into adulthood, we are all subjected to situations in which our personal histories and the world around us interact. On many occasions, the result of these interactions is questioning. We may question ourselves and our worldview. We may question why the world has to be the way it is. We may question the values and ideologies instilled in us by our caregivers and society. Through this questioning, we may ultimately decide that our core values need no significant adjustments. Or, we might decide that our core values need extensive restructuring.

Growing up in a very conservative, Baptist home in southern West Virginia, my parents taught me and my two older sisters that the United States of America is a great country. In fact, it is by far the greatest country on earth. And, the reason for this greatness was the fact that we are a God-fearing, Christian nation. In addition, we learned respect for those who are better (read "richer") than us, for they are the ones who were able to fulfill the American dream. They were the ones who, through hard work, dedication, and sacrifice, made this country the great nation that it is. 
The question remains, however, how to turn this paper from a narrative into an examination of myself and the values, beliefs, attitudes, and yes, biases that I bring to my research. The above mentioned excerpts of my life should help begin that process. I was taught to be afraid of the other and to objectify women. Perhaps from this fear and objectification came the desire to learn more about those individuals who were supposedly different, supposedly inferior. In fact, unconsciously, I might have questioned why my mother, the person that I respected most in the world and who was the most perfect person, to me, could be so alienated within the world she inhabited. This was true, in fact, whether she was in church, where she could vote but not speak, and in the house, where she earned money, took care of the house, but seemed to have few freedoms .

In so many ways I became, in my youth, the ultimate backseat Baptist. We sat in the back row of the church not so much to get out quickly, but because I was taught to believe that good church people don't show off. There is no reason to flaunt one's clothes, one's looks, or one's family in front of the others. The back row, inconspicuous and safe from the glaring and jealous eyes of the others was indeed the place to be. Because of this, and so many other instances from my youth in which I was "put in the rightful place of a child," I grew to 
detest individuals who occupied positions of authority. This was especially true when I considered these individuals to be inferior to me. I feel strongly that these early experiences caused me to embrace Libertarianism and its insistence upon individual action and self-reliance.

I attempted to live my life in a way that made me proud of and happy with my actions. I tried, and often failed, to treat people with respect based on their own life stories and individuality. That is why, perhaps, I was so disappointed when I entered graduate school at West Virginia University in 1989. I found that here, in what I assumed would be a bastion of openness and respect, the letters following one's name counted for more than what was inside one's mind and soul. I developed a deep dislike for faculty who were "professionally right" and cared more for the continuance of their power within the academic structure than for the individuals that they were teaching and mentoring. To me, this violated the spirit of education. From my perspective, however, the professors who engaged most readily in this behavior were those who taught foreign language literature. Those who were engaged in teaching applied subjects, such as Applied Linguistics and Teaching English as a Second Language (TESOL) were more often open to input from students and tended to create a community of learners in which all were equal yet different. 
After graduation, I became more and more convinced that the same professors that I had come to dislike during my days as a graduate student were in the process of ruining foreign language education. By privileging literature over language and by attempting to monopolize all conversation concerning the role and purpose of languages within the university academic context, these people were creating a situation in which language learning could be questioned and indeed removed from the basic educational core that underpins the American educational system. What they perceive as their privileged positions as literature and literary theory professors allow them to make pronouncements on all things "language" at the university and drive the conversation in ways that privilege their understanding of the role and purpose of language education.

My personal view of language is one that favors the acquisition of a second tongue for a myriad of purposes, each equally important and viable in society. These purposes include reading great works of literature. But, this is only one of the reasons why languages are important. And, it angers me to know that at least in colleges and universities, language education has been high-jacked by pompous professors who claim authority where none exists. I know that I want to study what professors view as the role of foreign language education within the context of the university for good reasons. I want to establish 
bridges on which dialog can be initiated. I want to find ways to reinvigorate language teaching at the university. I want to be a catalyst for change.

Yet, at the same time, I am afraid that my own personal biases against those who I feel have become "professionally right" will color the picture that I wish to paint. In some very meaningful ways, I feel that I have become the enemy. I am confident in my beliefs and therefore am not able, or at least willing, to compromise. I am right and they are wrong. In this way, I am no longer sitting in the back row of the church. I parade to the front and challenge those with who I am in disagreement, seeking conflict rather than accord. 


\title{
Appendix E
}

\author{
Exempt Application
}




\begin{tabular}{|c|c|c|c|c|c|c|}
\hline \multirow{2}{*}{\multicolumn{2}{|c|}{ Form Revised September 2006}} & & \multicolumn{4}{|c|}{ DO NOT WRITE IN THIS SPACE } \\
\hline & & & \multicolumn{4}{|c|}{ Protocol Number: } \\
\hline \multicolumn{7}{|c|}{ APPLICATION FOR EXEMPTION } \\
\hline \multicolumn{7}{|c|}{$\begin{array}{l}\text { Acknowledgement from the Office of Research Compliance or the school or college granting exemption must be received prior to beginning th } \\
\text { research described below. Please type all responses and submit this form with original signatures. All investigators must complete Human } \\
\text { Participant Protections (Ethics) Training before an acknowledgement will be granted. }\end{array}$} \\
\hline \multicolumn{7}{|c|}{\begin{tabular}{l|l} 
Title of Study: $\quad$ Faculty Attitudes Toward Foreign Language Education \\
\end{tabular}} \\
\hline \multirow{2}{*}{\multicolumn{2}{|c|}{ Reason for conducting research: }} & Professional & $\mathrm{X}$ & Dissertation & Thesis & Class Assignment \\
\hline & & Other (pleas & specify): & & & \\
\hline \multicolumn{3}{|c|}{ Faculty Advisor (name, PO Box, Phone, \& E-Mail): } & \multicolumn{4}{|c|}{$\begin{array}{l}\text { Dr. Patricia Obenauf, Allen Hall, WVU, Morgantown, WV 26506, } \\
\text { pobenauf@wvu.edu }\end{array}$} \\
\hline
\end{tabular}

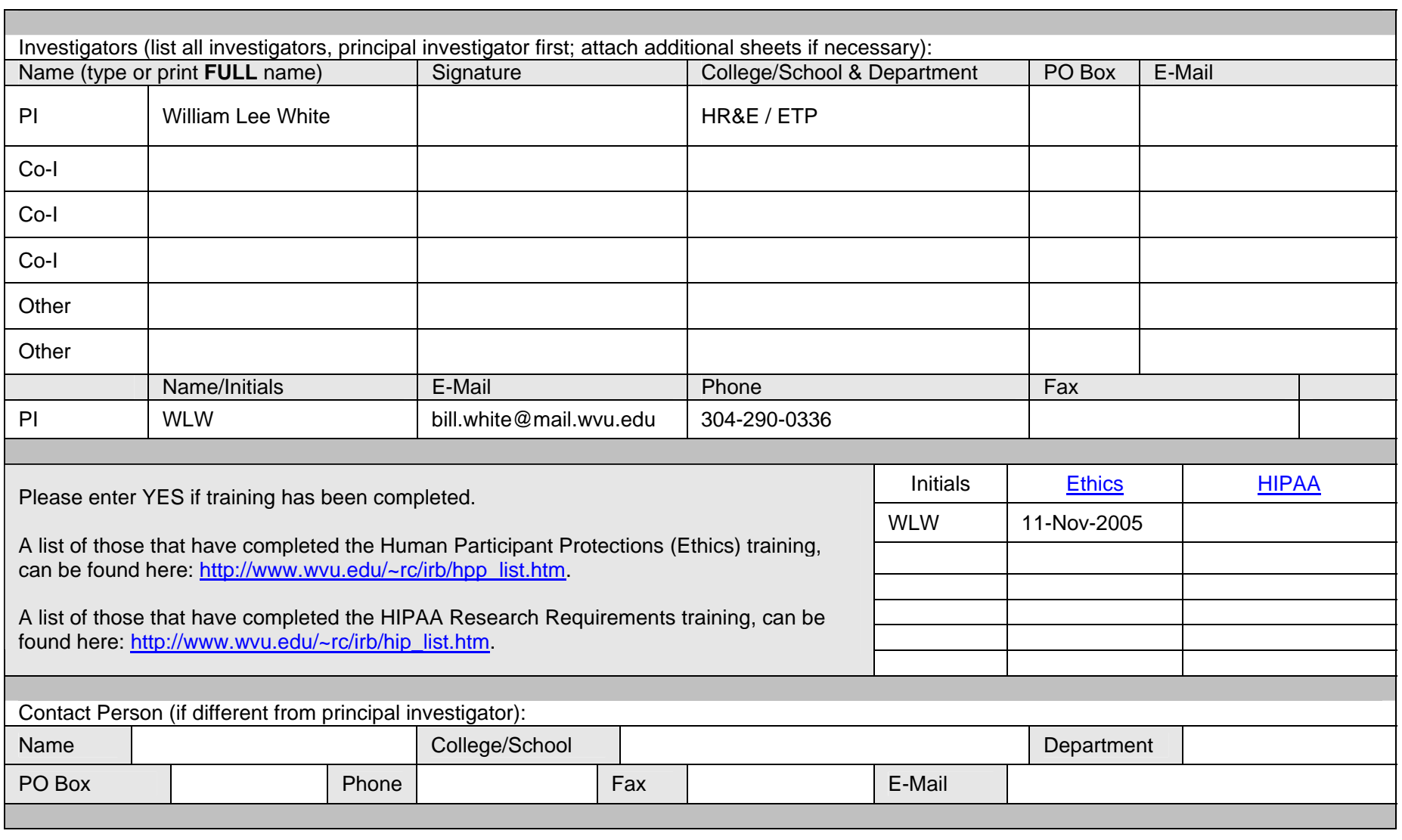

Proposed start/end date of project or human subject involvement:

Source of funding (if applicable):

Number of projected subjects:

NA
Start

Date:
Jan. 1, 2007

End Date: $\quad$ Dec. 31, 2007

Review the "Determination that a Proposed Activity is not Human Research According to DHHS or FDA Regulatory

Definition". If it is human subject research and if it corresponds to one of the categories for exempt research, according to Chapter II of the guidelines, indicate the category or categories that make this research eligible for an exemption determination:

Category (mandatory): 
In addition to fulfilling the requirements of being research and appropriate to one or more of the specified categories, the research must also: (please check, if appropriate and add adequate information for the reviewer)

$X$

$\mathrm{X}$ Adequately describe procedures and the purpose of the study. Individual interviews to explore the perspectives of 15 professors concerning the role of foreign language education at WVU. The research must present no more than minimal risk to participants.

Describe why you feel this study represents no more than minimal risk:

The study consists of interviews which participants can halt at any time. Additionally, prior to beginning the interviews, participants will be read a statement informing them that they may choose not to answer any questions that they are not comfortable answering or which they do not wish to answer.

X Describe in detail how participants will be chosen. Provide evidence that the selection of participants is equitable. Describe how participants are chosen to assure that the process is equitable:

Participants will be volunteers who possess tenure and a minimum of ten years of experience at WVU. Participants will be sought from WVU's Eberly College of Arts and Sciences, College of Business and Economics, and College of Engineering Sciences and Mineral Resources.

X Provide information in sufficient detail to establish that participants will not be subject to coercion or undue influence (if the possibility for coercion or undue influence exists.)

There are no known possibilities for coercion or undue influence in this study.

X Provide sufficient detail about how anonymity will be assured, if this is relevant Participant names will not be attached to data files and will not be revealed during the reporting phase of the study.

NA For medical records or chart reviews, describe the nature of the data to be recorded and assure that either no private identifying data are recorded, or provisions for maintaining the confidentiality of data are adequate and explained in sufficient detail. If a HIPAA waiver of authorization is required to obtain Protected Health Information (PHI), its use must be justified (Why cannot the research be practicably carried out without obtaining the PHI, and why cannot the PHI be practicably obtained without a waiver of authorization?). The request for a waiver of HIPAA authorization must be approved by the IRB prior to initiating the research.

NA Provide a complete list of variables to be collected from records or data set (variables list)

NA Provide justification for requesting a HIPAA waiver

$\mathrm{X}$

Discuss how data will be secured and how it will be disposed of at the end of the study, if not already discussed.

Data will be stored in a secure location in the researcher's home office and will be kept for a minimum of two years. After this time, all documents, including interview transcripts, digital files, and disk copies will be destroyed.

$\mathrm{X} \quad$ The research does not involve prisoners as participants

X The research does not involve interventions or interactions with participants. If the investigator will interact or intervene with participants it cannot be exempt. Intervention includes both physical procedures by which data are gathered (for example, venipuncture) and manipulation of the subject or the subject's environment that are performed for research purposes. Interaction includes communication or interpersonal contact between investigator and subject.

X Be sure to include copies of all advertisements, surveys, scripts, cover letters, and letters of permission

A cover letter addressed to respondents must accompany any survey or questionnaire. The Cover letter must be on the investigator's WVU departmental letterhead and must include the following:

1. a statement that the project is research and that it is being conducted in partial fulfillment of the requirements for a course, master's thesis, dissertation, etc.

2. purpose of study (what do you want to show)

3. a statement that subjects responses will be kept anonymous or confidential (explain extent of confidentiality if subjects' names are requested)

4. if audio taping, a statement that the subject is being audio taped (explain how tapes will be stored or disposed of during and after the study

5. a statement that subjects do not have to answer every question

6. a statement that the subject's class standing, grades, or job status (or status on an athletic team, if applicable) will not be affected by refusal to participate or by withdrawal from the study

7. a statement that participation is voluntary

8. if survey contains items that may be considered sensitive, provide phone numbers and a location where participant can obtain counseling. 
Faculty Perceptions - FLE 227

I request that this project be acknowledged as exempt from DHHS regulations, 45 CFR 46.

Investigator Signature

Date

Signatures: The protocol will not be reviewed without the signature of the departmental chair. For other protocols, the signature for hospital administration, faculty advisor, or others is required. By signing, department chairs acknowledge approval of this study on the basis of scientific merit and compliance with applicable professional standards. Other administrators signify their approval of the use of resources and faculty and student effort on the study. Multi-Unit protocols require the signatures of each chair and dean.

Dean Signature

Department Chair

Department Chair

Faculty Advisor

\begin{tabular}{c}
\hline Date \\
\hline Date \\
\hline Date \\
\hline Date
\end{tabular}

Date 


\section{Attachment One}

\section{Documents/Records Reviewed}

\section{West Virginia University Statistical Profiles}

West Virginia University Statistical Profiles 1998-1999, $29^{\text {th }}$ Edition. Morgantown, WV: West Virginia University Press.

West Virginia University Statistical Profiles 1995-1996, 26 ${ }^{\text {th }}$ Edition. Morgantown, WV: West Virginia University Press.

West Virginia University Statistical Profiles 1989-1990, 20 ${ }^{\text {th }}$ Edition. Morgantown, WV: West Virginia University Press.

West Virginia University Statistical Profiles $1985-86,16^{\text {th }}$ Edition. Morgantown, WV: West Virginia University Press.

West Virginia University Statistical Profiles 1980-1981, $11^{\text {th }}$ Edition. Morgantown, WV: West Virginia University Press.

West Virginia University Statistical Profiles 1974-1975, $5^{\text {th }}$ Edition. Morgantown, WV: West Virginia University Press.

West Virginia University Statistical Profiles 1970-1971. Morgantown, WV: West Virginia University Press.

\section{Annual Reports of the College of Arts and Sciences}

Annual Report, 1981-1982: College of Arts and Sciences, West Virginia University. Morgantown, WV: West Virginia University Press.

Annual Report, 1977-1978: College of Arts and Sciences, West Virginia University. Morgantown, WV: West Virginia University Press.

Annual Report, 1976-1977: College of Arts and Sciences, West Virginia University. Morgantown, WV: West Virginia University Press.

\section{West Virginia University Undergraduate Catalogs}

1999-2001 West Virginia University Undergraduate Catalog. Morgantown, WV: West Virginia University Press.

1995-1997 West Virginia University Undergraduate Catalog. Morgantown, WV: West Virginia University Press.

1985-1986 West Virginia University Undergraduate Catalog. Morgantown, WV: West Virginia University Press.

1980-1981 West Virginia University Undergraduate Catalog. Morgantown, WV: West Virginia University Press. 
1970-1971 West Virginia University Undergraduate Catalog. Morgantown, WV: West Virginia University Press.

1960-1961 West Virginia University Undergraduate Catalog. Morgantown, WV: West Virginia University Press.

\section{Variables Collected}

Credit hour production for academic areas housed within West Virginia University's Eberly College of Arts and Sciences, College of Business and Economics, and College of Engineering and Mineral Resources.

Number of faculty members in each of the colleges listed above.

Number of students in each of the colleges listed above for specific academic years.

Number of instructional staff at West Virginia University divided into tenure-track, lecturers, and adjunct faculty lines.

Academic requirements for graduation from each of the college.s listed above.

Example Plans of Study for majors within each of the colleges listed above 


\section{Attachment Two}

Interview Protocol - Script for Study

Good morning, good afternoon, good evening, thank you for participating in this research study. The purpose of the study is to explore faculty perspectives on foreign language study at universities, particularly at WVU. This study is being conducted in connection with my dissertation and doctoral degree in education. I would like to audiotape this interview in order to accurately represent what you say; may I have your permission to tape this interview? Before we begin I want to make sure you understand the following:

- Your responses will be kept anonymous or confidential; at no time will your name be revealed during reporting.

- Your name will not be attached to either the tape or notes from this interview, or to transcribed data.

- Your participation is entirely voluntary, you can choose to stop the interview at any time and you do not have to answer every question.

- Your class standing, grades, or job status will not be affected by your refusal to participate or to withdraw from the study.

Thank you again for your willingness to participate in this study.

The first of questions deals primarily with your background and experiences.

1. Could you please describe your current academic position at West Virginia University?

2. How long have you been employed here?

3. What is your educational background?

4. As a part of your program of studies for your undergraduate or graduate degree did you take a foreign language class? Did you enjoy the class? Why or why not? 
Let's move on to foreign language education and your thoughts on its role in higher learning.

5. I want to explore your ideas on why foreign language education is a traditional part of higher education? So, in your estimation, what is the purpose of foreign language learning?

6. What skills can learning a foreign language impart to students?

7. With your answer the previous question in mind, what skills does the WVU foreign language program teach their students?

As for the administration, we know that their views often differ slightly from faculty. So the next questions address your ideas on how the administration might view foreign language learning. Of course, you might consider your answer purely speculative, but with your experience here, I am sure that your thoughts are underpinned by more than just speculation.

8. Foreign language departments and classes have been a traditional part of higher education. Today, as foreign language enrollment declines, these programs are under pressure to downsize or in drastic cases to be removed from the university. In your mind, what role, if any, do foreign language programs play in the university curriculum?

9. University administrators often set agendas for the future of their universities. In your mind, how important is foreign language to university administrators and to the future of the university?

Moving on, I would like for use to discuss how foreign language programs can meet the needs of the university by connecting with other programs and academic areas.

10. What are some potential curricular links between the foreign language department and your program/department/college?

11. What role does foreign language education have in the education of students from your academic college? 
12. We talked about general skills that foreign language learning imparts to students. Now, let's discuss students from your academic area? What are some specific skills that foreign language learning might provide to students enrolled in your program?

Finally, accreditation is a word that many people don't like to hear. But, it is a reality at universities. Let's talk briefly about the influence that accreditation has on the curriculum in your area.

13. Can you speak to how accreditation standards have changed over the past 10 or 15 years? What impact has this had on the curriculum in your program?

14. What role do professional or general accrediting agencies have in determining the curriculum in your program?

15. Finally, I would like to thank you for your responses and ask whether there is anything that you would like to add or to clarify before we end the interview. 


\section{West VirginiaUniversity \\ College of Business and Economics}

January 2, 2006

Please note that Mr. William Lee White has the permission of this Office to conduct interviews of faculty in the College of Business and Economics for the purposes of his research study regarding the Foreign Language programs at WVU. My understanding is that responses are voluntary and anonymous and can assure you that there are no penalties associated with refusal to participate.

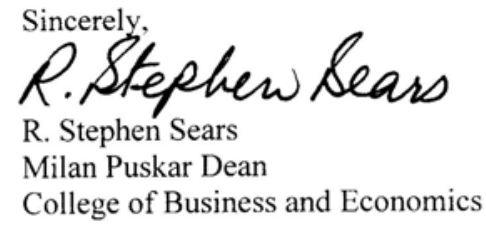




\section{WestVirginiaUniversity}

College of Engineering and Mineral Resources

December 13, 2006

To Whom It May Concern,

As Dean of the College of Engineering and Mineral Resources (CEMR) I am writing to give permission for William White to conduct his research study at West Virginia University. I understand this study will investigate faculty attitudes toward foreign language education and will include interviews with tenured professors from CEMR. I also understand that this study is part of a dissertation project for the degree of Ed.D.
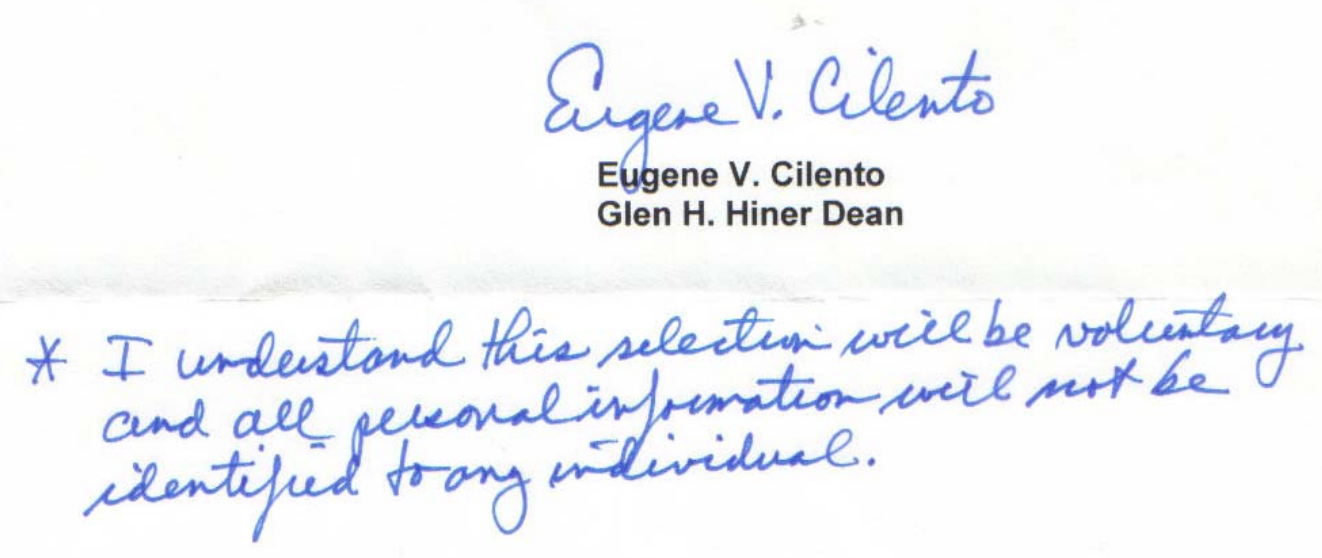
West higmia University

Eberly College of Arts and Scienctit

December 15, 2006

Please note that Mr. William Lee White has the permission of this Office to conduct interviews of faculty in the Eberly College of Arts and Sciences for the purposes of his research study regarding the Foreign Language programs at WVU. My understanding is penalties associated with refusal to participate.

Sincerely

Fred L. King

Associate Dean for Research and Graduate Studies 


\section{Appendix F}

Institutional Review Board Approval 


\section{WestVirginiaUniversity}

College of Human Resources and Education

January 11, 2007

MEMORANDUM

TO: William White $\quad 0$, L

FROM: Lynn Cartwright $\quad$ jur Interim Associate Dean

RE: Human Resources \& Education H.S. \#2007-003

Title: "Faculty Attitudes Toward Foreign Language Education"

Your Application for Exemption for the above-captioned research project has been reviewed under the Human Subjects Policies and has been approved.

This exemption will remain in effect on the condition that the research is carried out exactly as described in the application.

Best wishes for the success of your research.

cc: Deans Office

Student Advising and Records

Patricia Obenauf, Advisor 


\section{Appendix G}

Participant Pseudonyms and College Affiliation 
Participant Pseudonyms and College Affiliation

Eberly College of Arts and Sciences

Art

Martha

Patrick

Judy

College of Business and Economics

Ted

John

Robert

Tony

College of Engineering and Mineral Resources

Bill

David

Bob

Chuck 


\section{Appendix $\mathrm{H}$}

Seventeen Values of Foreign Language Study 
Seventeen Values of Foreign Language Study (Frantz, 1996)

1. Liberalizing

2. Reflection

3. Development of intellect

4. Respect for other peoples

5. Cultural literacy

6. Practical skills

7. Native language knowledge

8. Modes of thought

9. Sense of relevant past

10. Content and skills

11. Leisure activity

12. National goals

13. Personality

14. Transfer of training

15. Cultured nation

16. Point of integration for many disciplines

17. Access to information unavailable in English 


\section{Appendix I}

Invitation to Participate in the Study 
Invitation to Participate in the Study

Dear

As the final part of my doctoral program in education at WVU, I am exploring faculty attitudes toward foreign language education within the context of higher education. The backbone of this study is interviews with faculty members from various WVU colleges, including Eberly, the College of Business and Economics, and the College of Engineering and Mineral Resources. As you have probably guessed, I would like to take a few minutes of your time to discuss your thoughts on the role of foreign language education at WVU. This brief interview should last no more than 30 minutes and can take place at the time and place of your choosing.

I would like to thank you in advance for considering my request and I truly hope that I will have the opportunity to explore your ideas on this question.

Sincerely,

Bill White, Interim Coordinator Basic French Language Program WVU 


\section{Notes}

\footnotetext{
'Unfortunately, WVU ceased to publish these statistical profiles after 1998. The information once contained in an easily accessible book is now provided only upon official request accompanied by a detailed explanation of the researcher's intentions and a letter from an appropriate university official authorizing access. I contacted WVU's office for Institutional Analysis and Planning, but my requests for more recent information were denied or my phone calls and emails were left unanswered.

ii The American Council of Teachers of Foreign Languages (ACTFL) defines an Advanced Speaker as one who can narrate and describe in all major time frames as well as being able to handle situations that arise spontaneously and which have some minor complications (Shrum \& Glisan, 2005).

iii Dr. Henry Moon served as President of Midwestern State University in Wichita Falls, Texas during a portion of the time that I was employed at this institution. I knew Dr. Moon and had several personal as well as professional encounters with him.

iv The name of WVU's core educational requirements has changed three times over the past 37 years. In 1970, the core was called the "University Core Curriculum Requirements." By 1990, the name had been changed to the "Liberal Studies Program." More recently, the name has been changed to the General Education Curriculum." It is this final name that is used throughout this work.
} 